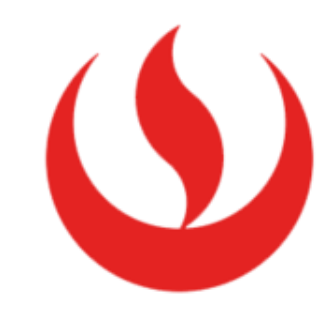

UNIVERSIDAD PERUANA DE CIENCIAS APLICADAS

FACULTAD DE NEGOCIOS

CARRERA DE MARKETING

\title{
Perfil la persona natural que realiza una donación monetaria a las Organizaciones No Gubernamentales que favorecen a niños en la ciudad de Lima
}

Tesis para optar el título profesional de Licenciado en Marketing

AUTOR

Bocanegra Lastra, Yesenia Margarita (0000-0002-6886-2091)

Rodríguez Cañamero, María Cecilia (0000-0001-7503-4035)

ASESOR DE TESIS:

Ikeda Tsukazan, Lucía Midori (0000-0003-2466-7232)

Lima, 7 de julio de 2018 


\section{DEDICATORIA}

A mi papá...

Yesenia Bocanegra L.

"Mira que te mando que te esfuerces y seas valiente; no temas ni desmayes, porque El Señor tu Dios estará contigo en dondequiera que vayas."

Josué 1:9

Cecilia Rodríguez Cañamero 


\section{RESUMEN EJECUTIVO}

Alrededor del mundo existen muchos problemas que atentan contra la noble lucha por mantener o alcanzar una vida digna, un planeta sano. Los gobiernos tratan de resolver estos problemas, pero sus intentos no siempre son suficientes y la injusticia social no solo se mantiene, sino que está creciendo.

Las Organizaciones no Gubernamentales (ONG) hacen una noble labor en beneficio de los más necesitados, para lo que requieren recursos económicos. Pero ¿Conocen estas organizaciones la forma que pueden mejorar sus ingresos?, según los expertos existen varias formas para llegar a este objetivo, sin embargo, uno de los que consideran más importante es el aporte de donaciones monetarias por parte de personas naturales.

Esta investigación se centra en resolver esta incógnita. Utilizamos una investigación del tipo descriptivo, ya que buscábamos describir características específicas de una persona natural. Las fuentes de información primaria fueron recabadas de los especialistas en el área de recaudación de fondos y de donantes. Los resultados obtenidos coinciden con la mayoría de las opiniones de los especialistas en ONG. La muestra de la encuesta se tomó entre los residentes del distrito de San Borja, puesto como confirmaron los especialistas, la mayoría de los donantes de Lima viven en la zona $7^{1}$ de la ciudad (San Borja, Miraflores, San Isidro, etc.) y de estos la gran mayoría en el distrito de San Borja.

Palabras Claves: ONG, niños, donante

\footnotetext{
${ }^{1}$ Zona 7 de Lima según la clasificación de distritos de APEIM (Asociación Peruana de Empresas Investigadoras de Mercado).
} 


\section{ABSTRACT}

Around the world there are many problems that attempt our struggle to maintain or achieve a dignified life, a better world. Governments try to solve these problems, but their attempts are not always enough.

NGOs do a noble job for the benefit of the most needy. Are these organizations aware of how they can improve their income to fulfill their work?, According to experts there are several ways to get to this objective, however, one of the most important is the contribution of donations of money from individuals.

This research is based on this great mystery. We decided to use descriptive research, since we were looking to describe specific characteristics of a natural person. The primary information sources were specialists with managerial positions in the area of fundraising. The results obtained confirm most of the opinions of NGO specialists. The survey sampling was taken between residents of San Borja District, because, as it was confirmed by the especialists, the most of donates of Lima live at the Zone $7^{2}$ of the city (San Borja, Miraflores, San Isidro, etc.) and of these, the most at the San Borja District.

Keywords: NGO, children, donate.

${ }^{2}$ Zone 7 according to APEIM (Asociación Peruana de Empresas Investigadoras de Mercado). 


\section{TABLA DE CONTENIDOS}

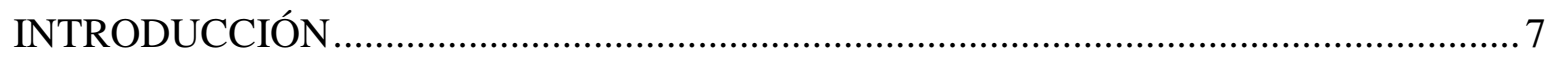

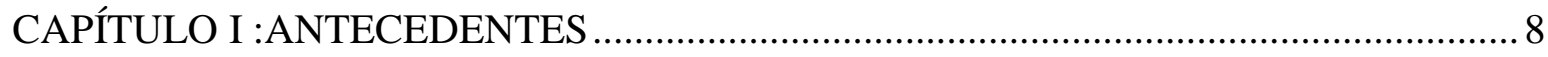

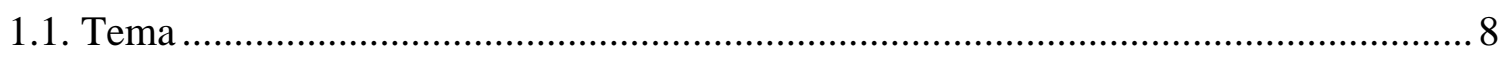

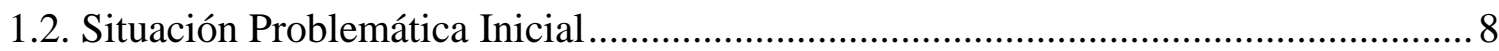

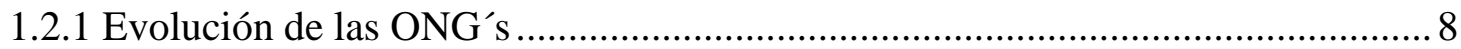

1.3. Preguntas de investigación .................................................................................... 11

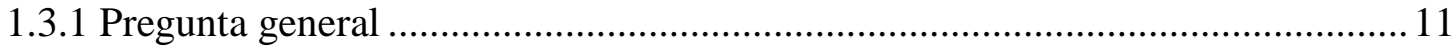

1.3.2 Preguntas específicas .................................................................................. 11

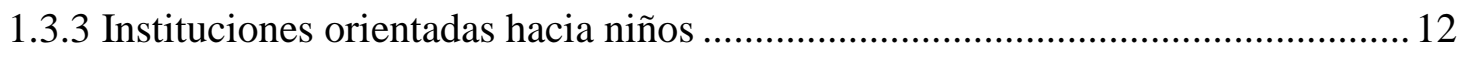

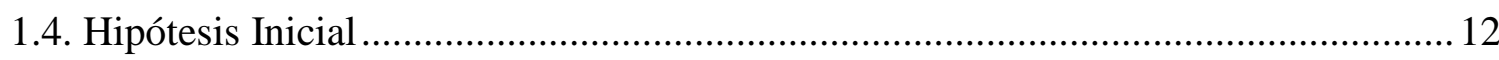

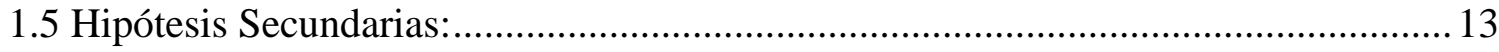

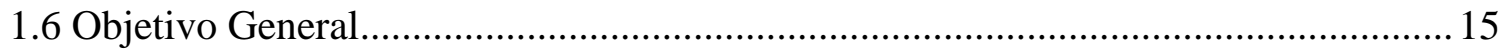

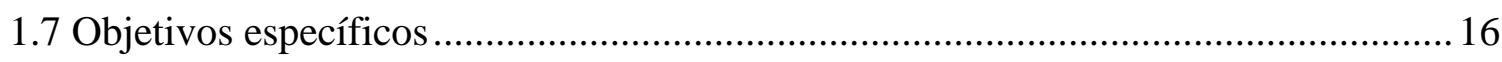

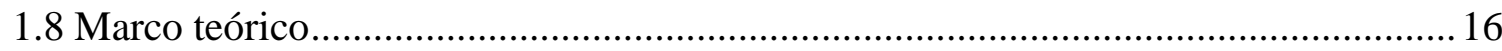

1.8.1 Organizaciones sin fines de lucro ................................................................... 19

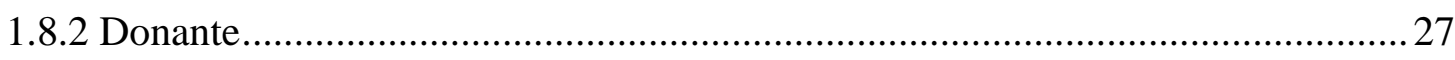

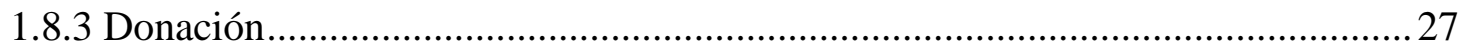

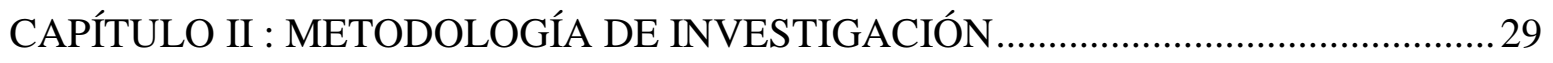

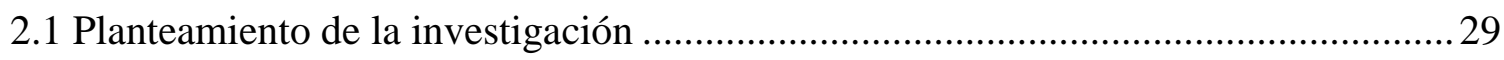

2.1.1 Propósito de la investigación ...............................................................................29

2.1.2 Tipo de investigación .......................................................................................2 29

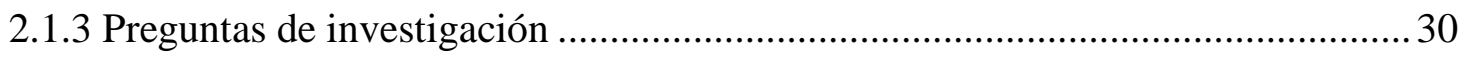

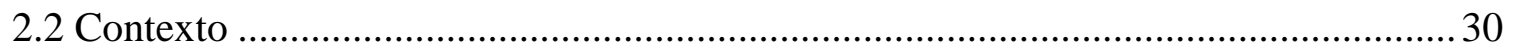

2.2.1 Descripción del contex to interno y externo ………………………………........ 30

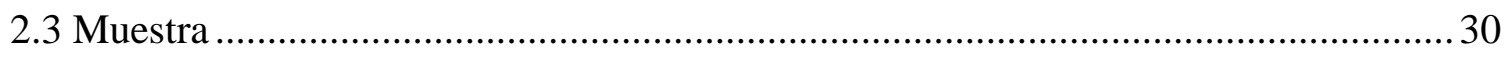

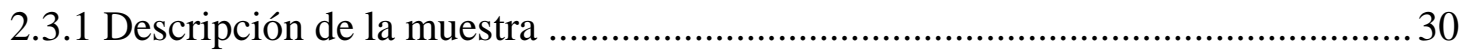

2.4 Diseño o abordaje principal ..................................................................................... 31

2.4.1 Identificación de la estructura de la entrevista o focus........................................... 31

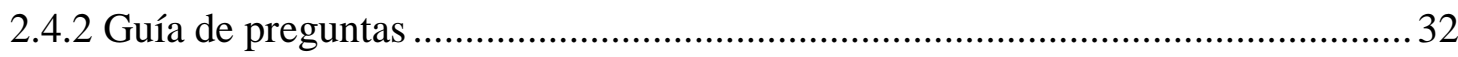

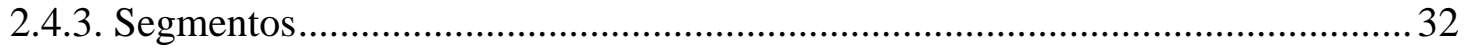




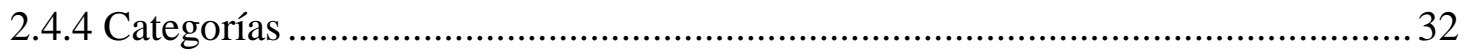

2.4.5 El instrumento de investigación ........................................................................... 33

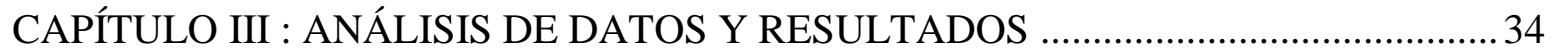

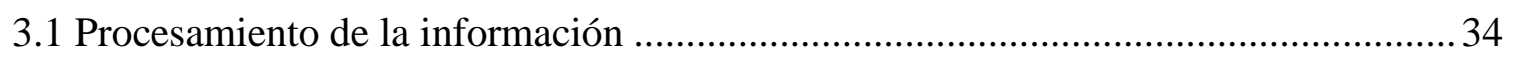

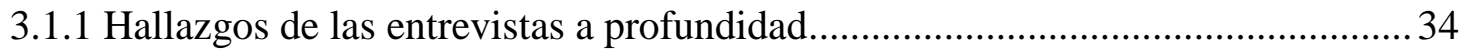

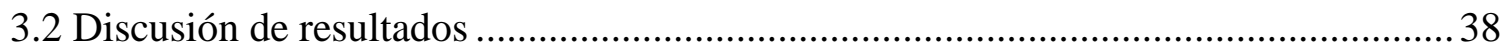

CAPÍTULO IV : CONCLUSIONES, HALLAZGOS Y RECOMENDACIONES .............40

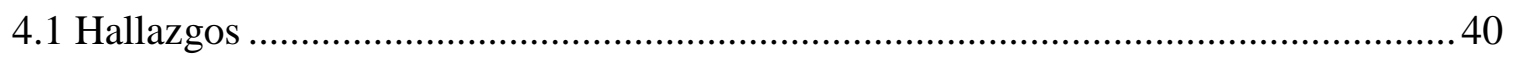

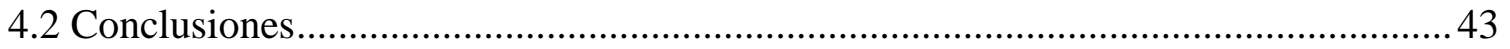

4.3 Limitaciones de la investigación .........................................................................4

4.4 Dificultades que se obtuvieron ............................................................................ 44

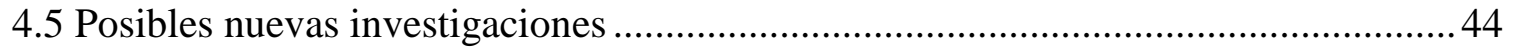

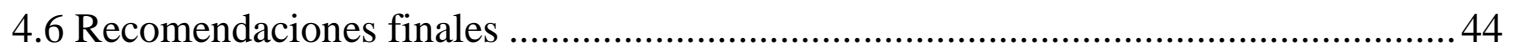

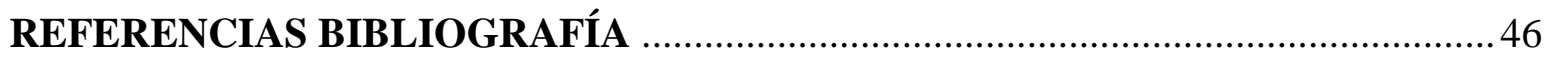

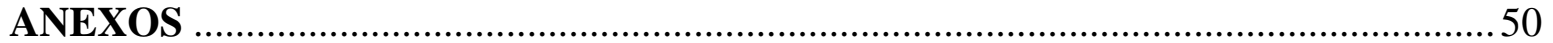

\section{INDICE DE TABLAS}

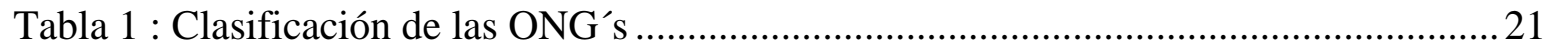

Tabla 2 : Clasificación de las ONG’s en Perú .....................................................................22

Tabla 3 : Resumen de Indicadores del Perfil del donante ..................................................... 37

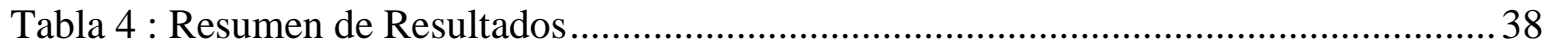




\section{INTRODUCCIÓN}

Como hemos visto pareciera que no hay muchas personas que se preocupan por el medio ambiente de hecho hay, pareciera que no hay personas que se preocupan por los niños pobres, de hecho, hay organizaciones, y la intensión de la tesis tiene que ver con ello, de ver que más se puede hacer, de conocer un poco a quien esta donando, de valorar lo que ellos hacen y de comparar este perfil con otros perfiles.

Este tema es trascendente, es sensible, hay más niños en abandono, y conociendo realidades como Chile, Europa donde la situación fue similar en algún momento nos ha animado a hacer la tesis, y esta tesis tiene que ver con "El perfil del donante que reside en Lima y apoya a ONG de niños en la ciudad de Lima" 


\section{CAPÍTULO I :ANTECEDENTES}

\subsection{Tema}

Perfil de una persona natural que realiza una donación monetaria a las ONG’s que favorecen a niños en la ciudad de Lima.

\subsection{Situación Problemática Inicial}

¿Cómo incrementar la captación de personas naturales que realizan una donación monetaria a las ONG's que favorecen a niños en la ciudad de Lima?

\subsubsection{Evolución de las ONG's}

Durante la década de los 80 's y 90 's, el descrédito de los gobiernos como actores de desarrollo creó un caldo de cultivo para la expansión vertiginosa de las ONG, en la creencia de que gozaban de una serie de ventajas comparativas en las tareas de reducción de la pobreza. Si bien no existen datos exactos, las estimaciones indican que el número de ONG's de desarrollo según la Organización de la Cooperación para el Desarrollo Económico (OCDE) alcanzaba los 2.500 a principios de los 90 frente a los 1.600 de principios de los 80 . Por su parte, las ONG's en el Sur experimentaron un crecimiento más acusado, al pasar de las 20.000 de inicios de los 70 a las más de 50.000 en la década de los años 90. (Suárez, 1995) Una explicación ha sido considerar que las $\mathrm{ONG}^{\prime}$ s -en términos generales, no sólo de desarrollo-, surgen como respuesta institucional ante las fallas tanto del mercado como del estado para acortar la brecha social.

Las ONGs, no tienen una meta económica o lucrativa. Generalmente son organizaciones que poseen fines comunitarios o de ayuda de algún tipo. (García, 2006)

Las entidades sin fines de lucro pueden adoptar la forma jurídica de asociación, fundación, mutualidad o cooperativa (las cooperativas pueden tener o carecer de ánimo de lucro) (Wilex, 2010), las organizaciones sin ánimo de lucro suelen ser organizaciones no gubernamentales 
(ONG), y por lo general reinvierten el excedente de su actividad en obra social para la cual fueron creadas.

Las ONG’s son organizaciones independientes y sin ánimo de lucro que surgen a raíz de iniciativas civiles y populares y que por lo general están vinculadas a proyectos sociales, culturales, de desarrollo u otros que generen cambios estructurales en determinados espacios, comunidades, regiones o países (Pérez, 2006).

Las organizaciones no gubernamentales internacionales tienen sus orígenes al menos en 1839. Se ha estimado que para 1914, había 1803 ONG’s. Las ONG’s internacionales eran importantes para el abolicionismo de la esclavitud y el movimiento por el sufragio de la mujer, y alcanzaron su auge en el momento de la Conferencia Mundial de Desarme. Sin embargo, la expresión "organización no gubernamental" no entró en uso popular hasta el establecimiento de la Organización de las Naciones Unidas en 1945 con lo establecido en el artículo 71 del capítulo 10 de la carta de las Naciones Unidas, una función consultiva para las organizaciones que no son parte del gobierno ni de los estados miembros (Estatus Consultivo). La definición de "organización no gubernamental internacional" (ONG) se da por primera vez en la resolución 288 del Consejo Económico y Social de las Naciones Unidas (ECOSOC) el 27 de febrero de 1950: "cualquier organización internacional que no esté fundada en un tratado internacional". El papel fundamental de las organizaciones no gubernamentales y otros "grupos principales" en el desarrollo sostenible fue reconocido en el capítulo 2738 del Programa 21, lo que llevó a los arreglos intensos para una relación consultiva entra la Organización de Naciones Unidas (ONU) y las organizaciones no gubernamentales. Se ha observado que el número de ONG's internacionales fundadas o disueltas coincide con el "estado del mundo" en general, el aumento de los períodos de crecimiento y disminución en periodos de crisis. El rápido desarrollo del sector no gubernamental se produjo en los países occidentales, como resultado de los procesos de reestructuración del bienestar de los estados. Además, la globalización de ese proceso se produjo después de la caída del sistema comunista y fue una parte importante del Consenso de Washington. Muchos de los problemas no pueden resolverse dentro de una nación. En un intento por contrarrestar esta tendencia, las $\mathrm{ONG}^{\prime}$ 's decidieron priorizar las cuestiones humanitarias, la ayuda al desarrollo sostenible. Un ejemplo destacado de ellos es el Foro Social Mundial que se celebra anualmente en enero en Davos, Suiza. El Quinto Foro Social 
Mundial se realizó en Porto Alegre, Brasil, en enero de 2005 y asistieron más de 1000 representantes de ONG's. En cuanto a las cuestiones ambientales y el desarrollo sostenible, la Cumbre de la Tierra en Río en 1992 fue la primera en mostrar el poder de las ONG’s internacionales, cuando cerca de 2400 representantes de ONG's representaron un rol importante en las deliberaciones. Cualquiera que sea el caso de las ONG's, la red transnacional es ahora más amplia. (Bernal, 1992, pág. 36).

Para complementar el estudio, se toma como base el trabajo realizado por el Magíster en Sociología, de la PUCP, Percy Bobadilla Díaz, cuyo aporte forma parte del Proyecto de investigación sobre "La Identidad y Rol Actual de las ONG". El estudio propone tres principales etapas en las que surgen y desarrollan las ONG en el país, empezando desde la década de los 60.

La primera etapa se da desde los años 1960 a los1980, de acuerdo con Toche (2003, en Bobadilla, 2017) entre la década de los 60 y 70 surgieron un sinfín de organizaciones que representaban la expresión sector urbano, los campesinos y los sindicatos que ganaban participación en temas sociales y políticos. Posteriormente, durante el gobierno militar de Velasco la relación entre las ONG y el estado era de interdependencia. Tiempo después, en el gobierno de Bermúdez, las ONG se transforman en la oferta laboral más atractiva para muchos profesionales, quienes llegaron a impulsar una participación más activa y constante del sector popular como de su desarrollo (Egaña, 1987 en Bobadilla, 2017).

La segunda etapa va desde los años 1980 a los 1990, décadas que se caracterizan por la liberación del modelo económico, ocasionando serios problemas en muchos sectores e iniciando así las luchas armadas por Sendero Luminoso. Factores clave que influyeron en el rediseño de identidad de las ONG, enfocándose en la defensa de los derechos humanos (Toche, 2003 en Bobadilla, 2017). Asimismo, se inicia una mayor relación entre las ONG y el Municipalidad de Lima con la finalidad de implementar estrategias de supervivencia a través de la creación de comedores populares y comités de vaso de leche (Valderrama y Pérez, 1998 en Bobadilla, 2017).

Tercera etapa va desde los años 1990 a 1999 durante el gobierno fujimorista del 93, se destinó mayores recursos económicos a programas sociales, generando la redefinición de la relación entre las ONG y su dependencia de Estado. Con el tiempo, pasaron de ser promotores de la 
desigualdad a formar parte de la lucha contra la pobreza que aqueja al país. Bajo esta nueva concepción, la identidad de las ONG ya no tenía como base la confrontación al Estado, sino se convertían en una entidad que prestadora de servicio, sustituyendo en cierta forma las labores del Estado (Edwards, 2008 en Bobadilla 2017).

En el nuevo contexto de crecimiento económico durante los años 2000 al 2016 las ONG han redefinido y desarrollado sus objetivos con la finalidad de captar nuevas fuentes de financiamiento.

\subsection{Preguntas de investigación}

\subsubsection{Pregunta general}

¿Cuál es el perfil de una persona natural que reside en Lima, que realiza una donación monetaria a las ONG's que favorecen a niños en la ciudad de Lima?

\subsubsection{Preguntas específicas}

Sobre la persona natural que reside en Lima y que realiza una donación monetaria a las ONGs que favorecen a niños en la ciudad de Lima:

1. ¿Cuál es el principal factor de sensibilización?

2. ¿Cuál es la motivación más importante?

3. ¿Cuál es el aspecto que más valora de una ONG?

4. ¿Cuál es la percepción del trabajo de una ONG?

5. ¿Cuál es la frecuencia con la que una persona natural realiza una donación monetaria a las ONG's?

6. ¿Cuál es el principal medio por el que realiza una donación monetaria?

7. ¿Quién o quiénes influencian a una persona natural para realizar una donación monetaria?

8. ¿Cuál es el medio de comunicación que prefiere una persona natural para enterarse de cómo realizar una donación monetaria?

9. ¿Cuál es el principal freno para que una natural no realice una donación monetaria? 


\subsubsection{Instituciones orientadas hacia niños}

Según (APCI, 2018) en la actualidad existen 188 ONG’s registradas en Lima. Del total, 50 organizaciones realizan labores en favor de los niños en diversos ámbitos.

Según la Superintendencia Nacional Tributaria (SUNAT, 2006) hay un proceso normado en el país que tienen que seguir las agrupaciones para constituirse como ONG's para la inscripción y requerimientos que tienen las entidades de auxilio mutuo, sociedades o instituciones religiosas y asociaciones:

- Exhibir el original y presentar fotocopia simple del instrumento de constitución, sus modificatorias y aclaratorias posteriores, así como del estatuto correspondiente, de ser el caso, y sus modificatorias y aclaratorias posteriores, inscritos en los Registros Públicos.

- Presentar fotocopia simple de la ficha de inscripción o partida registral, o acreditar la vigencia de la inscripción en el Registro de entidades e instituciones de cooperación técnica internacional del Ministerio de Relaciones Exteriores, según corresponda, con una antigüedad no mayor a treinta (30) días calendario.

\subsection{Hipótesis Inicial}

El perfil de una persona natural, que reside en Lima y que realiza una donación monetaria a las ONG's que favorecen a niños en la ciudad de Lima se ve influenciada principalmente por: factores de sensibilización, motivación, valoración, percepción del trabajo de la organización.

Variable dependiente:

A1. Donantes de ONG'

Variables independientes:

A1. Factores de sensibilización

A2. Motivación

A3. Valoración 
A4. Percepción del trabajo

A5. Frecuencia de donación monetaria

A6. Medios de donación monetaria

A7. Medio de comunicación

A8. Frenos de donación

La hipotesis y las variables independientes se eligieron en base al estudio de la Asociación Española de Fundraising (AEFr) 2016. La selección de la muestra se hizo en el distrito de San Borja, por la recomendación de la especialista en ONG: Ivette Muñoz-Aprendo Contigo. De acuerdo con los datos de APEIM (2017) la zona 7 (Miraflores, San Isidro, San Borja, Surco y La Molina) concentran los más altos porcentajes del total de nivel socioeconomía A y B. Del 100\% el 58.2\% pertenece al NSE A y del 100\% el 15.7\% pertenece al NSE B, siendo los porcentajes más altos de todas las zonas por cada NSE (APEIM, 2017).

“...mujeres de 45 años para arriba son los donantes, la mayoría son de San Borja pero también hay donantes en Miraflores, San Isidro y Surco pero son menos.” Ivette MuñozAprendo Contigo.

Por otro lado, el distrito de San Borja se encuentra altamente organizado y trabaja en programas de apoyo social, no solo para el residente del distrito sino también a nivel nacional. A través de su programa Ayúdanos a dar, se llevan a cabo acciones de apoyo humanitario por personas con alta sensibilidad social y vocación de servicio (MUNI San Borja, 2018).

\subsection{Hipótesis Secundarias:}

Se planteó las siguientes hipótesis:

1.5.1 Los niños con pobreza extrema es el principal factor de sensibilización, según los especialistas en ONG's: Giorgio Muñoz - COANIQUEM y Juana Burga- Aniquem. 
“...todos los temas de infancia siempre son mucho más sensibilizantes para las personas más que otro tema" Giorgio Muñoz-COANIQUEM

“...la gente se sensibiliza sobre todo con los niños de pobreza extrema, que tienen una carencia, que tienen una necesidad..." Juana Burga-ANIQUEM

1.5.2 La solidaridad es el principal factor que motivación, según la especialista en ONG : Juana Burga-ANIQUEM

"el querer ayudar uno, tus deseos de servicio, tus deseos de que tú veas que esos niños gracias a tu colaboración, a tu donación están recibiendo una atención...” Juana BurgaANIQUEM

1.5.3 La causa de la institución es el aspecto que más valora en una ONG, según el especialista en ONG: Giorgio Muñoz-COANIQUEM.

"El donante valora, que la causa sea clara y entendible...eso se valora mucho y es simple, por ejemplo, a Unicef, les cuesta mucho más explicar a veces lo que hacen" Giorgio MuñozCOANIQUEM

1.5.4 Se tiene una mala percepción del trabajo de una ONG, según la especialista en ONG: Ivette Muñoz-Aprendo Contigo

“...muchas $O N G$ 's que no han sido bien manejadas, han dado la impresión de que todas o casi todas podríamos no tener un manejo claro de los recursos, entonces eso hace que a nosotros los que tratamos de hacer un trabajo serio se nos dificulte." Ivette Muñoz-Aprendo Contigo

1.5.5 La principal frecuencia de donación es mensual, según la especialista en ONG: Juana Burga-ANIQUEM 
“...los donantes más comunes son los que donan cada mes, cada seis o tres meses, por último, dan una donación una vez el año, pero es una donación importante” Juana BurgaANIQUEM

1.5.6 El efectivo es el principal medio de donación, según la especialista en ONG’s Juana Burga- ANIQUEM

“...los donantes más comunes son los que donan cada mes, cada seis o tres meses, por último dan una donación una vez el año pero es una donación importante” Juana BurgaANIQUEM

1.5.7 El contacto directo (cara a cara) es la principal forma por la cual les gusta enterarse de cómo realizar una donación, según la especialista en ONG: Juana Burga- ANIQUEM.

“...todavía tengo en mi cabeza que el face to face o cara a cara es la mejor forma de comunicarse con el donante porque hay más feeling, tú tienes está relación cordial con esa persona, al escucharte se sensibiliza, le muestras los trabajos por medio de una foto" Juana Burga-ANIQUEM

1.5.8 La desconfianza en la ONG es el principal freno de donación, según el especialista en ONG’s Giorgio Muñoz- COANIQUEM.

“...el freno, básicamente puede tener algún nivel de desconfianza o básicamente no logra sensibilizar con la causa, también hay personas que son solidarias pero hay personas que no les gusta donar a una fundación que no les interesa... "Giorgio Muñoz-COANIQUEM.

\subsection{Objetivo General}

Identificar el perfil de una persona natural que reside en Lima que realiza una donación monetaria a las ONG's que favorecen a niños en la ciudad de Lima. 


\subsection{Objetivos específicos}

1. Identificar el principal factor de sensibilización del donante en estudio.

2. Identificar el factor de motivación más importante para el donante en estudio.

3. Identificar el aspecto más importante que valora de una ONG.

4. Identificar la percepción que tiene el donante del trabajo de las ONG's que favorecen a niños en la ciudad de Lima.

5. Identificar la frecuencia de donación típica del donante en estudio.

6. Identificar el medio principal por el cual realiza una donación monetaria.

7. Identificar el medio principal por el cual prefiere enterarse cómo realizar una donación monetaria.

8. Identificar el principal freno a la donación.

\subsection{Marco teórico}

Para el presente trabajo de investigación se ha tomado como base principal un estudio realizado por la Asociación Española de Fundraising (AEFr) desarrollado en el año 2016, una organización sin fines de lucro que busca mejorar la captación de fondos en base a un mayor conocimiento del perfil donante.

El estudio fue financiado por un grupo de instituciones que favorecen causas de interés público y general con el objetivo de mejorar la estrategia de captación de fondos. Es importante señalar que no existía información exhaustiva y profesional en el sector acerca de las personas que realizaban donaciones a las ONG. Debido a ello, existía la necesidad de conocer el perfil del donante, cuáles eran las dimensiones y causas que originaban la donación (AEF, 2016).

Es así como el estudio base sobre las ONG se inicia en noviembre del 2004, por el instituto de investigación SALVETI LLOMBAR, se continúa en el 2006, 2008, 2010, 2014, 2015 y 2016 con la finalidad de entender la evolución del sector. El estudio realizado por Asociación Española de Fundraising se centra en el perfil de personas pudientes, denominadas gente rica como técnica de captación de fondos menos conocida y empleada, por ende. De acuerdo con el estudio, las características de este segmento son distintas a las de la gente común. Les gusta ser escuchados, son poco propensos a donar altas sumas de dinero sin conocer el proyecto y 
formar parte de este, prefieren que la comunicación para solicitar el apoyo se realice de forma personal (AEF, 2016).

La investigación es descriptiva y su metodologia cuantitativa. Para la recolección de información se utilizó el cuestionario estructurado como herramienta a través de dos medios (on-line y presencial). Se considero dos segmentos: personas mayores de 18 años de ambos sexos, pertenecientes a la zona.CCAA ${ }^{3}$ y donantes vigentes de las ONG que colaboraron con el proyecto. Los tipos de muestreos fueron el Probabilístico, aplicado a 1213 personas mayores de 18 años de ambos sexos, pertenecientes a la zona.CCAA a través del medio online y el No Probabilístico aplicado a 1151 personas a que colaboraban de forma activa y se mantenían como donantes vigentes de alguna ONG, esto a través de entrevistas personales.

En el estudio participaron 29 ONG, de las cuales cuatro son las que tienen mayor número de socios Cruz Roja Española $(909,126)$, Médicos Sin Fronteras (487,722), Ayuda en Acción $(204,570)$ y UNICEF $(217,000)$ (Fundación Eroski, 2009).Con esta investigación se buscó cuantificar la opinión de las personas para conocer cómo el donante de ese país se ve influenciado por : factores de sensibilización, motivación, valoración, percepción del trabajo de la organización y frenos de donación, y así obtener mayor conocimiento del perfil del donante de España (AEF, 2018). Ver Anexo 1.A. A continuación, detallaremos los resultados del último estudio realizado el año 2016:

- El 35\% de personas se sensibilizan con la infancia.

- La mayoría, el $57 \%$ de personas realiza un aporte motivado por la solidaridad.

- El principal motivo que lleva a elegir una ONG es que les guste la causa.

- El 12\% de personas ha colaborado económicamente en los últimos 12 meses.

- El $52 \%$ de las personas no realiza un aporte económico porque sus necesidades económicas no se lo permiten.

(AGORA,2018) publicó un primer estudio sobre las tendencias globales de donación, en donde examina en detalle los hábitos solidarios de donantes de todo el mundo durante el último año, los vínculos con las causas con las que se comprometen y las instituciones

\footnotetext{
${ }^{3} \mathrm{CCAA}=$ Comunidades Autónomas de España.
} 
solidarias con las que trabajan, enfocados principalmente en la tecnología en línea y móvil en los actos solidarios.

Alrededor de unas 4.084 personas que donan y que han sido encuestadas vienen de 95 países, la mayor parte son de USA, Canadá, Australia y Reino Unido. Las respuestas recopiladas muestran una tendencia global en donación de 2017, que indican que la comunidad internacional de donantes se encuentra conformada en su mayoría por mujeres $(73 \%)$, que tienen una ideología liberal (61\%) y mayores de 37 años (73\%). Estas personas que donan lo prefieren hacer en línea (59\%) y viven en países desarrollados rico (93\%). Se encontró que el perfil de donante se ve influenciado por: medios de donación, frecuencia de donación y medios de comunicación. Ver Anexo 2

A continuación, los principales hallazgos:

- El 14\% de donantes del mundo prefieren realizar sus donaciones a través de Eventos de recaudación de fondos y correo directo.

- Del 54\% de los donantes que participan en un programa de donaciones periódicas, el 82\% dona de forma mensual.

- Las donaciones en línea están relacionadas de forma directa con los medios sociales digitales. El $42 \%$ de los donantes en línea mencionaron que se han sentido inspirados a dar debido a los medios sociales digitales. De estas personas, el 62\% se siente más inspirada por Facebook. El 15\% siente inspiración por Twitter y un 10\% por Instagram.

- Los medios tradicionales como la televisión y la radio solo inspiran al 5\% de los donantes, este porcentaje puede incrementar si aplicaciones como streaming en directo: Netflix y Pandora, adaptasen los servicios de su programación y publicidad a los requerimientos de las ONG.

Para el presente trabajo se consideró algunas pautas utilizadas en la investigación de la Asociación Española de Fundraising 2016, entre las cuales tenemos: tipo de investigación (descriptiva), metodología de investigación (cuantitativa) e instrumento (cuestionario estructurado). El aspecto más importante para la investigación fueron las variables que influencian en el perfil de un donante, entre las cuales se utilizaron: factores de sensibilización, motivación, valoración, percepción del trabajo de la organización y frenos de donación. Adicionalmente se utilizaron algunas variables de la investigación Agora 
Inteligencia Colectiva para la Sostenibilidad 2018, tales como: medios de donación, frecuencia de donación y medios de comunicación, con la finalidad de identificar el perfil del donante de Lima.

\subsubsection{Organizaciones sin fines de lucro}

\subsubsection{Definición de ONG's}

(PUCP, 2017) La definición para una Organización sin fines de lucro es una ser una entidad que no tiene como propósito un beneficio económico, sino el apoyo a través de obras sociales, cuya "limitación para distribuir beneficios generados por actividades económicas entre los directivos, asociados, administradores o trabajadores de la entidad no lucrativa, sea de manera directa o indirectamente" (párr. 5).

ONG, Organización no Gubernamental es la asociación que tiene la formación de una organización estable de personas naturales o jurídicas, o de ambas, que, a través de un fin no lucrativo, supone necesariamente que no se encuentre beneficiada con el goce de incentivos o beneficios tributarios, los cuales describiremos a continuación respecto al Impuesto a la Renta y el Impuesto General a las Ventas. Asimismo, “cuando realicen transferencias o importaciones de bienes y prestaciones de servicios que efectúen exclusivamente para sus fines propios no se encontrara gravada con el Impuesto General a las Ventas” (PUCP, 2017, párr. 50).

Las ONG son organizaciones independientes y sin ánimos de lucro que surgen a raíz de iniciativas civiles y populares por lo general están vinculadas a proyectos sociales de desarrollo que generen cambios estructurales en comunidades, regiones o países (ACNUR, 2018).

\subsubsection{2 ¿Cuál es la función de una ONG?}

Para que una organización no lucrativa sea catalogada como ONG debe cumplir algunos requisitos tales como cumplir fines humanitarios, carecer de fines de lucro, no se rigen por la administración pública. 
Las organizaciones No gubernamentales no dependen del estado, ni pretenden suplantar su labor, realizan actividades de apoyo social y humanitarias, generando interés y beneficios que involucran a los distintos miembros de una comunidad o grupo (NOMBRES, 2016).

Las ONG's persiguen el beneficio o la utilidad común, ya que no buscan lucrar, debido a que los beneficios son para las propias comunidades en las que se llevan a cabo los proyectos de transformación porque promueven la participación y la autogestión. Las ONG’s no buscan que las comunidades beneficiadas se conviertan en dependientes del apoyo que reciben. Al contrario, su objetivo principal es fomentar la participación y la autogestión de aquellas como motores de desarrollo. (Perez, Arango \& Sepulveda, 2011)

(ACNUR, 2017) Estas organizaciones defienden y trabajan en causas asistenciales sociales, humanitarias y medioambientales. Su función es apoyar la labor del estado, desarrollo social, concienciar y defender los derechos, por lo que, ofrecen servicios y asistencia a comunidades y pobladores que se encuentran en una situación negativa. Por lo general, los integrantes de las ONG's son voluntarios y hacen beneficencia, entre otras cosas.

La función de la ONG juega un papel muy importante para el desarrollo de la sociedad ya que son de gran ayuda al combatir diversos problemas sociales, según el blog de sociología Respuestas Tips 2018.

\subsubsection{Clasificación de las organizaciones sin fines de lucro}

(PROADE, 2017) Existen diversas clasificaciones que se le da a las organizaciones no lucrativas, algunos la conocen con ONG, asociaciones, entidades no lucrativas, entre otras. Desde el punto de vista jurídico y por el fin no lucrativo, ya que su formalización permite conseguir apoyo internacional, las organizaciones no lucrativas se clasifican en tres tipos: asociaciones, fundaciones y cooperativas sin fines de lucro. Se constituyen por un grupo de personas, estas pueden ser naturales o jurídicas sin fines de lucro con el objetivo de apoyar causas sociales

ONU (2017), como se cita en la Federación Antioqueña de ONG, 2018) la definición para una ONG es "cualquier grupo de ciudadanos voluntarios sin ánimo de lucro que surge en el ámbito local, nacional o internacional, de naturaleza altruista y dirigido por personas con un interés común” (párr. 1). Para el caso de las fundaciones la definición es distinta ya que 
"surgen de la iniciativa de algún particular, empresa o, incluso, gobierno, que crean un consenso para la consecución de fines de carácter social" según Pineda (1999, como se cita en Mediolanum, 2017, párr. 4).

Tabla 1 : Clasificación de las ONG's

\begin{tabular}{|l|l|}
\hline Fundación/ONG & Asociación/ONG \\
\hline $\begin{array}{l}\text { Entidad reguladora: Consejo de Supervigilancia de } \\
\text { Fundaciones y APCI }\end{array}$ & Entidad reguladora: APCI \\
\hline $\begin{array}{l}\text { Las donaciones nacionales e internacionales son } \\
\text { aceptadas inmediatamente después de la puede percibir donaciones internacionales } \\
\text { inscripción en registros públicos. Pero es necesario } \\
\text { el registro en APCI para recibir las internacionales }\end{array}$ & $\begin{array}{l}\text { No hasta después de dos años de su inscripción, pero } \\
\text { no hayoblemas con las donaciones nacionales. }\end{array}$ \\
\hline
\end{tabular}

\begin{tabular}{|l|l|}
\hline $\begin{array}{l}\text { Reciba o no donaciones extranjeras igual es } \\
\text { fiscalizada por el Consejo de Supervigilancia. }\end{array}$ & $\begin{array}{l}\text { Si no recibe donaciones extranjeras el APCI ni } \\
\text { ninguna otra entidad la fiscaliza (salvo en caso de } \\
\text { delitos o denuncias). }\end{array}$ \\
\hline $\begin{array}{l}\text { Ninguna persona que integre Amazon Rainforest } \\
\text { Conservation SAC ni sus familiares, pueden } \\
\text { formar parte de la fundación. }\end{array}$ & $\begin{array}{l}\text { Es posible que los integrantes de la empresa } \\
\text { también participen en la ONG, pero es } \\
\text { recomendable que no sea en cargos principales. }\end{array}$ \\
\hline $\begin{array}{l}\text { El nombre de la fundación puede ser el mismo que } \\
\text { el de la empresa. }\end{array}$ & $\begin{array}{l}\text { El nombre tiene que ser distinto, sin embargo se } \\
\text { acepta como válida la traducción de inglés a } \\
\text { castellano. }\end{array}$ \\
\hline
\end{tabular}

Fuente: Código civil Elaboración propia

Nota: Comparativo entre Fundación y Asociación Comparativo entre Fundación y Asociación Adaptado de Código Civil. Elaboración Propia

Como hemos visto existen varias formas formas de clasificar a las Organizaciones sin fines de lucro, como, por ejemplo: por su forma jurídica, por su nivel de orientación o nivel de operación, o por grandes rubros sobre fines específicos que abordan.

(DIGII,2018) según La Dirección General de Impuestos Internos, otra clasificación de las Asociaciones sin Fines de Lucro es:

- Asociaciones de beneficio público o de servicio: a terceras personas, quienes ofrecen servicios básicos en apoyo de toda la sociedad o de grupos especificos.

- Asociaciones de beneficio mutuo: que tienen como actividad principal la difusión de actividades de desarrollo y defensa de los derechos de sus asociados.

- Asociaciones mixtas, que su enfoque esta en diferentes actividades propias tanto de beneficio público y de beneficio mutuo. 
En el 2008 en el Perú había 1704 ONG’s según APCI, Agencia Peruana de Cooperación Internacional. Considerando la última forma de clasificación, tenemos el siguiente cuadro de las Organizaciones sin fines de lucro, donde se muestra la distribución de estos organismos según su tipo:

Tabla 2 : Clasificación de las ONG's en Perú

\begin{tabular}{|l|c|}
\hline Tipo de ONG & Total \\
\hline Asociaciones de beneficio público & 1133 \\
\hline Asociaciones de beneficio mutuo & 372 \\
\hline Asociaciones mixtas & 199 \\
\hline Total & 1704 \\
\hline
\end{tabular}

Nota: Distribución de las Organización sin fines de lucro. Elaboración Propia

\subsubsection{Percepción de las ONG en el Perú}

De acuerdo con la empresa líder en investigación social Imasen, el trabajo que vienen realizando las ONG en el Perú se asocia mayormente con el desarrollo social en poblaciones con escasos recursos y poco con los derechos humanos.

El sondeo de la empresa investigadora revela que de las 1,504 personas encuestas, el 45.9\% tienen muy buenas o buenas opiniones de las ONG, siendo más alta la percepción en los sectores de nivel socioeconómico alto y medio.

El $60.3 \%$ de las personas encuestadas se informan de las campañas comunicacionales de las ONG, según el sondeo, a través de medios tradicionales como la televisión y solo un $9.3 \%$ lo hace a través de Internet. Por lo que las ONG aún tienen una amplia brecha por trabajar en cuanto a nuevas formas de comunicación a través de las redes sociales.

Es importante mencionar, del sondeo, que solo el $24.7 \%$ de las personas encuestadas estarían dispuestas a apoyar a las ONG donar una fracción de sus ingresos. Mientras que el 51.8\% estaría interesado en formar parte de programas de voluntariado (Gestión, 2015). 
De acuerdo con el primer medio digital en español, EsGlobal, existen las ONG poderosas en el mundo que ejercen gran influencia en el campo de la política y la forma en el que mundo trabaja por el desarrollo de la sociedad (EsGlobal, 2008).

De las diez ONG más poderosas e influyentes en el Perú, se encuentra Caritas (ONG) en el quinto lugar. (Semana Económica, 2017).

De acuerdo con una encuesta realizada por El Comercio - Ipsos a 1,276 personas, sobre las instituciones en la que más confían los peruanos, se observa que más del 53\% de la población encuestada confía en las ONG, encontrándose en el puesto once de las entidades que generan mayor confianza (El Comercio, 2017).

\subsubsection{Las ONG's que favorecen niños en la ciudad de Lima}

Las organizaciones sin fines de lucro, según APCI que trabajan en favor de niños, y que están registradas en dicha organización son en total 188 (Anexo 3). Sin embargo, mediante el muestreo por juicio, los especialistas según su criterio basado en la experiencia en el rubro de ONG's eligieron 9 organizaciones que se responden a los fines de estudio del presente trabajo de investigación y las encuestas. A continuación, se detalla información de cada una de ellas:

1. Aldeas infantiles SOS Perú: Se encarga de preservar el derecho del niño a vivir bajo el cuidado familiar, cuando este por alguna causa no tiene acceso a ella, ya que el objetivo es que se mantenga dentro de una familia. Esta organización viene trabajando desde el año 1949, y fue fundada por el educador austriaco Hermann Gmeiner, su preocupación por los niños que habían perdido sus hogares, su seguridad y a sus familias en la Segunda Guerra Mundial. En el Perú se inició con esta labor en noviembre de 1975, un grupo de colaboradores identificados con el mismo espíritu solidario e ímpetu que profesaba el fundador, colocaron los cimientos de lo que hoy es la primera Aldea: La Aldea Infantil SOS Zárate (San Juan de Lurigancho), para luego a través de los años funden 11 más en diferentes regiones, ciudades y distritos a lo largo del país, creando así Aldeas Infantiles SOS Perú. En conclusión, es una organización independiente de desarrollo social que busca contribuir en dar solución a las situaciones de riesgo a las que se enfrentan miles de niñas, niños y 
adolescentes para que tengan la oportunidad de disfrutar de una infancia, crecimiento y desarrollo social feliz, en un entorno familiar seguro y protector caracterizado por experiencias positivas.

2. Techo para mi país: Se encarga de la construcción de viviendas, conjuntamente con las personas que lo necesitan con la finalidad de que cuenten con techo que los proteja. En 1997 un grupo de jóvenes comenzó a trabajar por el sueño de superar la situación de pobreza en la que vivían millones de personas. El sentido de urgencia en los asentamientos los movilizó masivamente a construir viviendas de emergencia en conjunto con las familias que vivían en condiciones inaceptables y a volcar su energía en busca de soluciones concretas a las problemáticas que las comunidades afrontan cada día. Esta iniciativa se convirtió en un desafío institucional que hoy se comparte en todo el continente. Desde sus inicios en Chile, seguido por El Salvador y Perú, la organización emprendió su expansión bajo el nombre "Un Techo para mi País".

Luego de 15 años de trabajo, TECHO mantiene operación en 19 países de Latinoamérica y el Caribe: Argentina, Bolivia, Brasil, Chile, Colombia, Costa Rica, Ecuador, El Salvador, Guatemala, Haití, Honduras, México, Nicaragua, Panamá, Paraguay, Perú, República Dominicana, Uruguay y Venezuela. Además, cuenta con una oficina en Estados Unidos.

3. Unicef: Se enfocan en preservar los derechos que tiene todo niño. UNICEF es la fuerza impulsora que contribuye a la creación de un mundo donde se respeten los derechos de todos y cada uno de los niños y niñas. La comunidad internacional nos ha dotado de la autoridad necesaria para influir sobre las personas encargadas de tomar decisiones y sobre diversos aliados de las comunidades de base, a fin de plasmar en la realidad las ideas más innovadoras. Por consiguiente, son una organización mundial sin par y también una organización sin par entre las que trabajan con los jóvenes. UNICEF lleva a cabo su labor en más de 190 países y territorios por medio de programas de país y Comités Nacionales. UNICEF está en el Perú desde 1948 para que la exclusión, discriminación y pobreza dejen de ser factores que obstaculicen el desarrollo de millones de niñas y niños peruanos. Contribuye con el Estado peruano en el cumplimiento de las políticas del Acuerdo Nacional relacionadas con la infancia y los objetivos de desarrollo sostenible. Trabaja a nivel nacional y en algunas regiones andinas y amazónicas en las que la inequidad y la exclusión social están 
especialmente acentuadas, y la situación de los derechos de la niñez es particularmente vulnerable. Lo hace con total respeto de la diversidad cultural y con enfoque de género. La estrategia de trabajo se basa en conjugar esfuerzos y voluntades para proteger los derechos de la niñez y adolescencia peruana, conjuntamente con aliados y contrapartes nacionales, la cooperación internacional y las agencias hermanas del sistema de Naciones Unidas.

4. Ponle Corazón: Brindan apoyo a las personas que tienen cáncer y que no cuentan con los recursos necesarios para costear el tratamiento de esta enfermedad. Entre las principales actividades que realiza se puede mencionar:

- Gestión del albergue lleva el nombre de la Srta. "Frieda Heller" (fundadora), en el que se reciben, de manera ininterrumpida y desde hace más de 50 años, a pacientes afectados por el cáncer provenientes de las diversas provincias del Perú y de escasos recursos; brindándoles alimentación, asistencia psicológica y espiritual.

- Colecta Pública Anual llamada "Ponle Corazón", que está dirigida a recaudar fondos para cubrir los costos de los medicamentos que requieren los pacientes. Además, un porcentaje del monto es utilizado para comprar instrumental médico que puedan requerir los pacientes para su atención.

- Capacitación de médicos peruanos, otorgando becas para que estudien en el extranjero y mejoren sus técnicas de atención a los pacientes.

- Donación de equipos y material médico a instituciones oncológicas como el INEN, Hospital Santa Rosa, Hospital María Auxiliadora, entre otras instituciones.

- Actividades de prevención como reparto de volantes con información sobre el cáncer y el cuidado preventivo, charlas preventivas a instituciones educativas y empresas y envío de médicos a provincias para realizar actividades de diagnóstico y prevención.

5. Cáritas del Perú: Es un organismo de la Iglesia Católica que fue fundado en el año 1955 por la Conferencia Episcopal Peruana con la finalidad de promover e incentivar programas en favor de las poblaciones más pobres y facilitar su desarrollo humano integral basado en los principios cristianos de justicia, solidaridad y respeto a la dignidad humana. 
En el ámbito nacional, Cáritas del Perú alienta la labor desplegada por una Red de 48 Cáritas Diocesanas que cubren toda la geografía del país.

Cáritas del Perú forma parte de la Confederación Mundial de Caritas International, entidad creada en 1951 y que agrupa a 165 organizaciones en más de 200 países y territorios. Asimismo, es miembro del Secretariado Latinoamericano y El Caribe de Cáritas - SELACC.

6. Liga contra el Cáncer: Brinda servicios para la detección y prevención de cáncer. La Liga Contra el Cáncer, es la institución pionera en la detección y prevención del cáncer en el Perú, fue fundada el 12 de noviembre de 1950, año en que el cáncer no era una enfermedad muy difundida y era la tercera causa de muerte en el país que generaba en la sociedad una atmósfera fatalista. Hoy en día, el cáncer es la segunda causa de muerte, sin embargo, existe una mayor información sobre sus orígenes, causas y consecuencias gracias al arduo trabajo de concientización y generación de cultura preventiva a través de diversas acciones de prevención como campañas informativas, educativas y despistajes gratuitos que permiten lograr una cultura preventiva y hábitos de vida saludable en la población a través de los años.

Así la institución hasta la fecha ha atendido a más de 1 millón de personas detectando a tiempo más de 9 mil casos con cáncer, a través de sus 4 centros detectores en Lima Metropolitana (Lima, Pueblo Libre, Surquillo y Comas) y 17 filiales en la Costa, Sierra y Selva del Perú (Arequipa, Cajamarca, Chepén, Chiclayo, Chincha, Cusco, Guadalupe, Huánuco, Huaraz, Ilo, Puerto Maldonado, Moquegua, Piura, Puno, Tacna, Tingo María y Trujillo). Además, realiza diferentes campañas de despistajes con sus 4 unidades móviles que recorren las zonas más vulnerables de la ciudad con el objetivo de prevenir y detectar a tiempo la enfermedad.

7. Fundades: Tiene por objetivo contribuir a mejorar la calidad de vida de personas vulnerables, especialmente de personas con discapacidad, a través de la promoción y ejecución de actividades y proyectos sociales relacionados con la salud, la niñez en abandono, la educación, el trabajo, el deporte y el medio ambiente.

8. Aprendo Contigo: Tiene como objetivo fundamental acompañar al paciente pediátrico durante su hospitalización y/o tratamiento médico a través de las tareas propias de la niñez: 
estudio y juego. Aprendo Contigo lleva al niño el mundo que éste ha tenido que dejar atrás debido a su enfermedad. Un aula hospitalaria es un espacio en el cual los niños pueden comportarse como lo que son: niños.

9. Aniquem: Brindan servicios de rehabilitación a los niños que han sufrido de quemaduras. Es una institución especializada que trabaja responsablemente en generar una cultura de prevención frente a las lesiones por quemaduras y provee rehabilitación integral al niño/ niña y adolescente hasta su reinserción social. ANIQUEM nació en el año 1999 y desde esa fecha atiende a cientos de niños brindándole terapia física, terapia ocupacional, confección de prendas, férulas, además de la atención psicológica al paciente y su familiar cercano. Asimismo, esta organización es la única organización en Latinoamérica que organiza campamentos para los niños adolescentes una vez al año, del mismo modo ANIQUEM confección máscaras de termoplástico siliconado que es una prenda que toma la medida exacta del rostro ejerciendo la presión adecuada para evitar deformaciones y queloides. En

paralelo trabajan el área de prevención a través de talleres y charlas a las zonas más vulnerables del país.

\subsubsection{Donante}

\subsubsection{Definición de benefactores o donantes}

Capriotti (1999) Define el término donaciones para las Organizaciones sin fines de lucro (ONG's) pero depende mucho de la capacidad de recaudamiento de la organización y de sus miembros, así como también de la cercanía del trabajo de la organización con la sociedad y los contactos con lograr una alianza con una empresa puede ser una buena opción. Estas siempre están buscando mejorar su imagen, por lo que un pacto beneficia a ambos. Sin embargo, un golpe a una de los dos Organizaciones.

Según (RAE, 2018) la palabra donante significa: que ha donado o pagado algo.

\subsubsection{Donación}

Según (RAE, 2018) la palabra “donación” es el acto de hacer llegar de forma gratuita, algo que te pertenece con la finalidad de beneficiar a otra persona 
(Castán, 1998) acto que se da por elección en el que una persona da algo que favorece a otra, que lo acepta. 


\section{CAPÍTULO II : METODOLOGÍA DE INVESTIGACIÓN}

\subsection{Planteamiento de la investigación}

En la presente investigación se acoto la toma de la muestra de donantes al distrito de San Borja, ya que es el lugar de residencía de la mayoria de cantidad de donantes, según la opinión de: Ivette Muñoz - Aprendo Contigo, especialista en ONG. Esta información se recopilo de una entrevista a profundidad.

“...mujeres de 45 años para arriba son los donantes, la gran mayoría son de San Borja, pero también hay donantes en Miraflores, San Isidro y Surco, pero no son tan representativos.” Ivette Muñoz - Aprendo Contigo

\subsubsection{Propósito de la investigación}

Identificar el perfil de una persona natural de Lima que realiza una donación monetaria a las ONG's que favorecen a niños en la ciudad de Lima, para conseguir este propósito utilizaremos dos metodologías de investigación exploratorio y descriptiva.

\subsubsection{Tipo de investigación}

El diseño de la investigación inicialmente es exploratorio, es decir, que se aplica la investigación cualitativa a través de entrevistas a profundidad a los especialistas en ONG's Se uso está investigación para conocer un poco más sobre las variables independientes, ahondar en el conocimiento sobre el tema del perfil de una persona que realiza una donación monetaria, confirmar nuestras hipótesis y elaborar nuestro cuestionario.

Posteriormente se desarrolló una investigación descriptiva con metodología cuantitativa a través de encuestas realizadas a las personas naturales que residen en San Borja y que cuentan con 25 años a más. Se uso está investigación para cuantficar las opiniones de las personas con relación a las variables que influyen en el perfil de un donante. 


\subsubsection{Preguntas de investigación}

El presente trabajo tiene como objetivo responder la siguiente pregunta:

¿Cuál es el perfil de una persona natural que reside en Lima, que realiza una donación monetaria a las ONG's que favorecen a niños en la ciudad de Lima?

Sobre esta base, se elaboró la guía de indagación a especialistas y el cuestionario. Ver Anexo 4 y Anexo 5

\subsection{Contexto}

\subsubsection{Descripción del contexto interno y externo}

Con relación al segmento de especialistas, se realizaron entrevistas a profundidad a tres personas que cuentan con experiencia en puestos de jefatura o gerenciales en ONG's y que por lo menos contaran con cinco años de experiencia en dichos cargos, ver Anexo 6. Por cuestiones de tiempo y facilidad para las entrevistas, las reuniones se realizarán en sus centros laborales, previa coordinación de fecha y hora. En dichas reuniones se les realizará una serie de preguntas para recolectar información sobre factores de sensibilización, motivación, valoración, percepción del trabajo, frecuencia de donación monetaria, medios de donación monetaria, medios de comunicación, influenciador y frenos de donación.

Con relación al segmento de persona natural, se realizó una encuesta en San Borja. Las fechas en las que se llevó a cabo el trabajo de campo fueron los días sábado 12 y sábado 19 de mayo, en el horario de 10am a 5pm. Los lugares dónde se realizó la encuesta son lugares de alto tránsito como el mercado Santa Rosa y el parque de La Mujer, el primero está a media cuadra y el segundo a un par de cuadras de la Av. San Luis con Las Artes Norte en San Borja.

\subsection{Muestra}

\subsubsection{Descripción de la muestra}

Para el presente trabajo se plantearon dos tipos de muestras:

A. Muestreo por juicio: se eligieron a los especialistas según criterio del investigador. Los mismos que fueron: profesionales con estudios universitarios concluidos y que cuenten con mínimo de cinco años de experiencia en puestos de jefatura o gerenciales en ONG's 
generando recursos económicos, lo cual indicaba que tienen conocimiento del manejo de dicho sistema.

Tamaño de la muestra de especialistas:

- Tres entrevistas a especialistas en el tema de ONG's.

B. Mediante muestreo probabilístico aleatorio simple, se determinó que la muestra es de 224 personas naturales, las cuales son representativas del comportamiento del mercado. Todas las personas que transitan por la puerta del mercado Santa Rosa y en el parque de La Mujer en San Borja han tenido la misma probabilidad de ser elegidas para completar la encuesta. Las personas de la muestra son de ambos sexos, cuyas edades fluctúan entre 25 años a más, sin distinción de su estado civil y que residan en el distrito de San Borja. A continuación, la determinación de la muestra:

\section{Determinación de la muestra:}

Población total San Borja: 116700

Población de 25 años a más: 68502.9

Fórmula: $\mathrm{n}=\mathrm{N} * \mathrm{Z} 2 * \mathrm{p} * \mathrm{q}$

$$
\mathrm{d} 2 *(\mathrm{~N}-1)+\mathrm{Z} 2 * \mathrm{P} * \mathrm{Q}
$$

$\mathrm{N}: 116700 \quad$ p: $0.50 \quad$ d: 0.05

Z: $1.96 \quad$ q: 0.50

$\mathrm{n}=382$

Muestra: $68502.9 * 382=224$

116700

Según la aplicación de la fórmula encontramos que la muestra mínima debía de ser 224 personas.

\subsection{Diseño o abordaje principal}

\subsubsection{Identificación de la estructura de la entrevista o focus}

La entrevista a profundidad realizada a los especialistas en ONG's fue del tipo semiestructurada, ya que contó con una serie de preguntas previamente establecidas, pero 
permite incluir más preguntas según crea conveniente el entrevistador con la finalidad de encontrar más información que permita contestar la pregunta de investigación. Con relación a la encuesta, se utilizaron preguntas cerradas (preguntas con alternativas para marcar) ya que se buscó cuantificar y validar algunas variables obtenidas del estudio del perfil del donante de España 2016.

\subsubsection{Guía de preguntas}

Las preguntas realizadas a los especialistas en el tema de $\mathrm{ONG}^{\prime}$ s, están elaboradas en función a las categorías, que busca conocer las opiniones sobre el comportamiento que tienen las personales naturales que realizan aportes económicos a las ONG’s que favorecen a niños.

\subsubsection{Segmentos}

Se cuenta con dos segmentos, los cuales se detalla a continuación:

\subsubsection{Segmentos de los especialistas en ONG's}

Se buscó profesionales que cuenten con al menos cinco años de experiencia laboral desempeñando puestos de jefatura o gerenciales en $\mathrm{ONG}^{\prime}$ s generando recursos económicos.

\subsubsection{Segmentos de donantes (personas naturales)}

Se eligió a personas de ambos sexos, cuyas edades son de 25 años a más, sin distinción de su estado civil y que residan en San Borja.

\subsubsection{Categorías}

Las categorías han sido establecidas según la importancia que tienen los factores para conocer el perfil del donante. A continuación, se detalle cada una de ellas:

1. Factores de sensibilización.

2. Factores de motivación para realizar una donación monetaria.

3. Factores que valora una persona natural de una ONG. 
4. Percepción del trabajo de las ONG’s.

5. Frecuencia de donación.

6. Medio por el cual realiza una donación.

7. Medio por el cual una persona prefiere enterarse cómo realizar una donación.

8. Frenos de donación.

\subsubsection{El instrumento de investigación}

A continuación, los instrumentos de investigación:

A. Entrevistas a profundidad:

- Instrumento: guía de indagación para los especialistas. Cuenta con una serie de temas que se tocará durante las entrevistas, las preguntas están establecidas previamente, pero se permitirá incluir más preguntas según crea conveniente el entrevistador. Ver Anexo 4

B. Encuestas:

- Instrumento: cuestionario cerrado. Cuenta con dos preguntas filtro para determinar a qué persona se le aplicará está encuesta. En total son 16 preguntas, que cuentan con sus respectivas alternativas para marcar. Ver Anexo 5

Con las dos metodologías mencionadas se busca elaborar el perfil del donante. 


\section{CAPÍTULO III : ANÁLISIS DE DATOS Y RESULTADOS}

En esta sección se presentará los resultados obtenidos de la investigación cualitativa y cuantitativa.

\subsection{Procesamiento de la información}

Después de aplicar los instrumentos de la investigación cualitativa y cuantitativa, se realizó el análisis de los resultados para conocer el perfil del donante y verificar las hipótesis propuestas.

Las preguntas de las encuestas fueron procesadas con la ayuda del programa SPSS.

\subsubsection{Hallazgos de las entrevistas a profundidad}

Se analizaron los resultados del segmento de los especialistas en ONG's, cuyos resultados más importantes son los siguientes:

1. Los niños en pobreza extrema es el factor que más sensibiliza a la persona que realiza una donación monetaria a las $\mathrm{ONG}^{\prime} \mathrm{s}$

“...todos los temas de infancia siempre son mucho más sensibilizantes para las personas más que otro tema” Giorgio Muñoz-COANIQUEM

“...la gente se sensibiliza sobre todo con los niños de pobreza extrema, que tienen una carencia, que tienen una necesidad..." Juana Burga-ANIQUEM

2. El factor que más motiva a una persona natural que realiza una donación monetaria a las ONG's es su vocación de servicio, de querer brindar ayuda a otra persona.

"el querer ayudar uno, tus deseos de servicio, tus deseos de que tú veas que esos niños gracias a tu colaboración, a tu donación están recibiendo una atención..." Juana BurgaANIQUEM 
3. El aspecto que más valora una persona que realiza una donación monetaria es la causa que persigue la institución.

"El donante valora, que la causa sea clara y entendible...eso se valora mucho y es simple, por ejemplo, a Unicef, les cuesta mucho más explicar a veces lo que hacen” Giorgio MuñozCOANIQUEM

4. Las personas que realizan una donación monetaria tienen una mala percepción del trabajo de las ONG's debido a que otras instituciones no han realizado un buen uso de los fondos recaudados.

“...muchas $O N G$ 's que no han sido bien manejadas, han dado la impresión de que todas o casi todas podríamos no tener un manejo claro de los recursos, entonces eso hace que a nosotros los que tratamos de hacer un trabajo serio se nos dificulte.” Ivette Muñoz-Aprendo Contigo

5. La frecuencia principal con la que una persona natural realiza una donación monetaria es mensual.

“...los donantes más comunes son los que donan cada mes, cada seis o tres meses, por último dan una donación una vez el año pero es una donación importante” Juana BurgaANIQUEM

6. El efectivo es el medio más usado por una persona natural que realiza una donación monetaria.

“...cuando se busca hacer el uso de la tarjeta es muy dificil, los donantes creo que prefieren hacerlo de forma efectiva..." Juana Burga-ANIQUEM

7. El medio por el cual una persona natural prefiere enterarse de cómo realizar una donación es el cara a cara porque les genera más confianza. 
“...todavía tengo en mi cabeza que el face to face o cara a cara es la mejor forma de comunicarse con el donante porque hay más feeling, tú tienes está relación cordial con esa persona, al escucharte se sensibiliza, le muestras los trabajos por medio de una foto" Juana Burga-ANIQUEM

8. El principal freno de la donación es la desconfianza en las ONG's

“...ha habido mucho abuso, muchas ONG's hablan de gastos administrativos altísimos, muchas veces tienen gastos de unos sueldazos y tú dices 25 dólares mensuales y al niño le llegan 3 dólares...” Ivette Muñoz- Aprendo Contigo

“...el freno, básicamente puede tener algún nivel de desconfianza o básicamente no logra sensibilizar con la causa, también hay personas que son solidarias pero hay personas que no les gusta donar a una fundación que no les interesa... "Giorgio Muñoz-COANIQUEM.

Se analizaron los resultados del segmento de persona natural. La encuesta se realizó a un total de 224 personas de ambos sexos, que por lo menos tengan 25 años y que residan en San Borja.

A continuación, encontramos la siguiente información: 


\section{Tabla 3 : Resumen de Indicadores del Perfil del donante}

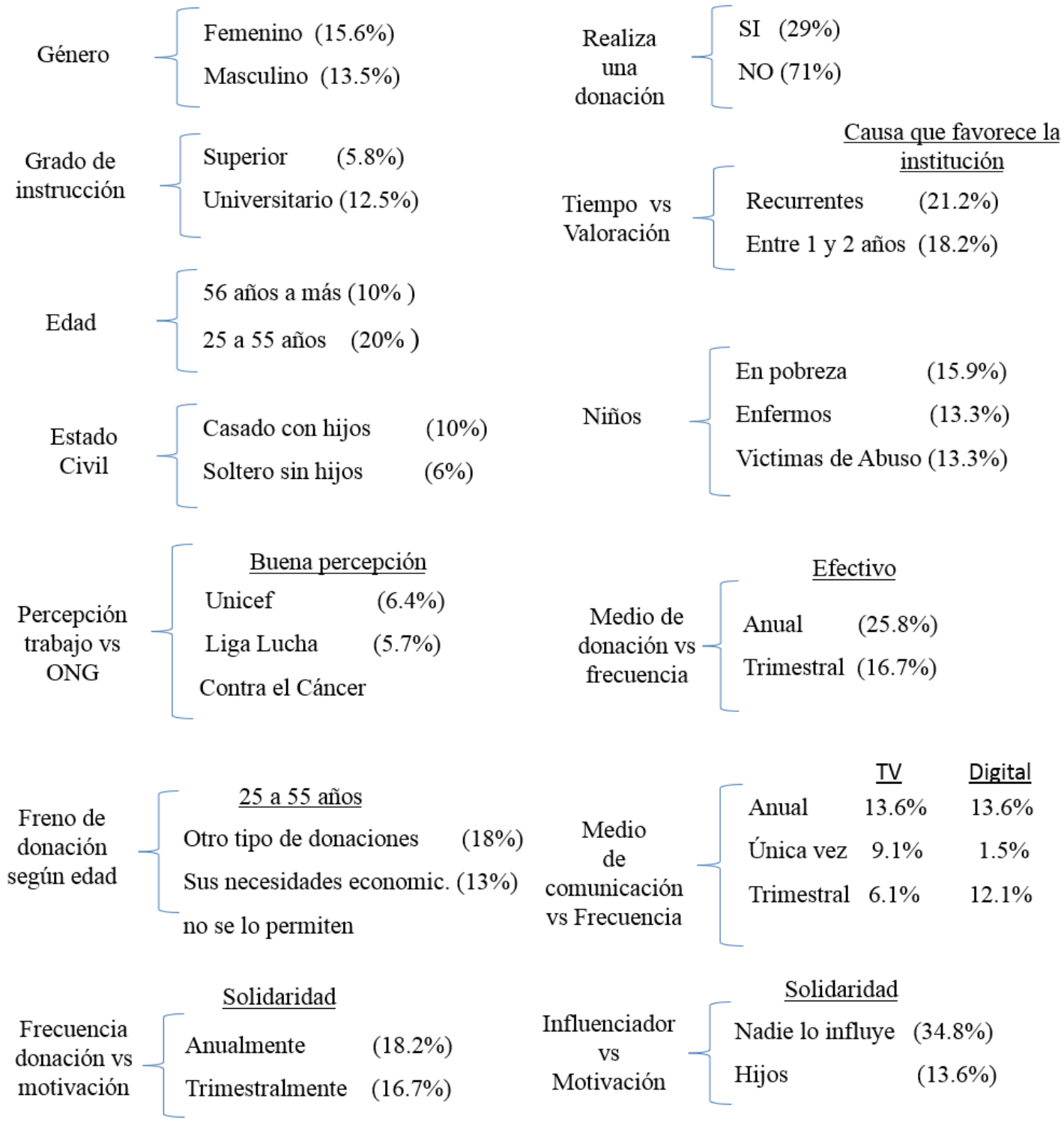

Nota: Resumen del perfil de una persona que reside en San Borja que realiza una donación monetaria a una ONG de niños en la ciudad de Lima. Elaboración propia

Como podemos observar, tres de cada diez personas realizan una donación monetaria. La mayoría de estas personas son del género femenino. El grado de instrucción de estas personas es superior, en su mayoría se encuentran en el rango de edad de 25 a 55 años. La mayoría se encuentra casado y con hijos, quienes suelen realizar siempre una donación monetaria 
valoran lo hacen porque valoran la causa que favorece la institución. El factor que más sensibiliza a estas personas son los niños en pobreza. Sin importar la ONG estás tienen en mayor o menor grado una buena percepción del trabajo que realizan estas instituciones. El efectivo es el medio por el cual prefieren realizar una donación. Estas personas suelen realizar una donación por elección propia, lo que significa que nadie las influencia y su principal motivación es la solidaridad. Uno de los principales frenos de donación se encuentra su preferencia por realizar otro tipo de donaciones como ropa o alimentos. Ver Anexo 7

\subsection{Discusión de resultados}

Tabla 4 : Resumen de Resultados

\begin{tabular}{|l|l|l|}
\hline \multicolumn{1}{|c|}{ Hipótesis } & Entrevista Profundidad & \multicolumn{1}{|c|}{ Encuestas } \\
\hline $\begin{array}{l}\text { Los niños con pobreza extrema } \\
\text { es el principal factor de } \\
\text { sensibilización. }\end{array}$ & $\begin{array}{l}\text { Los niños en pobreza } \\
\text { extrema es el factor que más } \\
\text { los sensibiliza. }\end{array}$ & $\begin{array}{l}\text { El factor más importante } \\
\text { de sensibilización son los } \\
\text { niños en pobreza } \\
\text { extrema. }\end{array}$ \\
\hline $\begin{array}{l}\text { La solidaridad es el principal } \\
\text { factor que motivación. }\end{array}$ & $\begin{array}{l}\text { El factor que más motiva a } \\
\text { donar es su vocación de } \\
\text { servicio yde brindar ayuda. }\end{array}$ & $\begin{array}{l}\text { La principal motivación } \\
\text { de donación monetaria es } \\
\text { la solidaridad. }\end{array}$ \\
\hline $\begin{array}{l}\text { La causa de la institución es el } \\
\text { aspecto que más valora en una } \\
\text { ONG }\end{array}$ & $\begin{array}{l}\text { Lo que más valora una } \\
\text { persona natural en una } \\
\text { ONG es la causa que } \\
\text { persigue la institución. }\end{array}$ & $\begin{array}{l}\text { El aspecto que más valora } \\
\text { una persona de una ONG } \\
\text { es la causa que favorecen. }\end{array}$ \\
\hline $\begin{array}{l}\text { Se tiene una mala percepción } \\
\text { del trabajo de una ONG }\end{array}$ & $\begin{array}{l}\text { Tienen una mala percepción } \\
\text { del trabajo de las ONG's } \\
\text { debido a que otras no han } \\
\text { realizado un buen uso de los } \\
\text { fondos recaudados. }\end{array}$ & $\begin{array}{l}\text { La percepción de trabajo } \\
\text { de las ONG's es buena. } \\
\text { obtenido esta calificación } \\
\text { son UNICEF y La Liga } \\
\text { de Lucha Contra el } \\
\text { Cáncer. }\end{array}$ \\
\hline $\begin{array}{l}\text { La principal frecuencia de } \\
\text { donación es mensual }\end{array}$ & $\begin{array}{l}\text { La frecuencia de donación } \\
\text { monetaria es mensual. }\end{array}$ & $\begin{array}{l}\text { La principal frecuencia } \\
\text { de donación monetaria a } \\
\text { las ONG's es mensual, lo } \\
\text { cual son motivados por la } \\
\text { solidaridad. }\end{array}$ \\
\hline
\end{tabular}




\begin{tabular}{|l|l|l|}
\hline $\begin{array}{l}\text { El efectivo es el principal } \\
\text { medio de donación. }\end{array}$ & $\begin{array}{l}\text { El efectivo es el medio más } \\
\text { usado de donación } \\
\text { monetaria. }\end{array}$ & $\begin{array}{l}\text { El efectivo es el medio } \\
\text { que más usa una persona } \\
\text { natural para realizar una } \\
\text { donación monetaria a las } \\
\text { ONG's, según los que } \\
\text { donande forma mensual. }\end{array}$ \\
\hline $\begin{array}{l}\text { El contacto directo (cara a cara) } \\
\text { es la principal forma por la cual } \\
\text { les gusta enterarse de cómo } \\
\text { realizar una donación. }\end{array}$ & $\begin{array}{l}\text { Face to face (cara a cara) es } \\
\text { la mejor forma que se } \\
\text { enteren de cómo realizar } \\
\text { una donación. }\end{array}$ & $\begin{array}{l}\text { La televisión es el } \\
\text { principal medio por el } \\
\text { cual las personas que } \\
\text { realizan donación } \\
\text { monetaria anual prefieren } \\
\text { para enterarse cómo } \\
\text { realizar estos aportes } \\
\text { económicos. }\end{array}$ \\
\hline $\begin{array}{l}\text { La desconfianza en la ONG es } \\
\text { el principal freno de donación. }\end{array}$ & $\begin{array}{l}\text { El principal freno de la } \\
\text { donación es la desconfianza } \\
\text { en las ONG's. }\end{array}$ & $\begin{array}{l}\text { El principal freno de } \\
\text { donación es la } \\
\text { preferencia de realizar } \\
\text { otro tipo de donaciones } \\
\text { (voluntariado, ropa y } \\
\text { comida, etc.). }\end{array}$ \\
\hline
\end{tabular}

Nota: Cruce de información de las encuestas con las entrevistas a profundidad y el marco teórico definido. Elaboración propia

Ver Anexo 8 


\section{CAPÍTULO IV : CONCLUSIONES, HALLAZGOS Y RECOMENDACIONES}

\subsection{Hallazgos}

Sobre la hipótesis inicial:

El perfil de una persona natural, que reside en Lima y que realiza una donación monetaria a las ONG’s que favorecen a niños en la ciudad de Lima se ve influenciada principalmente por: factores de sensibilización, motivación, valoración y percepción del trabajo de la organización.

Se procederá a responder la problemática inicial y las preguntas de investigación.

Para responder dicha pregunta;

1. ¿Cuál es el principal factor de sensibilización?

Para ambos segmentos: donante (personas naturales) y los especialistas ONG’s, el factor más importante de sensibilización son los niños en pobreza extrema.

El 15.9\% que ha realizado una donación monetaria, indico que el factor más importante de sensibilización es Niños en pobreza.

“...todos los temas de infancia siempre son mucho más sensibilizantes para las personas más que otro tema" Giorgio Muñoz-COANIQUEM

“...la gente se sensibiliza sobre todo con los niños de pobreza extrema, que tienen una carencia, que tienen una necesidad..." Juana Burga-ANIQUEM

2. ¿Cuál es la motivación más importante?

Para ambos segmentos: donante (personas naturales) y los especialistas ONG's, la principal motivación de la donación monetaria es la solidaridad.

El $28.7 \%$ que ha realizado una donación monetaria, indico que lo hizo motivado por la solidaridad. 
"el querer ayudar uno, tus deseos de servicio, tus deseos de que tú veas que esos niños gracias a tu colaboración, a tu donación están recibiendo una atención... ”Juana BurgaANIQUEM

3. ¿Cuál es el aspecto que más valora de una ONG?

Para ambos segmentos: donante (personas naturales) y los especialistas ONG's, el aspecto de las ONG's que más valora una persona natural es la causa que favorece dicha institución. El $21.2 \%$ que ha realizado una donación monetaria, indico que lo que más valora de una ONG es la causa que favorece la institución.

"El donante valora, que la causa sea clara y entendible...eso se valora mucho y es simple, por ejemplo, a Unicef, les cuesta mucho más explicar a veces lo que hacen" Giorgio MuñozCOANIQUEM

4. ¿Cuál es la percepción del trabajo de una ONG?

Según el segmento de donantes (personas naturales), la percepción del trabajo es buena, según la institución a la que uno se refiere, ya que existen algunas que tienen poca o mala percepción y hasta en algunos casos se desconoce algunas $\mathrm{ONG}^{\prime}$ s por lo cual no se tiene ninguna percepción. UNICEF y la Liga Contra el Cáncer son dos de las ONG’s que mejor percepción de trabajo tienen.

El 6.4\% que ha realizado una donación monetaria a UNICEF, indico que su percepción del trabajo de una ONG es buena.

El 5.7\% que ha realizado una donación monetaria a Liga Contra el Cáncer, indico que su percepción del trabajo de una ONG es buena.

Según el segmento de especialistas la percepción del trabajo de las ONG’s es mala, debido al mal uso de los fondos de otras instituciones similares.

“...muchas $O N G$ 's que no han sido bien manejadas, han dado la impresión de que todas o casi todas podríamos no tener un manejo claro de los recursos, entonces eso hace que a nosotros los que tratamos de hacer un trabajo serio se nos dificulte." Ivette Muñoz-Aprendo Contigo 
5. ¿Cuál es la frecuencia con la que una persona natural realiza una donación monetaria a las ONG's?

Para ambos segmentos: donante (personas naturales) y los especialistas ONG's, la principal frecuencia de donación monetaria es mensual.

El $12.1 \%$ que ha realizado una donación monetaria motivado por la solidaridad, indico que realiza una donación de forma mensual.

“...los donantes más comunes son los que donan cada mes, cada seis o tres meses, por último, dan una donación una vez el año, pero es una donación importante” Juana BurgaANIQUEM

6. ¿Cuál es el principal medio por el que realiza una donación monetaria?

Para ambos segmentos: donante (personas naturales) y los especialistas ONG's, de investigación el medio de donación monetaria más usado es el efectivo.

El 25.8\% que ha realizado una donación monetaria de forma anual, indico que lo hizo por medio de efectivo.

“...los donantes más comunes son los que donan cada mes, cada seis o tres meses, por último dan una donación una vez el año pero es una donación importante” Juana BurgaANIQUEM

7. ¿Cuál es el medio de comunicación que prefiere una persona natural para enterarse de cómo realizar una donación monetaria?

Para el segmento de donantes (personas naturales), el medio de preferencia son los digitales como Facebook, Instagram o Correo electrónico.

El 9.1\% que ha realizado una donación monetaria de forma anual, indico que el medio de comunicación que prefiere son los medios digitales (Facebook, Youtube, Instagram, etc). Para el segmento de los especialistas en ONG's el medio de preferencia es el face to face. “...todavía tengo en mi cabeza que el face to face o cara a cara es la mejor forma de comunicarse con el donante porque hay más feeling, tú tienes está relación cordial con esa persona, al escucharte se sensibiliza, le muestras los trabajos por medio de una foto" Juana Burga-ANIQUEM 
8. ¿Cuál es el principal freno para que una natural no realice una donación monetaria?

Para el segmento de donantes (personas naturales), el principal freno de donación es la preferencia de realizar otro tipo de donaciones (voluntariado, ropa y comida, etc).

El $29.1 \%$ no realiza una donación monetaria, ya que prefiere donar con otro tipo de donaciones (voluntariado, ropa, comida, etc)

Para el segmento de los especialistas en ONG's, el principal freno de donación es la desconfianza en dichas instituciones.

“...el freno, básicamente puede tener algún nivel de desconfianza o básicamente no logra sensibilizar con la causa, también hay personas que son solidarias pero hay personas que no les gusta donar a una fundación que no les interesa... "Giorgio Muñoz-COANIQUEM.

\subsection{Conclusiones}

- La desconfianza en los medios digitales de pago es una fuerte barrera de entrada para que las personas realicen una donación monetaria a las ONG's. Todavía se tiene la creencia que los datos que se proporcionan por estas plataformas pueden causar robos o pérdidas de su dinero. También está el hecho que estas instituciones no cuentan con pasarelas de pago para efectuar una transacción online que brinde seguridad a las personas y en el caso de que algunas pocas lo tengan, no lo comunican a su público objetivo. Caso que no ocurre en España, ya que de acuerdo con nuestro estudio de referencia es la tendencia, dado que este tipo de transacciones son más frecuentes, consideramos que en un futuro cercano este tipo de pago será más usual en nuestro país.

- Uno de los principales motivos por el cual no se realiza una donación monetaria es debido a la preferencia por realizar donaciones de especies como comida o ropa, principalmente por la desconfianza en el uso de los fondos que tienen estas instituciones. Tres de cada 10 entrevistados lo confirman.

- Las mujeres en promedio de 45 años, con grado de instrucción superior y que tienen 3hijos son quienes más realizan donaciones monetarias, del mismo modo la frecuencia favorita de donación es una vez al año. 
- Conocer la causa que favorecen las ONG’s es el factor más importante para que una donante se decida a apoyar o no económicamente a estas instituciones.

\subsection{Limitaciones de la investigación}

La falta de información sobre las variables para elaborar el perfil de una persona natural que reside en Lima, que realiza una donación monetaria a las ONG's fue una de las principales limitaciones. Buscamos en diversas fuentes de información tales como: repositorios de universidades, libros, publicaciones científicas y libros, pero está fue limitada.

\subsection{Dificultades que se obtuvieron}

La disponibilidad de tiempo de los especialistas en ONG's fue un factor de dificultad para realizar las entrevistas a profundidad. Con relación a las encuestas los factores de dificultad que encontramos fueron: poca predisposición y desconfianza por las personas que abordamos, ya que tenían la percepción que la encuesta era de un tema político por lo que mostraban cierta incomodidad.

\subsection{Posibles nuevas investigaciones}

Perfil de una persona natural, que reside en Lima Metropolitana, que tiene potencial para realizar una donación monetaria a las ONG’s que favorecen niños en la ciudad de Lima.

Perfil de una persona natural, que reside en Lima Metropolitana, que realiza una donación monetaria recurrente a las ONG’s que favorecen niños en la ciudad de Lima.

\subsection{Recomendaciones finales}

Para dar a conocer la labor importante que realizan las ONG’s formales en Lima es necesario comunicar su valioso trabajo en diversos medios de consumo masivo como medios digitales, televisión y prensa escrita. Las personas deben tener conocimiento de qué hacen y a quienes favorecen estas instituciones para que de esta forma generen confianza. Esto se puede lograr a través de convenios con empresas de publicidad, de canjes, contactar a famosos influencers y personas mediáticas para que apoyen la causa incondicionalmente. 
Se recomienda a las ONG que se enfoquen en la captación de donantes a través del sistema "face to face" para que incrementen sus donantes, ya que esta forma de captación permite tener un contacto directo con la persona para explicarle la causa de la institución, a quienes favorece y los trabajos que han realizado. De esta forma la persona se sensibiliza y accede a realizar una donación monetaria, generando el incremento de donantes para la organización. 


\section{REFERENCIAS BIBLIOGRAFÍA}

Alberto, F. (2001). Constitución Política 1993. Lima : Fondo Editorial Ágora Inteligencia Colectiva para la Sostenibilidad (AGORA) (2018). ¿Tienes perfil de buen donante? Tendencias mundiales de donación. Recuperado de https://bit.ly/2nWxHVr [Consulta : 21 de marzo 2018].

Araque, M. (2003). La Responsabilidad Social de la empresa en el ámbito del Marketing. España : María José Montero.

Asociación Española de Fundraising (AEFr) (2016). Perfil del donante 2016. Séptima oleada. España: AEFr. Recuperado de https://bit.ly/2Bric1p [Consulta: 03 de febrero 2018]. Asociación Española de Fundraising (AEFr) (2018). Cómo obtener grandes donaciones de personas pudientes. España: AEFr. Recuperado de https://bit.ly/2MQ3xS0 [Consulta: 20 de junio de 2018].

Asociación Peruana de Investigación de Mercados (APEIM) (2017). Niveles socioeconómicos 2017. Lima: APEIM. Recuperado de https://bit.ly/2wKadVO [Consulta: 23 de junio de 2018].

Asociación Proade (PROADE) (2017). Tipos de organizaciones no lucrativas. España: PROADE. Recuperado de https://bit.ly/2MXBS1K [Consulta: 9 de junio de 2018].

Banco Mediolanum (MEDIOLANUM) (2018). Tres diferencias entre una ONG y una fundación. España: MEDIOLANUM. Recuperado de https://bit.ly/2wmrExo [Consulta: 8 de junio de 2018].

Bartoli, A. (1992). La organización comunicante y la comunicación organizada. España: Paidos.

Bernal, J. A. (1992). Definición, Tipología y características de las ONG.

Blog Pontificia Universidad Católica del Perú (PUCP) (2017). Aspectos tributarios de las asociaciones sin fines de lucro. Lima: PUCP. Recuperado de https://bit.ly/2PDrdHT [Consulta: 10 de junio de 2018].

Bobadilla, P. (2017). Las ONG en la era de la globalización: cambios y permanencias en su identidad y rol institucional. Recuperado de https://bit.ly/2BPja7V [Consulta: 22 de junio de 2018].

Capriotti, P. (1999). Planificación Estratégica de la Imagen Corporativa. Barcelona: Ariel. 
Carneiro, M. (2004). La responsabilidad Social Corporativa Interna. Madrid: Deusto.

Castán, J. (1998). Derecho Civil Español, Común y Foral. Madrid: Reus.

Christian, B. (2007). Cómo Administrar una organización No Gubernamental ONG. Buenos Aires : Universidad Católica Argentina. Ágora Inteligencia Colectiva para la Sostenibilidad Costa, J. (2004). La Imagen de la Marca: Un fenómeno Social. Madrid: Ibérica.

Dirección General de Impuestos Internos (DIGII) (2018). Asociaciones sin fines de lucro. Recuperado de https://www.dgii.gov.do/informacionTributaria/publicaciones/manualesTributarios/Docum ents/RevistaAsociacionesSinFinesdeLucro.pdf [Consulta: 19 de abril 2018]

El Comercio (2017). En qué instituciones confían los peruanos. El Comercio. Recuperado de https://bit.ly/2J2IWF0 [Consulta: 19 de junio de 2018].

Fundación Eroski (EROSKI) (2009). Las ONG españolas ganan socios y logran aumentar su presupuesto a pesar de la crisis. España: EROSKI. Recuperado de http://ong.consumer.es/conclusiones/ [Consulta: 8 de junio de 2018].

EsGlobal (ESGLOBAL) (2008). Las ONG más poderosas. España: ESGLOBAL. Recuperado de https://bit.ly/2ofq0tD [Consulta: 17 de junio de 2018].

Federación Antioqueña ONG (FAONG) (2018). Qué es una ONG. Colombia: FAONG.

Fernández, G. (2005). Administración de la responsabilidad social corporativa. Madrid: Thompson.

García, A. (2006). Ley No 27692, APCI. Recuperado de https://bit.ly/2LfXfpQ [Consulta: 06 de diciembre 2018].

Georgina, N. (2010). Responsabilidad Social Corporativa una nueva cultura empresarial. Madrid: Club Universitario.

Gestión (2015). ONG estigmatizadas. Un 79.7\% de peruanos tiene una percepción positiva sobre estas organizaciones. Gestión. Recuperado de https://bit.ly/2LtRJ2Y [Consulta: 15 de junio de 2018].

Ghemawat, P. (2007). Estrategia y el Panorama Empresarial. España: Prentice Hall.

Keller, K. (2008). Administración estratégica de marca. México: Pearson.

Agora Inteligencia Colectiva para la Sostenibilidad (AGORA) (2018). ¿Tienes perfil de buen donante? Tendencias mundiales de donación. Recuperado de https://bit.ly/2nWxHVr [Consulta: 21 de marzo 2018] 
La Agencia de la ONU para los Refugiados (ACNUR) (2018). Conoce Acnur Protegemos a los refugiados en cualquier parte del mundo. Recuperado de https://eacnur.org/es/que-esacnur [Consulta: 15 de mayo 2018]

Marin, L. (1997). La comunicación en las empresas y en las organizaciones. Barcelona: Bosh.

Municipalidad de San Borja (MUNISANBORJA) (2018). Ayúdanos a dar. Lima: MUNISANBORJA. Recuperado de https://bit.ly/2Mwdxk2 [Consulta 24 de junio de 2018]. Nombres ABC (NOMBRES) (2016). Ejemplos de ONG y sus funciones. España: NOMBRES. Recuperado de https://bit.ly/2Mz6uqV [Consulta 13 de junio de 2018].

Paul, A. (2014). Comunicación Estratégica y su contribución a la reputación. Argentina: Mc Graw Hill.

Pérez, G. (2006). Organizaciones no Gubernamentales ONG: Conceptualización y contextualización. Medellín : Tragaluz

Pérez, G, Arango, M \& Sepúlveda, L. (2011). Las organizaciones no gubernamentales ONG: hacia la construcción de su significado. Recuperado de https://bit.ly/2zoEheT [Consulta: 14 de junio de 2018].

Pineda, J. (1999). Las organizaciones sin ánimo de lucro para el desarrollo. Colombia Innovar.

Pintado, E. (2003). INFORME N. ${ }^{\circ}$ O66-2015-SUNAT/5D0000. Lima: Ministerio de Justicia. Pizzolante, N. I. (2004). El Poder de la Comunicación Estratégico. Bogotá: Universidad Javeriana.

Real Academia Española (RAE) (2018). Diccionario. España: RAE. Recuperado de https://bit.ly/2L8m2fC [Consulta: 01 de abril 2018].

Respuestas Tips (RESPUESTAS TIPS) (2016) Qué es una ONG y cuál es su función. España: RESPUESTAS TIPS. Recuperado de https://bit.ly/2LvDhaR [Consulta: 16 de junio de 2018].

Semana Económica (2017). Cuáles son las ONG más poderosas en el Perú. Semana Económica. Recuperado de https://bit.ly/2PCtG5c [Consulta: 18 de junio de 2018].

Suárez, F. (1995). Debilidades de la ONG. Buenos Aires: Enoikos.

United Nations System (UNS). (2009). About. Lima : UNS. Recuperado de https://bit.ly/2w1FYff [Consulta : 5 de febrero de 2018]. 
Wilex, D. L. (2010). Relaciones Publicas, estratégicas y Tácticas. Lima Pearson. 


\section{ANEXOS}

ANEXO 1: Perfil del donante 2016

\section{Situación de partida}

La Asociación Española de Fundfraising (AEFr) es una organización no lucrativa cuya misión es contribuir al éxito del sector de la captación de fondos mediante su profesionalización. Representa los intereses de toda clase de instituciones que defienden causas de interés público y general, para la financiación de cuyas actividades, programas y servicios desarrollan estrategias de captación de fondos privados comprometiendo a la ciudadanía y a instituciones privadas.

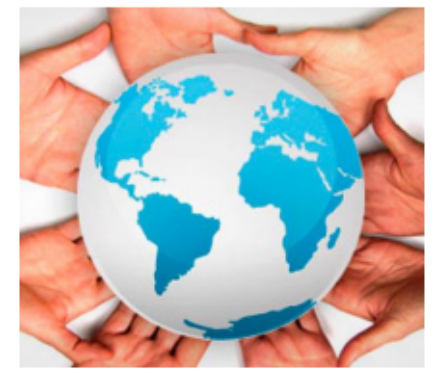

Debido a la inexistencia de una referencia rigurosa, útil y aceptada por el sector, surgió la necesidad de realizar un estudio sobre el perfil del donante y las dimensiones y causas de la donación.

Por todo ello, en Noviembre del 2004, SALVETTILLOMBART realizó un estudio de base sobre el mercado de las ONG, con el fin de realizarse con cierta periodicidad y convertirse en referencia para el sector y para la sociedad en general. De esta manera, en Mayo de 2006, en Noviembre de 2008, en Diciembre del 2010 y en noviembre del 2014, se llevaron a cabo sucesivas olas del estudio para entender la evolución que se había producido durante el tiempo, y en la actualidad se ha realizado una séptima ola con el mismo fin.

En el presente informe se recogen los resultados de esta séptima y última ola hasta la fecha. 


\section{ONG que han participado en el Estudio}

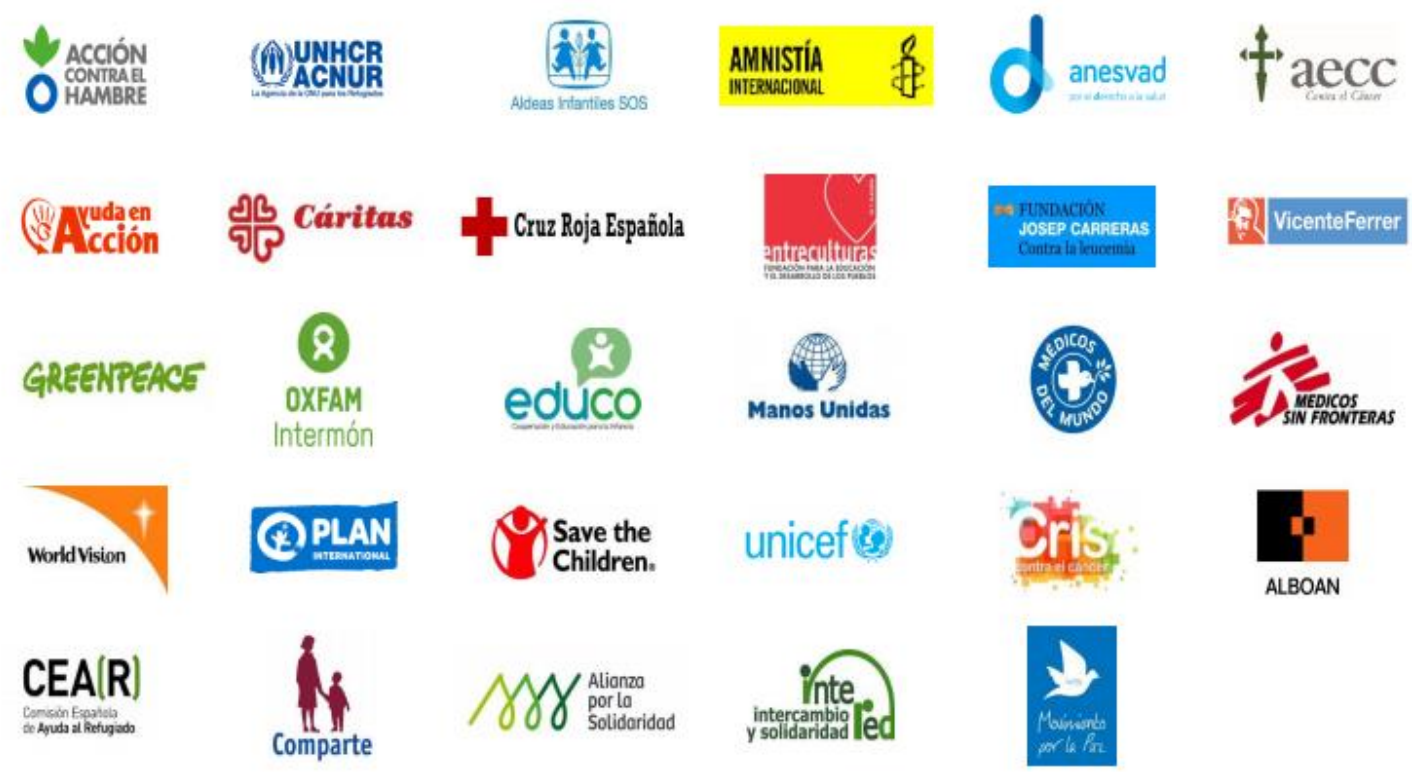

\section{FICHA TÉCNICA DEL ESTUDIO}

\subsection{3 entrevistas aleatorias +1.151 entrevistas forzadas de socios/donantes actuales $=2.364$ entrevistas}

UNIVERSO OBJETO DE ESTUDIO

(3) Personas de ambos sexos de 180 más años, de todas las clases sociales.

9 ÁMBITO GEOGRÁFICOY PUNTOS DE MUESTREO

b) Todo territorio nacional: Varios puntos de muestreo por CCAA.

TAMAÑO MUESTRAL Y DISTRIBUCIÓN MUESTRA

$\sqrt{\Gamma}$ Hay dos muestras de entrevistados diferentes:

- Muestra aleatoria población +18 años (1.213 entrevistas)

- Adicionalmente se ha realizado una muestra booster (forzada) para cada una de las ONG que colaboran en el proyecto (1.151 entrevistas)

F PLAN MUESTRAL/VARIABLESESTRATIFICACIÓN

Cuotas:

- Sexo

- Edad

- Zona CCAA

- ONG con la que colabora (sólo para los donantes actuales) 


\section{Situaciones que generan mayor sensibilización}

\% individuos

Base donantes actuales $y$ donantes potenciales

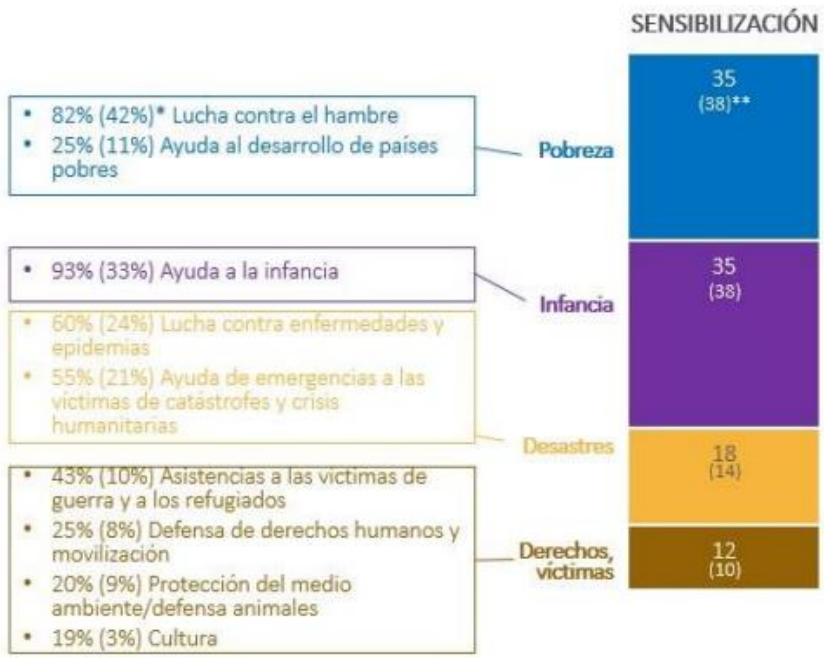

LA INFANCIA Y LA POBREZA SON LAS POBLACIONES QUE GENERAN MAYOR SENSIBIUZACIÓN.

Se han identificado 4 tipologias de donantes que se diferencian según la causa que los mueve para donar a una ONG:

" El comprometido con el desarrollo de los paises pobres $(35 \%)$

- El sensibilizado con la infancia (35\%)

" Los que se movilizan ante emergencias / catástrofes (18\%). Este target es muy susceptible a movilizarse ante causas sociales. La presión mediática de los medios de comunicación ante hechos de este tipo es el elemento clave que activa la sensibilización de este tipo de perfil ante estas situaciones de emergencia.

" Un grupo más reducido (12\%) vinculado a ONG que trabajan por la defensa de los derechos hurnanos $y$ sectores marginados.

\section{Percepción del trabajo de las ONG}

¿QUÉ INSTITUCIONES CONIRIBUYEN A PAUIAR / CORREGIR PROBLEMAS QUE ENFRENTAN AL MUNDO?
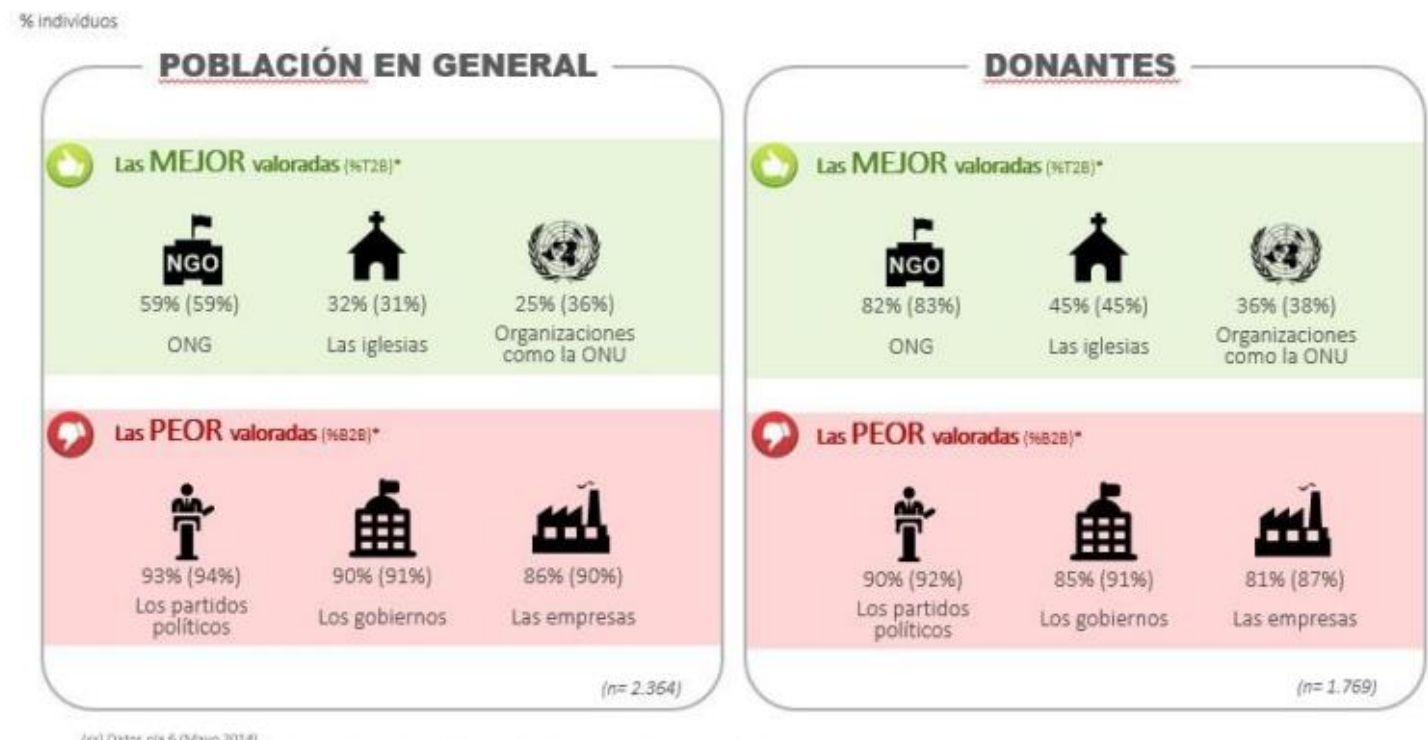

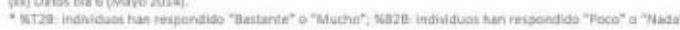




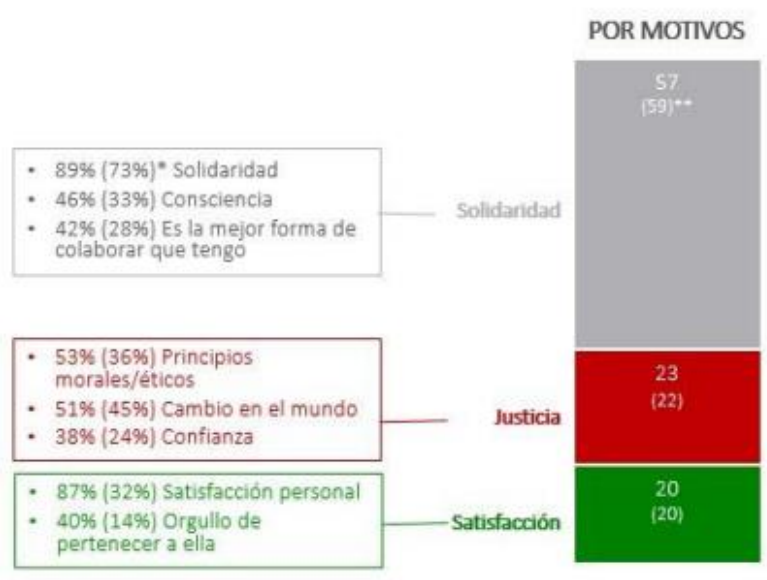

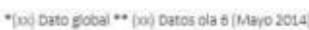

EL DONANTE SIGUE APORTANDO PRINCIPAIMENTE POR SOUIDARIDAD.

Se han identificado tres tipologías de donantes en función de sus motivos para donar:

" La gran mayoría, el 57\%, aporta por solidaridad. Siente que es justo solidarizarse con los más necesitados.

- Otro 23\% tiene un perfil más idealista, el de justicia colabora bajo el convencimiento de que se puede mejorar el mundo.

* Un 20\% colabora por satisfacción personal (sentirse bien consigo mismo).

$(n=2100)$

\section{Frenos a la Donación}

\% individuos

Base: no potenciales

\section{FRENOS A LA COLABORACIÓN ${ }^{*}$}

$24 \%$

Han buscado información sobre alguna ONG

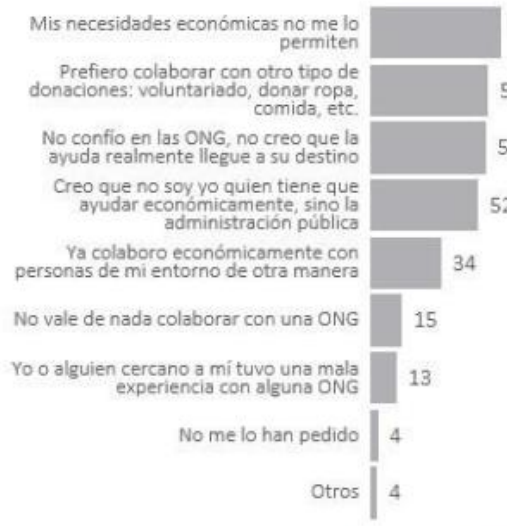

$63(64 \%) 82 \% \quad 52 \%$

$57 \quad(53 \%) \quad 57 \% \quad 58 \%$

$56 \quad(40 \%) \quad 45 \% \quad 63 \%$

52 (61\%) $43 \% \quad 58 \%$

(40\%) $41 \% \quad 31 \%$

(12\%) $9 \% \quad 19 \%$

(13\%) $14 \% \quad 129$

(11\%) $3 \% \quad 4 \%$

(3\%) $4 \% \quad 3 \%$

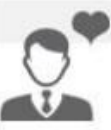

QUÉ LE MOTIVARÍA A COLABORAR

$12 \%$ (11\%)

Se ha planteado colaborar económicamente alguna vez

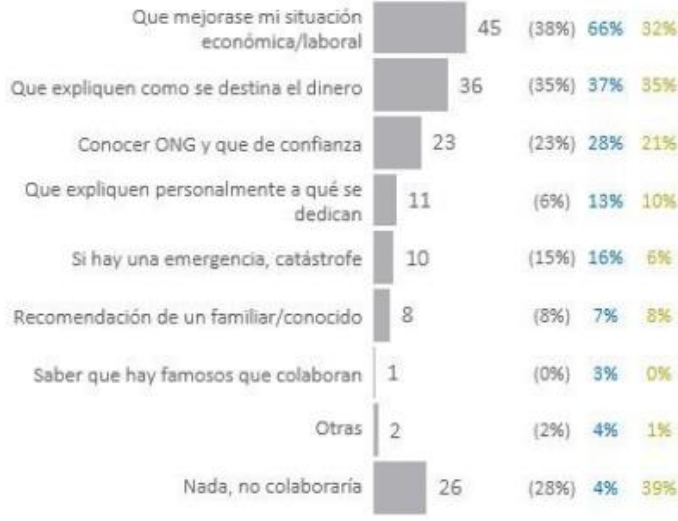
$(n=264)(n=81)(n=183)$ 


\section{Valoración de las ONG en general}

\% individuos

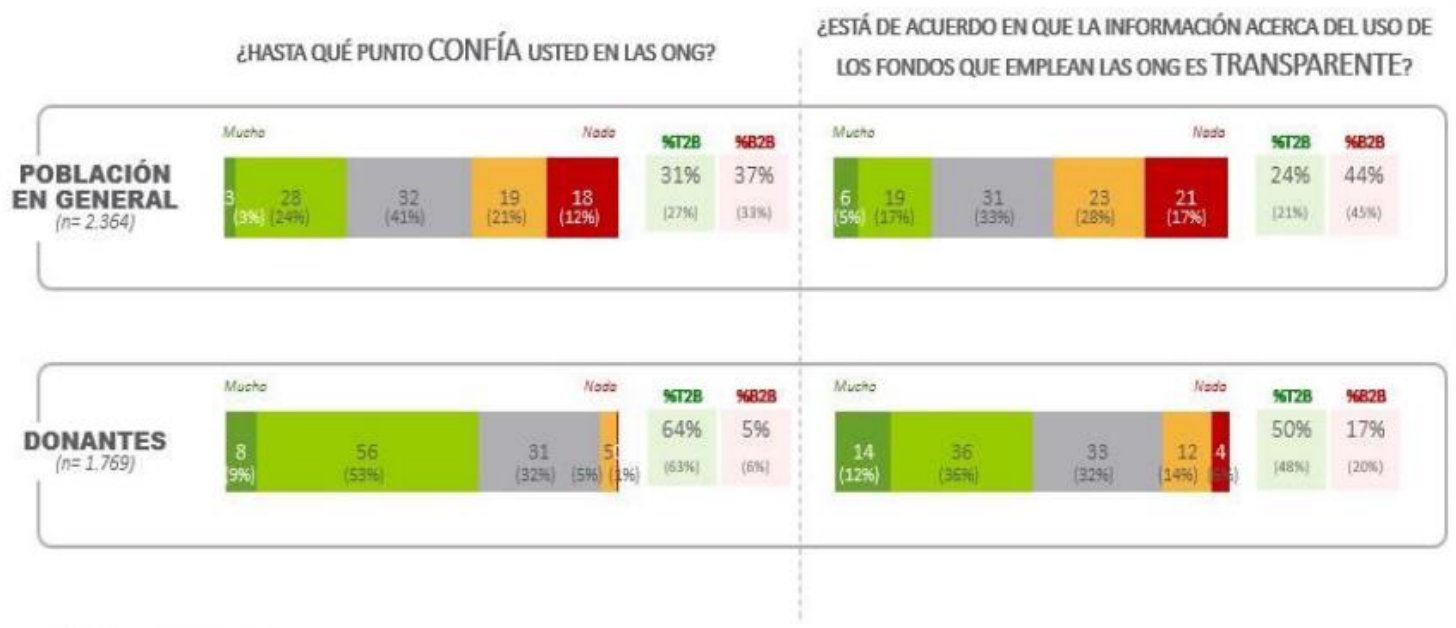

(xo) Datos ola 6 (Mayo 2014).

\section{Perfil del Donante , ¿Cómo es? (I de II)}
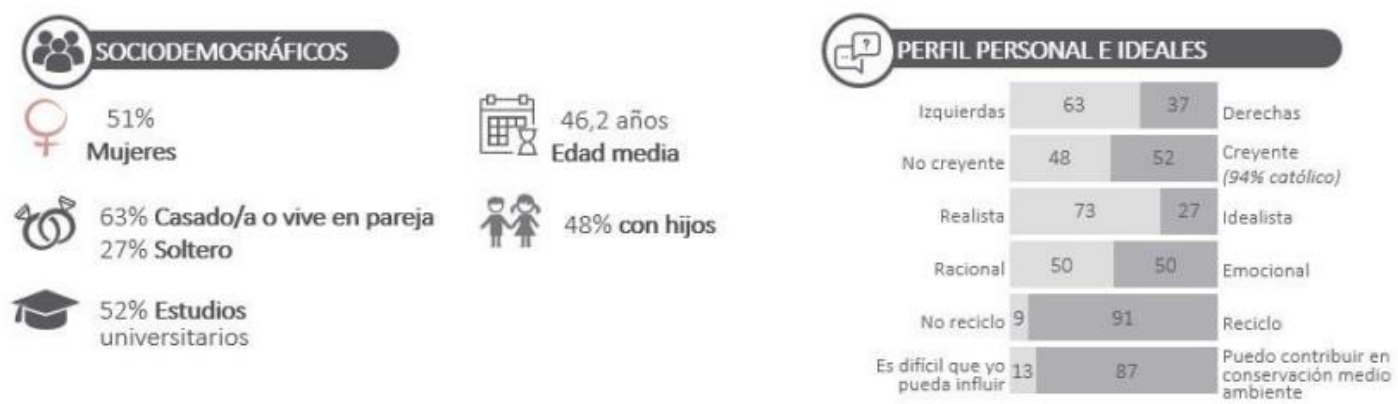


\section{Perfil del Donante , ¿Cómo es? (II de II)}

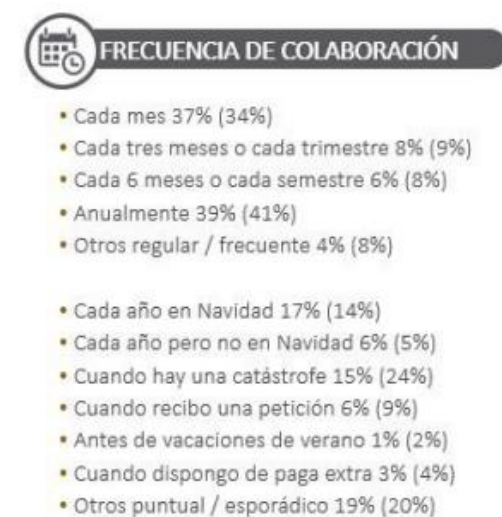

(xoj) Oatos ola 6 (Mayo 2014). = $9672 B$ : Individuos han respondido "Seguro que si" "Probablemente si" o "Quizás"
INTENCIÓN FUTURA DE REMPLAZO ENTRE ONG

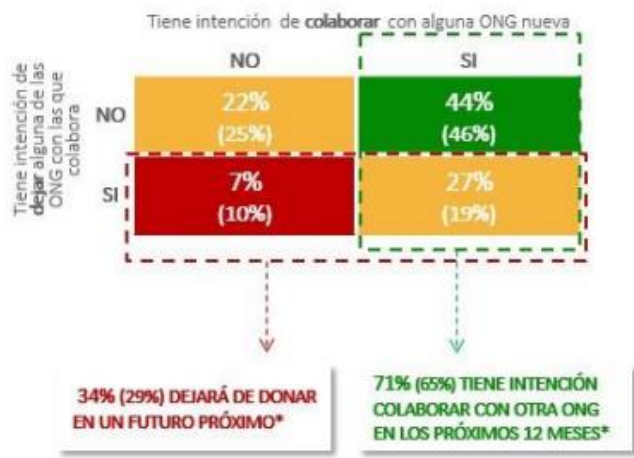

$(n=1.769)$

\section{Situación de Partida}

- Más de 9.300 .000 personas declaran haber colaborado económicamente con el tercer sector durante el último año (el $24 \%$ de la población) y un $12 \%$ (unos 4.500 .000 individuos) lo hacen de forma regular. Esto implica que el mercado a nivel cuantitativo aumenta 4 puntos respecto la última ola.

- La mitad de los individuos también han realizado microdonaciones en el último año, sobre todo mediante compra de productos, recolectas y SMS.

- Se mantiene elevado el volumen de mercado que no confía / no considera transparentes a las entidades del tercer sector: un tercio de la población no confía en ellas y casi la mitad cree que no son del todo transparentes. Sin embargo, mejora ligeramente la imagen de las ONG respecto al año pasado en general (mejora $18 \%$ vs $12 \%$ ). Continúan siendo las ONG las instituciones mejor valoradas a la hora de paliar los problemas que enfrentan el mundo.

- Otras referencias al territorio colaborativo son la Iglesia en segundo lugar y organizaciones como la ONU en tercer lugar. Pero en ningún caso son los partidos políticos, los gobiernos o las empresas.

- Los donantes escogen colaborar con su ONG por la buena labor que realizan y por la confianza que tienen depositada en ella. Un 34\% de los donantes se plantea dejar de colaborar con alguna ONG en el próximo año, principalmente por motivos económicos/desempleo o porque prefiere ir cambiando de ONG para que el dinero llegue a más causas. Sin embargo, un $44 \%$ también declara que seguramente o probablemente ampliará su colaboración a otras ONG.

- Los principales frenos a la colaboración por parte de los no potenciales, además de los económicos (63\%), son la preferencia por la colaboración en especie (57\%) y la desconfianza en las ONG (56\%). 
ANEXO 2: Tendencias mundiales de donación

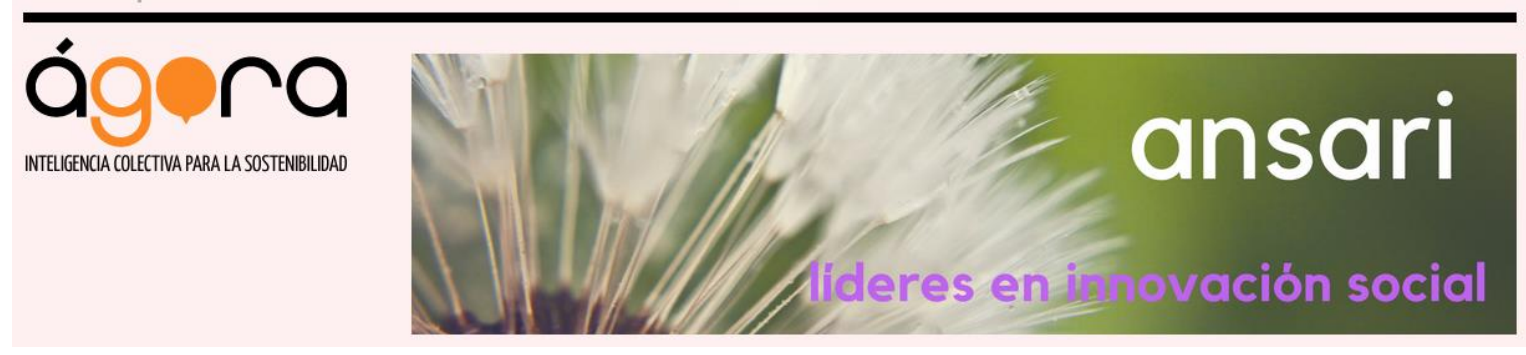

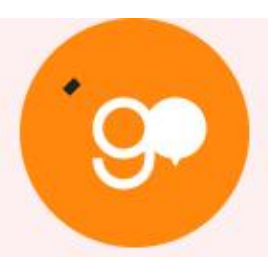

AGORA

\section{¿Tienes perfil de buen donante? Tendencias mundiales de donación}

LOS DONANTES DE TODO EL MUNDO PREFIEREN DONAR:

\begin{tabular}{|c|c|c|}
\hline ए & En linea & $61 \%$ \\
\hline 6 & Eventos de recaudación de fondos & $14 \%$ \\
\hline i & Correo directo & $14 \%$ \\
\hline & Móvil & $6 \%$ \\
\hline & Lugar de trabajo & $5 \%$ \\
\hline
\end{tabular}

EL $61 \%$ DE LOS DONANTES SE SIENTEN MÁS INSPIRADOS DURANTE LAS FESTIVIDADES.

Las cinco principales

EL $61 \%$ DE LOS DONANTES SE SIENTEN MÁS INSPIRADOS DURANTE LAS FESTIVIDADES.

Las cinco principales

\begin{tabular}{l|r} 
Navidad & $\mathbf{7 7} \%$ \\
dy Pascua & $2 \%$ \\
(*) Eid al-Fitr & $2 \%$ \\
(5) Rosh Hashanah & $2 \%$ \\
ili Janucá & $1 \%$
\end{tabular}

EL 54\% DE LOS DONANTES PARTICIPAN EN UN PROGRAMA DE DONACIONES PERIÓDICAS.

\begin{tabular}{ll|r}
$\frac{17}{1}$ Mensual & $\mathbf{8 2} \%$ \\
\hline 122 & Anual & $9 \%$ \\
\hline 52 & Semanal & $6 \%$ \\
\hline 42 & Trimestral & $3 \%$
\end{tabular}

EL $91 \%$ DE LOS DONANTES DURANTE FESTIVIDADES DICEN QUE LES INSPIRAN LA ESPERANZA Y LA EMPATIA.

Las cinco principales causas durante las festividades

EL $91 \%$ DE LOS DONANTES DURANTE FESTIVIDADES DICEN QUE LES INSPIRAN LA ESPERANZA Y LA EMPATÍA.

Las cinco principales causas durante las festividades

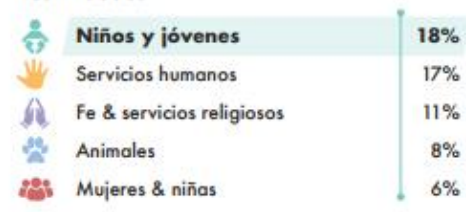

EL 45\% DE LOS DONANTES DONAN A ASOCIACIONES SIN FINES DE LUCRO Y ONG FUERA DE SU PAÍS DE RESIDENCIA.

Los cinco principales paises
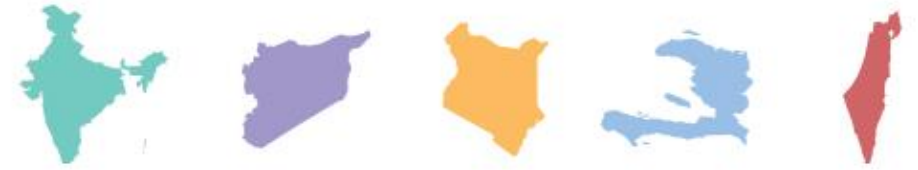


\section{4,541 ENCUESTADOS}

Donaron el año anterior

No donaron el año anterior

$91.4 \%$

$8.6 \%$

\section{DESTINO DE LAS DONACIONES}

Animales

Artes \& cultura

Niños \& jóvenes

Desarrollo comunitario

Educación

Medioambiente

Salud \& seguridad

Derechos humanos \& civiles

Servicios humanos

Desarrollo internacional

Paz \& no violencia

$\mathrm{Fe} \&$ servicios religiosos

Investigación \& política pública

Mujeres \& niñas

\section{REGIONES}

África

Asia

Australia \& Oceanía

Europa

Norteamérica

Suramérica
SEXO

Mujer

$73 \%$

Hombre

$26.5 \%$

No binario

$.5 \%$

\section{GENERACIÓN}

Generación Z (a partir de 1998)

$1.6 \%$

Mileniales (1981-1997)

$25.7 \%$

Generación X (1965-1980)

$30 \%$

Baby Boomers (1946-1964)

$36.7 \%$

Generaciones anteriores (antes de 1945)

$6 \%$

\section{IDEOLOGÍA}

Muy liberal

Bastante liberal

Moderado

Bastante conservador

Conservador

$28.1 \%$

$33.8 \%$

$24.6 \%$

$9.9 \%$

$3.6 \%$

\section{PAISES}

\section{Estados Unidos}

$47.1 \%$

Canadá

Australia

$25.5 \%$

$9.2 \%$

$3.8 \%$

$1.5 \%$

India

Otros 


\section{ANEXO 3: Directorio APCI (ONG’́s de Niños inscritas)}

DIRECTORIO DE ONGD QUE TRABAJAN TEMAS RELACIONADOS A: EDUCACION - SALUD - VIVIENDA

\begin{tabular}{|c|c|c|c|c|c|c|}
\hline $\mathrm{N}^{\circ}$ & R.U.C. & INSTITUCION & DEPARTAMENTO & PROVINCIA & SECTOR & TEMA \\
\hline 1 & 20516231930 & ACCION HUMANITARIA SIN FRONTERAS & LIMA & LIMA & EDUCACION/MUJER Y DESARROLLO SOCIAL/SALUD/ & $\begin{array}{l}\text { EDUCACION - SALUD - OTROS SERVICIOS E } \\
\text { INFRAESTRUCTURAS SOCIALES - }\end{array}$ \\
\hline 2 & 20417319159 & ACCION POR LOS NIÑOS & LIMA & LIMA & $\begin{array}{l}\text { EDUCACION/MUJER Y DESARROLLO SOCIAL/SALUD/TRABAJO Y } \\
\text { PROMOCION SOCIAL/ }\end{array}$ & $\begin{array}{l}\text { EDUCACION - SALUD Y NUTRICION - DESARROLLO Y } \\
\text { PROTECCION DEL NIÑO Y ADOLESCENTE - POBLACION } \\
\text { - }\end{array}$ \\
\hline 3 & 20514883182 & ACCION SOCIAL E INTEGRACION & LIMA & LIMA & $\begin{array}{l}\text { ECONOMIA Y F FINANZAS/EDUCACION/MUJER Y DESARROLLO } \\
\text { SOCIAL/SALUD/ }\end{array}$ & EDUCACIÓN - SALUD - MUJER Y DESARROLLO - \\
\hline 4 & 20138861300 & $\begin{array}{l}\text { AGENCIA ADVENTISTA PARA EL DESARROLLO Y } \\
\text { RECURSOS ASISTENCIALES - PERU }\end{array}$ & LIMA & LIMA & EDUCACION/MUJER Y DESARROLLO SOCIAL/SALUD/OTROS/ & $\begin{array}{l}\text { DESARROLLO SOCIAL - AYUDA HUMANITARIA - } \\
\text { EDUCACION - SALUD Y NUTRICION - AYUDA Y/O } \\
\text { SEGURIDAD ALIMENTARIA - POBLACION - }\end{array}$ \\
\hline 5 & 20136745582 & $\begin{array}{l}\text { ALTERNATIVA CENTRO DE INVESTIGACION } \\
\text { SOCIAL Y EDUCACION POPULAR }\end{array}$ & LIMA & LIMA & SALUD/PCM/ & $\begin{array}{l}\text { SALUD Y NUTRICION - SANEAMIENTO BASICO - } \\
\text { GENERACION DE EMPLEO/INGRESOS - PEQUENAA Y } \\
\text { MEDIANA EMPRESA - }\end{array}$ \\
\hline 6 & 20511799512 & $\begin{array}{l}\text { ALTERNATIVAS SOCIALES DE DESARROLLO - } \\
\text { PERU }\end{array}$ & LIMA & LIMA & SALUD/ & DESARROLLO SOCIAL - SALUD Y NUTRICION - \\
\hline 7 & 20514035092 & APORTES PARA EL DESARROLLO HUMANO & LIMA & LIMA & EDUCACION/MUJER Y DESARROLLO SOCIAL/ & EDUCACIÓN - MUJER Y DESARROLLO - \\
\hline 8 & 20137530911 & APOYO A PROGRAMAS DE POBLACION - APROPO & LIMA & LIMA & EDUCACION/MUJER Y DESARROLLO SOCIAL/SALUD/PCM/OTROS/ & $\begin{array}{l}\text { OTROS - DESARROLLO SOCIAL - TRANSFERENCIA } \\
\text { TECNOLOGICA - AYUDA HUMANITARIA - EDUCACION - } \\
\text { SALUD Y NUTRICION - DESARROLLO Y PROTECCION } \\
\text { DEL NIÑO Y ADOLESCENTE - POBLACION - }\end{array}$ \\
\hline 9 & 20545329540 & $\begin{array}{l}\text { ASOCIACION BENEFICA MARIA ECHEVARRIA } \\
\text { SAONA }\end{array}$ & LIMA & LIMA & MUJER Y DESARROLLO SOCIAL/SALUD/ & SALUD - \\
\hline
\end{tabular}




\begin{tabular}{|c|c|c|c|c|c|c|}
\hline 10 & 20156178889 & ASOCIACION BENEFICA PRISMA & LIMA & LIMA & AGRICULTURA/MUJER Y DESARROLLO SOCIAL/SALUD/PCM/ & $\begin{array}{l}\text { AYUDA HUMANITARIA - SALUD Y NUTRICION - AYUDA } \\
\text { Y/O SEGURIDAD ALIMENTARIA - AGRARIO - }\end{array}$ \\
\hline 11 & 20553740313 & ASOCIACION BUENA EDUCACION & LIMA & LIMA & EDUCACION/ & EDUCACIÓN - \\
\hline 12 & 20515763733 & ASOCIACION CASAS DE LA MISERICORDIA & LIMA & LIMA & EDUCACION/MUJER Y DESARROLLO SOCIAL/SALUD/ & EDUCACIÓN - SALUD - MUJER Y DESARROLLO - \\
\hline 13 & 20549430326 & ASOCIACION CHOQUE AUQUI & LIMA & LIMA & SALUD/OTROS/ & SALUD - PROTECCIÓN GENERAL MEDIO AMBIENTE - \\
\hline 14 & 20509870609 & $\begin{array}{l}\text { ASOCIACION CIVIL ALIANZA PARA EL } \\
\text { DESARROLLO TUMI }\end{array}$ & LIMA & LIMA & $\begin{array}{l}\text { AGRICULTURA/EDUCACION/TURISMO/MUJER Y Y DESARROLLO } \\
\text { SOCIAL/SALUD/TRABAJO Y PROMOCION SOCIAL/VIVIENDA Y } \\
\text { CONSTRUCCION/OTROS/ }\end{array}$ & $\begin{array}{l}\text { OTROS - DESARROLLO SOCIAL - TRANSFERENCIA } \\
\text { TECNOLOGICA - DESARROLLO ECONOMICO - } \\
\text { EDUCACION - SALUD Y NUTRICION - VIVIENDA - } \\
\text { GENERACION DE EMPLEO/NGRESOS - POBLACION - } \\
\text { FORMACION-EDUCACION TECNICA Y PROFESIONAL - } \\
\text { DESARROLLO ALTERNATIVO - PEQUENAA Y MEDIANA } \\
\text { EMPRESA - TURISMO - }\end{array}$ \\
\hline 15 & 20429082235 & ASOCIACION CIVIL DIVINO NIÑO JESUS & LIMA & LIMA & $\begin{array}{l}\text { EDUCACION/MUJER Y DESARROLLO SOCIAL/SALUD/TRABAJO Y } \\
\text { PROMOCION SOCIAL/OTROS/ }\end{array}$ & $\begin{array}{l}\text { OTROS - TRANSFERENCIA TECNOLOGICA - AYUDA } \\
\text { HUMANITARIA - EDUCACION - SALUD Y NUTRICION - } \\
\text { DESARROLLO Y PROTECCION DEL NIÑO Y } \\
\text { ADOLESCENTE - POBLACION - }\end{array}$ \\
\hline 16 & 20536464680 & ASOCIACION CIVIL ESENCIAS & LIMA & LIMA & EDUCACION/JUSTICIA/ & EDUCACIÓN - Derechos humanos. \\
\hline 17 & 20550570875 & $\begin{array}{l}\text { ASOCIACION CIVIL FORJANDO TALENTOS } \\
\text { ANDRES BELLO }\end{array}$ & LIMA & LIMA & EDUCACION/MUJER Y DESARROLLO SOCIAL/ & EDUCACIÓN - MUJER Y DESARROLLO - \\
\hline 18 & 20503611954 & $\begin{array}{l}\text { ASOCIACION CIVIL FUNDACION CONTRA EL } \\
\text { HAMBRE Y LA POBREZA EN EL CALLAO }\end{array}$ & LIMA & CALLAO & MUJER Y DESARROLLO SOCIAL/SALUD/ & SALUD - MUJER Y DESARROLLO - \\
\hline 19 & 20474666876 & ASOCIACION CIVIL IMPACTA SALUD Y EDUCACION & LIMA & LIMA & EDUCACION/SALUD/ & EDUCACION - SALUD Y NUTRICION - \\
\hline 20 & 20514680583 & $\begin{array}{l}\text { ASOCIACION CIVIL PARA LA GESTION DEL AGUA } \\
\text { EN CUENCAS }\end{array}$ & LIMA & LIMA & SALUD/ & SALUD - \\
\hline 21 & & $\begin{array}{l}\text { ASOCIACION CIVIL POR LA SALUD, LA EDUCACION } \\
\text { YEL TRABAJO }\end{array}$ & LIMA & LIMA & $\begin{array}{l}\text { AGRICULTURA/EDUCACION/ENERGIA } \\
\text { DESARROLLO SOCIAL/ }\end{array}$ & $\begin{array}{l}\text { España : ÓN - AGRICULTURA - RECURSOS MINERALES } \\
\text { Y MINERÍA - MUJER Y DESARROLLO - }\end{array}$ \\
\hline
\end{tabular}




\begin{tabular}{|c|c|c|c|c|c|c|}
\hline 22 & 20515342126 & $\begin{array}{l}\text { ASOCIACION CIVIL POR LA SALUD, LA EDUCACION } \\
\text { YEL TRABAJO LOS HIJOS DEL SOL }\end{array}$ & LIMA & LIMA & EDUCACION/OTROS/ & EDUCACIÓN - Política de empleo y gestión administrativa. - \\
\hline 23 & 20513578769 & ASOCIACION CIVIL SOLIDARIOS ABC & LIMA & LIMA & MUJER Y DESARROLLO SOCIAL/SALUD/ & SALUD - MUJER Y DESARROLLO - \\
\hline 24 & 20541406060 & ASOCIACION COMPARTIENDO VIDA Y SALUD & LIMA & LIMA & $\begin{array}{l}\text { AGRICULTURA/EDUCACION/MUJER } \\
\text { SOCIAL/SALUD/ }\end{array}$ & $\begin{array}{l}\text { EDUCACIÓN - SALUD - PROTECCIÓN GENERAL MEDIO } \\
\text { AMBIENTE - MUJER Y DESARROLLO - }\end{array}$ \\
\hline 25 & 20138693326 & $\begin{array}{l}\text { ASOCIACION COMUNION, PROMOCION, } \\
\text { DESARROLLO Y LIBERACION COPRODELI }\end{array}$ & LIMA & CALLAO & AGRICULTURA/EDUCACION/JUSTICIA/SALUD/PCM/ & EDUCACION - SALUD Y NUTRICION - \\
\hline 26 & 20535964361 & $\begin{array}{l}\text { ASOCIACION CONTRA LA POBREZA DEL NINNO Y } \\
\text { ADOLESCENTE }\end{array}$ & LIMA & LIMA & EDUCACION/MUJER Y DESARROLLO SOCIAL/SALUD/OTROS/ & EDUCACIÓN - SALUD - MUJER Y DESARROLLO - \\
\hline 27 & 20547482213 & ASOCIACION CULTURAL EXPRESION & LIMA & LIMA & EDUCACION/OTROS/ & EDUCACIÓN - \\
\hline 28 & 20156801055 & ASOCIACION CULTURAL JOHANNES GUTENBERG & LIMA & LIMA & EDUCACION/MUJER Y DESARROLLO SOCIAL/SALUD/ & $\begin{array}{l}\text { EDUCACION - SALUD Y NUTRICION - MUJER Y } \\
\text { DESARROLLO - }\end{array}$ \\
\hline 29 & 20548110123 & $\begin{array}{l}\text { ASOCIACION DE APOYO INTERNACIONAL PARA EL } \\
\text { DESARROLLO }\end{array}$ & LIMA & LIMA & EDUCACION/MUJER Y DESARROLLO SOCIAL/SALUD/ & EDUCACIÓN - SALUD - MUJER Y DESARROLLO - \\
\hline 30 & 20492335585 & $\begin{array}{l}\text { ASOCIACION DE APOYO NEFROLOGICO RENAL } \\
\text { CARE }\end{array}$ & LIMA & LIMA & SALUD/ & SALUD BÁSICA - \\
\hline 31 & 20456565353 & ASOCIACION DE AYUDA AL NIÑO QUEMADO & LIMA & LIMA & EDUCACION/MUJER Y DESARROLLO SOCIAL/SALUD/ & $\begin{array}{l}\text { DESARROLLO SOCIAL - AYUDA HUMANITARIA - } \\
\text { EDUCACION - SALUD Y NUTRICION - DESARROLLO Y } \\
\text { PROTECCION DEL NIÑO Y ADOLESCENTE - }\end{array}$ \\
\hline 32 & 20139606311 & $\begin{array}{l}\text { ASOCIACION DE DEFENSA Y DESARROLLO DE LAS } \\
\text { COMUNIDADES ANDINAS DEL PERU }\end{array}$ & LIMA & LIMA & $\begin{array}{lcl}\text { AGRICULTURA/PCM/ MUJER } & \text { Y } & \text { POBLACIONES } \\
\text { VULNERABLES/JUSTICIA Y DERECHOS HUMANOS/ } & \end{array}$ & $\begin{array}{l}\text { SALUD Y NUTRICION - DERECHOS HUMANOS - MUJER } \\
\text { - }\end{array}$ \\
\hline 33 & 20136458923 & $\begin{array}{l}\text { ASOCIACION DE DESARROLLO DE LA EDUCACION } \\
\text { Y LA SALUD }\end{array}$ & LIMA & LIMA & EDUCACION/SALUD/ & EDUCACIÓN - SALUD - \\
\hline 34 & 20543847349 & $\begin{array}{l}\text { ASOCIACION DE EMPRENDIMIENTO Y BIENESTAR } \\
\text { PARA EL DESARROLLO SOLIDARIO }\end{array}$ & LIMA & LIMA & EDUCACION/ & EDUCACIÓN - \\
\hline
\end{tabular}




\begin{tabular}{|c|c|c|c|c|c|c|}
\hline 35 & 20512211331 & $\begin{array}{l}\text { ASOCIACION DE ENFERMOS DE TUBERCULOSIS } \\
\text { VICTORIA CASTILLO DE CANALES-COMAS }\end{array}$ & LIMA & LIMA & MUJER Y DESARROLLO SOCIAL/SALUD/ & SALUD - MUJER Y DESARROLLO - \\
\hline 36 & 20143704808 & $\begin{array}{l}\text { ASOCIACION DE PROMOCION Y DESARROLLO } \\
\text { SOCIAL }\end{array}$ & LIMA & CALLAO & $\begin{array}{l}\text { EDUCACION/NDUSTRIA/MUJER } \\
\text { SOCIAL/SALUD/OTROS/ }\end{array}$ & $\begin{array}{l}\text { DESARROLLO SOCIAL - AYUDA HUMANITARIA - } \\
\text { EDUCACION - SALUD Y NUTRICION - MUJER - } \\
\text { DESARROLLO Y PROTECCION DEL NINOO Y } \\
\text { ADOLESCENTE - SANEAMIENTO BASICO - POBLACION } \\
-\end{array}$ \\
\hline 37 & 20506073058 & $\begin{array}{l}\text { ASOCIACION DE PSICOLOGIA APLICADA A LA } \\
\text { SOCIEDAD }\end{array}$ & LIMA & LIMA & AGRICULTURA/JUSTICIA/SALUD/OTROS/ & $\begin{array}{l}\text { SALUD - Derechos humanos. - PROTECCIÓN GENERAL } \\
\text { MEDIO AMBIENTE - }\end{array}$ \\
\hline 38 & 20193336397 & ASOCIACION EMMANUEL & LIMA & LIMA & EDUCACION/MUJER Y DESARROLLO SOCIAL/SALUD/OTROS/ & $\begin{array}{l}\text { OTROS - AYUDA HUMANITARIA - EDUCACION - SALUD } \\
\text { Y NUTRICION - DESARROLLO Y PROTECCION DEL NIÑO } \\
\text { Y ADOLESCENTE - POBLACION - }\end{array}$ \\
\hline 39 & 20516074141 & ASOCIACION EMPRESARIOS POR LA EDUCACION & LIMA & LIMA & EDUCACION/ & EDUCACIÓN - \\
\hline 40 & 20508330384 & ASOCIACION ESPERANZA, AGUA Y VIDA & LIMA & LIMA & AGRICULTURA/EDUCACION/VIVIENDA Y CONSTRUCCION/ & $\begin{array}{l}\text { EDUCACIÓN - CONSTRUCCIÓN - PROTECCIÓN } \\
\text { GENERAL MEDIO AMBIENTE - }\end{array}$ \\
\hline 41 & 20138453872 & ASOCIACION GRUPO DE TRABAJO REDES & LIMA & LIMA & EDUCACION/MUJER Y DESARROLLO SOCIAL/SALUD/ & $\begin{array}{l}\text { EDUCACION - SALUD Y NUTRICION - MUJER - } \\
\text { DESARROLLO Y PROTECCION DEL NIÑO Y } \\
\text { ADOLESCENTE - }\end{array}$ \\
\hline 42 & 20148102776 & $\begin{array}{l}\text { ASOCIACION INTERETNICA DE DESARROLLO DE } \\
\text { LA SELVA PERUANA }\end{array}$ & LIMA & LIMA & $\begin{array}{l}\text { AGRICULTURA/EDUCACION/SALUD/TRABAJO } \quad Y \quad \text { PROMOCION } \\
\text { SOCIAL/PCM/ }\end{array}$ & $\begin{array}{l}\text { FORTALECIMIENTO INSTITUCIONAL - EDUCACION - } \\
\text { SALUD Y NUTRICION - CULTURA - POBLACION - }\end{array}$ \\
\hline 43 & 20492863921 & $\begin{array}{l}\text { ASOCIACION INVESTIGACIONES EDUCATIVAS } \\
\text { CIENTIFICAS }\end{array}$ & LIMA & LIMA & EDUCACION/ & EDUCACIÓN BÁSICA - \\
\hline 44 & 20112714724 & $\begin{array}{l}\text { ASOCIACION KALLPA PARA LA PROMOCION } \\
\text { INTEGRAL DE LA SALUD Y EL DESARROLLO }\end{array}$ & LIMA & LIMA & SALUD/PCM/ & $\begin{array}{l}\text { EDUCACION - SALUD Y NUTRICION - DESARROLLO Y } \\
\text { PROTECCION DEL NINNO Y ADOLESCENTE - }\end{array}$ \\
\hline 45 & & ASOCIACION KANTU - SEMBRANDO ESPERANZA & LIMA & LIMA & MUJER Y DESARROLLO SOCIAL/SALUD/ & SALUD - MUJER Y DESARROLLO - \\
\hline 46 & 20517297659 & $\begin{array}{l}\text { ASOCIACION } \\
\text { BIOTECNOLOGIA }\end{array}$ & LIMA & LIMA & MUJER Y DESARROLLO SOCIAL/SALUD/ & $\begin{array}{l}\text { SALUD - OTROS SERVICIOS E INFRAESTRUCTURAS } \\
\text { SOCIALES - }\end{array}$ \\
\hline
\end{tabular}




\begin{tabular}{|c|c|c|c|c|c|c|}
\hline 47 & 20544984625 & $\begin{array}{l}\text { ASOCIACION MEJORANDO VIDAS HEMODIALISIS } \\
\text { PERU }\end{array}$ & LIMA & LIMA & MUJER Y DESARROLLO SOCIAL/SALUD/ & SALUD - MUJER Y DESARROLLO - \\
\hline 48 & 20536092791 & ASOCIACION NUTRICION Y SALUD & LIMA & LIMA & SALUD/ & SALUD - \\
\hline 49 & 20517756866 & ASOCIACION OPORTUNIDADES PARA LA VIDA & LIMA & LIMA & EDUCACION/MUJER Y DESARROLLO SOCIAL/SALUD/PCM/ & $\begin{array}{l}\text { EDUCACIÓN - SALUD - PROTECCIÓN GENERAL MEDIO } \\
\text { AMBIENTE - MUJER Y DESARROLLO - }\end{array}$ \\
\hline 50 & 20536869230 & $\begin{array}{l}\text { ASOCIACION ORQUESTAS INFANTILES } Y \\
\text { JUVENILES DEL PERU }\end{array}$ & LIMA & LIMA & EDUCACION/ CULTURA/ & EDUCACIÓN - \\
\hline 51 & 20147726008 & $\begin{array}{l}\text { ASOCIACION PARA EL DESARROLLO DE LA } \\
\text { ENSENNANZA UNIVERSITARIA }\end{array}$ & LIMA & LIMA & EDUCACION/ & EDUCACIÓN - \\
\hline 52 & 20508764465 & $\begin{array}{l}\text { ASOCIACION PARA EL DESARROLLO EQUITATIVO } \\
\text { SUSTENTABLE }\end{array}$ & LIMA & LIMA & $\begin{array}{l}\text { AGRICULTURA/EDUCACION/COMERCIO/TRABAJO Y PROMOCION } \\
\text { SOCIAL/VIVIENDA Y CONSTRUCCION/OTROS/ }\end{array}$ & $\begin{array}{l}\text { OTROS - DESARROLLO SOCIAL - TRANSFERENCIA } \\
\text { TECNOLOGICA - MEDIO AMBIENTE - DESARROLLO } \\
\text { ECONOMICO - EDUCACION - SALUD Y NUTRICION - } \\
\text { SANEAMIENTO BASICO - GENERACION DE } \\
\text { EMPLEO/NGRESOS - AYUDA YIO SEGURIDAD } \\
\text { ALIMENTARIA - POBLACION - FORMACION-EDUCACION } \\
\text { TECNICA Y PROFESIONAL - MANEJO Y CONSERVACION } \\
\text { DE RECURSOS NATURALES - DESARROLLO } \\
\text { ALTERNATIVO - AGRARIO - PEQUENA Y MEDIANA } \\
\text { EMPRESA - }\end{array}$ \\
\hline 53 & 20524224268 & $\begin{array}{l}\text { ASOCIACION PARA EL DESARROLLO INTEGRAL } \\
\text { DE LA SELVA PERUANA (ADISEL PERU) }\end{array}$ & LIMA & LIMA & AGRICULTURA/SALUD/ & $\begin{array}{l}\text { SALUD - AGRICULTURA - Desarrollo agrario. - Programas } \\
\text { de Seguridad Alimentaria y Ayuda de Alimentos - }\end{array}$ \\
\hline 54 & 20508212691 & $\begin{array}{l}\text { ASOCIACION PARA EL DESARROLLO SOSTENIBLE } \\
\text { DEL PERU }\end{array}$ & LIMA & LIMA & EDUCACION/MUJER Y DESARROLLO SOCIAL/SALUD/ & DESARROLLO SOCIAL - EDUCACION - SALUD - \\
\hline 55 & 20300254587 & ASOCIACION PARA LA NIÑEZ Y SU AMBIENTE & LIMA & LIMA & EDUCACION/SALUD/ & $\begin{array}{l}\text { 050. Cultura y recreación - 120. Educación forestal } \\
\text { /capacitación - EDUCACION - SALUD - }\end{array}$ \\
\hline 56 & 20545179394 & ASOCIACION PASITOS DE ESPERANZA & LIMA & LIMA & MUJER Y DESARROLLO SOCIAL/SALUD/ & SALUD - MUJER Y DESARROLLO - \\
\hline 57 & 20515268139 & ASOCIACION PERU YANTALO FOUNDATION & LIMA & LIMA & MUJER Y DESARROLLO SOCIAL/SALUD/ & SALUD - MUJER Y DESARROLLO - \\
\hline
\end{tabular}




\begin{tabular}{|c|c|c|c|c|c|c|}
\hline 58 & 20518563921 & $\begin{array}{l}\text { ASOCIACION PERUANA DE PREVENCION DE LA } \\
\text { SORDERA Y AYUDA AL DISCAPACITADO AUDITIVO } \\
\text { - UYARI }\end{array}$ & LIMA & LIMA & SALUD/ & SALUD - \\
\hline 59 & 20505453850 & $\begin{array}{l}\text { ASOCIACION PERUANA PARA LA PREVENCION DE } \\
\text { EMBARAZOS NO DESEADOS }\end{array}$ & LIMA & LIMA & EDUCACION/SALUD/ & EDUCACION - SALUD Y NUTRICION - \\
\hline 60 & 20101267467 & ASOCIACION PERUANO JAPONESA & LIMA & LIMA & EDUCACION/MUJER Y DESARROLLO SOCIAL/SALUD/ & $\begin{array}{l}\text { SALUD Y NUTRICION - AYUDA Y/O SEGURIDAD } \\
\text { ALIMENTARIA - CULTURA - }\end{array}$ \\
\hline 61 & 20515806726 & ASOCIACION PERU-AUSTRIA INTERNACIONAL & LIMA & LIMA & $\begin{array}{l}\text { EDUCACION/INDUSTRIA/MUJER } \\
\text { SOCIAL/SALUD/PCM/ }\end{array}$ & $\begin{array}{l}\text { EDUCACIÓN - SALUD - INDUSTRIA - PROTECCIÓN } \\
\text { GENERAL MEDIO AMBIENTE - MUJER Y DESARROLLO - }\end{array}$ \\
\hline 62 & 20524116961 & ASOCIACION PROPUESTA LATINA & LIMA & LIMA & AGRICULTURA/MUJER Y DESARROLLO SOCIAL/SALUD/OTROS/ & $\begin{array}{l}\text { SALUD BÁSICA - Política de empleo y gestión } \\
\text { administrativa. - PROTECCIÓN GENERAL MEDIO } \\
\text { AMBIENTE - Mujer y desarrollo. - }\end{array}$ \\
\hline 63 & 20551049303 & ASOCIACION QUIMIY & LIMA & LIMA & EDUCACION/MUJER Y DESARROLLO SOCIAL/ & EDUCACIÓN - MUJER Y DESARROLLO - \\
\hline 64 & 20536454021 & ASOCIACION RED INNOVA & LIMA & LIMA & EDUCACION/MUJER Y DESARROLLO SOCIAL/SALUD/ & EDUCACIÓN - SALUD - MUJER Y DESARROLLO - \\
\hline 65 & 20516992116 & ASOCIACION RUNAYAY & LIMA & LIMA & EDUCACION/MUJER Y DESARROLLO SOCIAL/SALUD/ & EDUCACIÓN - SALUD - MUJER Y DESARROLLO - \\
\hline 66 & 20511924279 & ASOCIACION RUPAJAMPI & LIMA & LIMA & SALUD/ & SALUD - \\
\hline 67 & 20549955046 & $\begin{array}{l}\text { ASOCIACION SIN FINES DE LUCRO: CARITAS SIN } \\
\text { LAGRIMAS - PERU }\end{array}$ & LIMA & LIMA & EDUCACION/MUJER Y DESARROLLO SOCIAL/SALUD/ & EDUCACIÓN - SALUD - MUJER Y DESARROLLO - \\
\hline 68 & 20469799311 & ASOCIACION SOLARIS PERU & LIMA & LIMA & EDUCACION/SALUD/ & SALUD Y NUTRICION - EDUCACIÓN - \\
\hline 69 & 20510216572 & ASOCIACION SUMAQ ILLARI & LIMA & LIMA & EDUCACION/SALUD/TRABAJO Y PROMOCION SOCIAL/ & EDUCACION - SALUD Y NUTRICION - CULTURA - \\
\hline 70 & 20159470980 & ASOCIACION TALLER DE LOS NINNOS & LIMA & LIMA & MUJER Y DESARROLLO SOCIAL/SALUD/PCM/ & $\begin{array}{l}\text { SALUD } \quad \text { Y } \\
\text { EMPLEO/INGRESOS - CULTURA - }\end{array}$ \\
\hline 71 & 20503808405 & ASOCIACION TARPUSUNCHIS & LIMA & LIMA & AGRICULTURA/EDUCACION/SALUD/ & EDUCACION - SALUD Y NUTRICION - AGRARIO - \\
\hline
\end{tabular}




\begin{tabular}{|c|c|c|c|c|c|c|}
\hline 72 & 20138896782 & ASOCIACION VIA LIBRE & LIMA & LIMA & SALUD/PCM/ & EDUCACION - SALUD Y NUTRICION - \\
\hline 73 & 20550746582 & ASOCIACION VIDA, INCLUSION Y DESARROLLO & LIMA & LIMA & EDUCACION/MUJER Y DESARROLLO SOCIAL/SALUD/OTROS/ & $\begin{array}{l}\text { EDUCACIÓN - SALUD - PROTECCIÓN GENERAL MEDIO } \\
\text { AMBIENTE - MUJER Y DESARROLLO - }\end{array}$ \\
\hline 74 & 20546063381 & ASTALENTUM & LIMA & LIMA & EDUCACION/ & EDUCACIÓN - Fortalecimiento sociedad civil - \\
\hline 75 & 20425853431 & $\begin{array}{l}\text { AYNE PERU TRINITARIAS, SOLIDARIDAD Y } \\
\text { DESARROLLO }\end{array}$ & LIMA & LIMA & EDUCACION/SALUD/TRABAJO Y PROMOCION SOCIAL/ & $\begin{array}{l}\text { DESARROLLO SOCIAL - EDUCACION - SALUD Y } \\
\text { NUTRICION - GENERACION DE EMPLEO/INGRESOS - }\end{array}$ \\
\hline 76 & 20160705052 & $\begin{array}{l}\text { AYNI - GRUPO DE COOPERACION PARA EL } \\
\text { DESARROLLO SOCIAL }\end{array}$ & LIMA & LIMA & $\begin{array}{l}\text { EDUCACION/MUJER Y DESARROLLO SOCIAL/SALUD/TRABAJO Y } \\
\text { PROMOCION SOCIAL/ }\end{array}$ & $\begin{array}{l}\text { OTROS - DESARROLLO SOCIAL - AYUDA HUMANITARIA } \\
\text { - SALUD Y NUTRICION - DESARROLLO Y PROTECCION } \\
\text { DEL NIÑO Y ADOLESCENTE - POBLACION - }\end{array}$ \\
\hline 77 & 20536083457 & AYUDANDO A VIVIR MEJOR & LIMA & LIMA & EDUCACION/MUJER Y DESARROLLO SOCIAL/SALUD/ & EDUCACIÓN - SALUD - MUJER Y DESARROLLO - \\
\hline 78 & 20525163238 & CARE PERU & LIMA & LIMA & EDUCACION/MUJER Y DESARROLLO SOCIAL/SALUD/ & EDUCACIÓN - SALUD - MUJER Y DESARROLLO - \\
\hline 79 & 20147739835 & CARITAS DEL PERU & LIMA & CALLAO & AGRICULTURA/INDUSTRIA/SALUD/ & $\begin{array}{l}\text { MEDIO AMBIENTE - AYUDA HUMANITARIA - SALUD Y } \\
\text { NUTRICION - AYUDA Y/O SEGURIDAD ALIMENTARIA - } \\
\text { AGRARIO - }\end{array}$ \\
\hline 80 & 20522383822 & CATOLICAS POR EL DERECHO A DECIDIR-PERU & LIMA & LIMA & JUSTICIA/SALUD/ & SALUD - Derechos humanos. - \\
\hline 81 & 20124476632 & CENTRO ANN SULLIVAN DEL PERU & LIMA & LIMA & EDUCACION/ & EDUCACION - SALUD Y NUTRICION - \\
\hline 82 & 20253767571 & CENTRO CULTURAL NOSOTROS & LIMA & LIMA & EDUCACION/MUJER Y DESARROLLO SOCIAL/ & EDUCACIÓN - MUJER Y DESARROLLO - \\
\hline 83 & 20511267421 & $\begin{array}{l}\text { CENTRO DE APOYO ARMONIZACION SALUD Y } \\
\text { CULTURA "SPLENDOR" CASA HOGAR PARA LA } \\
\text { TERCERA EDAD }\end{array}$ & LIMA & LIMA & SALUD/ & SALUD - \\
\hline 84 & 20506347522 & CENTRO DE ATENCION PSICOSOCIAL - CAPS & LIMA & LIMA & EDUCACION/SALUD/TRABAJO Y PROMOCION SOCIAL/OTROS/ & $\begin{array}{l}\text { OTROS - DESARROLLO SOCIAL - TRANSFERENCIA } \\
\text { TECNOLOGICA - DESARROLLO ECONOMICO - AYUDA } \\
\text { HUMANITARIA - EDUCACION - SALUD Y NUTRICION - }\end{array}$ \\
\hline
\end{tabular}




\begin{tabular}{|c|c|c|c|c|c|c|}
\hline & & & & & & $\begin{array}{l}\text { DESARROLLO Y PROTECCION DEL NIÑO Y } \\
\text { ADOLESCENTE - POBLACION - }\end{array}$ \\
\hline 85 & 20109252311 & $\begin{array}{lllll}\text { CENTRO DE } & \text { DESARROLLO } & \text { Y } & \text { ASESORIA } \\
\text { PSICOSOCIAL } & & & \end{array}$ & LIMA & LIMA & MUJER Y DESARROLLO SOCIAL/SALUD/ & SALUD Y NUTRICION - \\
\hline 86 & 20499604417 & $\begin{array}{l}\text { CENTRO DE ESTUDIOS DE PREVENCION, } \\
\text { TRATAMIENTO, INVESTIGACION Y DE SALUD }\end{array}$ & LIMA & LIMA & MUJER Y DESARROLLO SOCIAL/SALUD/ & $\begin{array}{l}\text { SALUD Y NUTRICION - DESARROLLO Y PROTECCION } \\
\text { DEL NIÑO Y ADOLESCENTE - }\end{array}$ \\
\hline 87 & 20217639426 & $\begin{array}{l}\text { CENTRO DE ESTUDIOS DE PROBLEMAS } \\
\text { ECONOMICOS Y SOCIALES DE LA JUVENTUD }\end{array}$ & LIMA & LIMA & $\begin{array}{l}\text { EDUCACION/MUJER Y DESARROLLO SOCIAL/SALUD/TRABAJO Y } \\
\text { PROMOCION SOCIAL/PCM/ }\end{array}$ & $\begin{array}{l}\text { EDUCACION - SALUD Y NUTRICION - MUJER - } \\
\text { DESARROLLO Y PROTECCION DEL NINOO Y } \\
\text { ADOLESCENTE - POBLACION - FORMACION- } \\
\text { EDUCACION TECNICA Y PROFESIONAL - }\end{array}$ \\
\hline 88 & 20376547281 & $\begin{array}{l}\text { CENTRO DE ESTUDIOS PARA LA EDIFICACION } \\
\text { CON TIERRA Y EL DESARROLLO SOSTENIBLE }\end{array}$ & LIMA & LIMA & AGRICULTURA/EDUCACION/SALUD/VIVIENDA Y CONSTRUCCION/ & $\begin{array}{l}\text { TRANSFERENCIA TECNOLOGICA - EDUCACION - } \\
\text { SALUD Y NUTRICION - VIVIENDA - AGRARIO - }\end{array}$ \\
\hline 89 & 20109358658 & $\begin{array}{l}\text { CENTRO DE ESTUDIOS Y PREVENCION DE } \\
\text { DESASTRES }\end{array}$ & LIMA & LIMA & SALUD/TRABAJO Y PROMOCION SOCIAL/PCM/OTROS/ & $\begin{array}{l}\text { OTROS - DESARROLLO SOCIAL - TRANSFERENCIA } \\
\text { TECNOLOGICA - MEDIO AMBIENTE - AYUDA } \\
\text { HUMANITARIA - EDUCACION - SALUD Y NUTRICION - } \\
\text { SANEAMIENTO BASICO - POBLACION - AGRARIO - }\end{array}$ \\
\hline 90 & 20258304668 & $\begin{array}{l}\text { CENTRO DE INVESTIGACION COMUNAL Y } \\
\text { AGROPECUARIA DEL PERU }\end{array}$ & LIMA & LIMA & AGRICULTURA/EDUCACION/ & EDUCACIÓN - AGRICULTURA - \\
\hline 91 & 20516749106 & $\begin{array}{l}\text { CENTRO DE INVESTIGACION CONOCIMIENTO Y } \\
\text { DESARROLLO }\end{array}$ & LIMA & LIMA & EDUCACION/SALUD/ & EDUCACIÓN - SALUD - \\
\hline 92 & 20514502561 & $\begin{array}{l}\text { CENTRO DE INVESTIGACION Y DESARROLLO LA } \\
\text { LLAVE DE LA CIENCIA } 1 \text { - CIDELLCI }\end{array}$ & LIMA & LIMA & EDUCACION/INDUSTRIA/MUJER Y DESARROLLO SOCIAL/ & EDUCACIÓN - INDUSTRIA - MUJER Y DESARROLLO - \\
\hline 93 & 20147857528 & $\begin{array}{l}\text { CENTRO DE INVESTIGACION, DOCUMENTACION, } \\
\text { EDUCACION, ASESORIA Y SERVICIOS }\end{array}$ & LIMA & LIMA & $\begin{array}{l}\text { AGRICULTURA/ECONOMIA Y } \quad \text { FINANZAS/SALUD/TRABAJO Y } \\
\text { PROMOCION SOCIAL/OTROS/ }\end{array}$ & $\begin{array}{l}\text { OTROS - TRANSFERENCIA TECNOLOGICA - MEDIO } \\
\text { AMBIENTE - SALUD Y NUTRICION - DESARROLLO Y } \\
\text { PROTECCION DEL NINOO Y ADOLESCENTE - } \\
\text { GENERACION DE EMPLEO/INGRESOS - AYUDA Y/O } \\
\text { SEGURIDAD ALIMENTARIA - POBLACION - MANEJO Y } \\
\text { CONSERVACION DE RECURSOS NATURALES - } \\
\text { PEQUENAA Y MEDIANA EMPRESA - MEJORA DE LA } \\
\text { CALIDAD DE SERVICIO DE SALUD - }\end{array}$ \\
\hline
\end{tabular}




\begin{tabular}{|c|c|c|c|c|c|c|}
\hline 94 & 20126141956 & $\begin{array}{l}\text { CENTRO DE LA MUJER PERUANA "FLORA } \\
\text { TRISTAN" }\end{array}$ & LIMA & LIMA & JUSTICIA/MUJER Y DESARROLLO SOCIAL/SALUD/PCM/ & $\begin{array}{l}\text { EDUCACION - SALUD Y NUTRICION - DERECHOS } \\
\text { HUMANOS - MUJER - PEQUENA Y MEDIANA EMPRESA - }\end{array}$ \\
\hline 95 & 20148085669 & $\begin{array}{l}\text { CENTRO DE PROMOCION DEL DESARROLLO Y LA } \\
\text { EDUCACION }\end{array}$ & LIMA & HUARAL & EDUCACION/PRODUCCION/ & EDUCACIÓN - SECTORES PRODUCTIVOS - \\
\hline 96 & 20518986482 & CENTRO LATINOAMERICANO DE AYUDA SOCIAL & LIMA & LIMA & EDUCACION/MUJER Y DESARROLLO SOCIAL/SALUD/ & EDUCACIÓN - SALUD - MUJER Y DESARROLLO - \\
\hline 97 & 20112280627 & CENTRO PERUANO DE ESTUDIOS SOCIALES & LIMA & LIMA & AGRICULTURA/PCM/ & $\begin{array}{l}\text { EDUCACION - SALUD Y NUTRICION - DERECHOS } \\
\text { HUMANOS - PEQUENA Y MEDIANA EMPRESA - } \\
\text { MEJORAMIENTO DE LA PRODUCION Y } \\
\text { PRODUCTIVIDAD - }\end{array}$ \\
\hline 98 & 20332150619 & CONSEJO DE JUVENTUDES NACIONALES & LIMA & LIMA & $\begin{array}{l}\text { EDUCACION/JUSTICIA/SALUD/TRABAJO } \\
\text { SOCIAL/PCM/ }\end{array}$ & $\begin{array}{l}\text { OTROS - DESARROLLO SOCIAL - TRANSFERENCIA } \\
\text { TECNOLOGICA - AYUDA HUMANITARIA - EDUCACION - } \\
\text { SALUD Y NUTRICION - DERECHOS HUMANOS - } \\
\text { DESARROLLO Y PROTECCION DEL NIÑO Y } \\
\text { ADOLESCENTE - POBLACION - }\end{array}$ \\
\hline 99 & 20544290615 & $\begin{array}{l}\text { COOPERACION INTEGRAL AL DESARROLLO } \\
\text { SOCIALY PRODUCTIVO }\end{array}$ & LIMA & LIMA & EDUCACION/SALUD/ & EDUCACIÓN - SALUD - \\
\hline 100 & 20503280745 & CORDILLERA LOS ANDES & LIMA & LIMA & AGRICULTURA/EDUCACION/MUJER Y DESARROLLO SOCIAL/ & EDUCACIÓN - AGRICULTURA - MUJER Y DESARROLLO \\
\hline 101 & 20550605091 & DAR CON ALEGRIA & LIMA & LIMA & $\begin{array}{l}\text { EDUCACION/MUJER Y DESARROLLO SOCIAL/SALUD/TRABAJO Y } \\
\text { PROMOCION SOCIAL/ }\end{array}$ & $\begin{array}{l}\text { EDUCACIÓN - SALUD - OTROS SERVICIOS E } \\
\text { INFRAESTRUCTURAS SOCIALES - MUJER Y } \\
\text { DESARROLLO - APOYO AL DESARROLLO DE } \\
\text { PROGRAMAS DE SEGURIDAD ALIMENTARIA - }\end{array}$ \\
\hline 102 & 20505744072 & DESARROLLO INTEGRAL DE LA NIÑEZ & LIMA & LIMA & $\begin{array}{l}\text { EDUCACION/MUJER Y DESARROLLO SOCIAL/SALUD/TRABAJO Y } \\
\text { PROMOCION SOCIAL/OTROS/ }\end{array}$ & $\begin{array}{l}\text { OTROS - DESARROLLO SOCIAL - AYUDA HUMANITARIA } \\
\text { - EDUCACION - SALUD Y NUTRICION - GENERACION DE } \\
\text { EMPLEO/INGRESOS - CULTURA - POBLACION - }\end{array}$ \\
\hline 103 & 20506293333 & $\begin{array}{llll}\text { DESARROLLO } & \text { INTEGRAL } & \text { DE } & \text { NUEVO } \\
\text { PACHACUTEC } & & & \end{array}$ & LIMA & LIMA & $\begin{array}{l}\text { EDUCACION/MUJER Y DESARROLLO SOCIAL/SALUD/TRABAJO Y } \\
\text { PROMOCION SOCIAL/VIVIENDA Y CONSTRUCCION/PCM/ }\end{array}$ & $\begin{array}{l}\text { OTROS - DESARROLLO SOCIAL - TRANSFERENCIA } \\
\text { TECNOLOGICA - DESARROLLO ECONOMICO - AYUDA } \\
\text { HUMANITARIA - EDUCACION - SALUD Y NUTRICION - } \\
\text { DESARROLLO Y PROTECCION DEL NIÑO Y } \\
\text { ADOLESCENTE - SANEAMIENTO BASICO - } \\
\text { GENERACION DE EMPLEO/INGRESOS - POBLACION - }\end{array}$ \\
\hline
\end{tabular}




\begin{tabular}{|c|c|c|c|c|c|c|}
\hline & & & & & & $\begin{array}{l}\text { DESARROLLO ALTERNATIVO - PEQUEÑA Y MEDIANA } \\
\text { EMPRESA - }\end{array}$ \\
\hline 104 & 20137431182 & $\begin{array}{l}\text { DIACONIA, ASOCIACION EVANGELICA LUTERANA } \\
\text { DE AYUDA PARA EL DESARROLLO COMUNAL }\end{array}$ & LIMA & LIMA & AGRICULTURA/SALUD/PCM/ & $\begin{array}{l}\text { FORTALECIMIENTO INSTITUCIONAL PUBLICO - SALUD } \\
\text { Y NUTRICION - SANEAMIENTO BASICO - } \\
\text { INFRAESTRUCTURA AGRARIA - }\end{array}$ \\
\hline 105 & 20521793512 & ECOCEANICA & LIMA & LIMA & AGRICULTURA/EDUCACION/ & $\begin{array}{l}\text { EDUCACIÓN - PROTECCIÓN GENERAL MEDIO } \\
\text { AMBIENTE - }\end{array}$ \\
\hline 106 & 20464350102 & EDUVIDA & LIMA & LIMA & EDUCACION/SALUD/ & EDUCACION - SALUD Y NUTRICION - \\
\hline 107 & 20521345871 & EL EDEN DEL DIVINO NIÑO JESUS & LIMA & LIMA & EDUCACION/MUJER Y DESARROLLO SOCIAL/SALUD/ & EDUCACIÓN - SALUD - MUJER Y DESARROLLO - \\
\hline 108 & 20492354458 & EMPEZAMOS CRECIENDO & LIMA & LIMA & EDUCACION/ & EDUCACIÓN - MUJER Y DESARROLLO - \\
\hline 109 & 20544446305 & ERART & LIMA & LIMA & EDUCACION/ & SALUD - \\
\hline 110 & 20128444921 & $\begin{array}{l}\text { FILOMENA TOMAIRA PACSI, SERVICIOS A LA } \\
\text { MUJER MINERA }\end{array}$ & LIMA & LIMA & INDUSTRIA/SALUD/PCM/ & $\begin{array}{l}\text { SALUD Y NUTRICION - MUJER - INFRAESTRUCTURA DE } \\
\text { SALUD - MINERIA - }\end{array}$ \\
\hline 111 & 20551206093 & FUTURO CAJAY - PERU & LIMA & LIMA & MUJER Y POBLACIONES VULNERABLES/EDUCACION/ & EDUCACIÓN - MUJER Y DESARROLLO - \\
\hline 112 & 20503641942 & GLOBAL HUMANITARIA PERU & LIMA & LIMA & MUJER Y DESARROLLO SOCIAL/ & $\begin{array}{l}\text { 004. Investigación en la educación - } 015 \text {. Servicios médicos } \\
\text { - 018. Nutrición básica - }\end{array}$ \\
\hline 113 & 20516785242 & GRUPO GESTOR KIPECE & LIMA & LIMA & EDUCACION/MUJER Y DESARROLLO SOCIAL/SALUD/ & EDUCACIÓN - SALUD - MUJER Y DESARROLLO - \\
\hline 114 & 20509049115 & HOGAR DE VIDA & LIMA & LIMA & MUJER Y DESARROLLO SOCIAL/SALUD/ & AYUDA HUMANITARIA - SALUD Y NUTRICION - \\
\hline 115 & 20507511717 & HORIZONTE CORPORATIVO & LIMA & LIMA & EDUCACION/SALUD/ & $\begin{array}{l}\text { MULTISECTORIAL - Educación / formación medioambiental. } \\
\text { _ }\end{array}$ \\
\hline
\end{tabular}




\begin{tabular}{|c|c|c|c|c|c|c|}
\hline 116 & 20509849740 & INMED ANDES & LIMA & LIMA & EDUCACION/ & EDUCACIÓN - \\
\hline 117 & & $\begin{array}{l}\text { INSTITUTO CALIDAD DE VIDA FAMILIAS } Y \\
\text { MAESTROS SALUDABLES }\end{array}$ & LIMA & LIMA & $\begin{array}{l}\text { EDUCACION/MUJER Y Y DESARROLLO SOCIAL/TRABAJO Y } \\
\text { PROMOCION SOCIAL/ }\end{array}$ & EDUCACIÓN - OTROS MULTISECTORIAL - \\
\hline 118 & 20510013973 & INSTITUTO DAMOS VISION & LIMA & LIMA & SALUD/ & $\begin{array}{l}\text { 014. Investigación médica - 016. Cuidados básicos de la } \\
\text { salud - }\end{array}$ \\
\hline 119 & 20142485878 & INSTITUTO DE DESARROLLO URBANO & LIMA & LIMA & TRABAJO Y PROMOCION SOCIAL/VIVIENDA Y CONSTRUCCION/ & VIVIENDA - \\
\hline 120 & 20126158174 & INSTITUTO DE DESARROLLO Y MEDIO AMBIENTE & LIMA & LIMA & AGRICULTURA/EDUCACION/ & $\begin{array}{l}\text { MEDIO AMBIENTE - DESARROLLO ECONOMICO - } \\
\text { EDUCACION - SALUD Y NUTRICION - MANEJO Y } \\
\text { CONSERVACION DE RECURSOS NATURALES - }\end{array}$ \\
\hline 121 & 20155156601 & INSTITUTO DE EDUCACION Y SALUD & LIMA & LIMA & EDUCACION/MUJER Y DESARROLLO SOCIAL/SALUD/OTROS/ & $\begin{array}{l}\text { OTROS - AYUDA HUMANITARIA - EDUCACION - SALUD } \\
\text { Y NUTRICION - MUJER - DESARROLLO Y PROTECCION } \\
\text { DEL NINNO Y ADOLESCENTE - POBLACION - }\end{array}$ \\
\hline 122 & 20517403947 & $\begin{array}{l}\text { INSTITUTO DE ESTUDIOS EN SALUD, SEXUALIDAD } \\
\text { Y DESARROLLO HUMANO }\end{array}$ & LIMA & LIMA & SALUD/ & SALUD - \\
\hline 123 & 20156195384 & $\begin{array}{l}\text { INSTITUTO DE ESTUDIOS POR LA INFANCIA Y LA } \\
\text { FAMILIA }\end{array}$ & LIMA & LIMA & EDUCACION/MUJER Y DESARROLLO SOCIAL/ & EDUCACIÓN - MUJER Y DESARROLLO - \\
\hline 124 & 20145919828 & $\begin{array}{l}\text { INSTITUTO DE FOMENTO DE UNA EDUCACION DE } \\
\text { CALIDAD }\end{array}$ & LIMA & LIMA & SALUD/TRABAJO Y PROMOCION SOCIAL/PCM/ & $\begin{array}{l}\text { MEDIO AMBIENTE - EDUCACION - SALUD Y NUTRICION } \\
\text { - GENERACION DE EMPLEO/INGRESOS - }\end{array}$ \\
\hline 125 & 20117792634 & INSTITUTO DE INVESTIGACION NUTRICIONAL & LIMA & LIMA & EDUCACION/SALUD/PCM/OTROS/ & $\begin{array}{l}\text { DESARROLLO SOCIAL - TRANSFERENCIA } \\
\text { TECNOLOGICA - DESARROLLO ECONOMICO - AYUDA } \\
\text { HUMANITARIA - EDUCACION - SALUD Y NUTRICION - } \\
\text { DESARROLLO Y PROTECCION DEL NIÑO Y } \\
\text { ADOLESCENTE - POBLACION - }\end{array}$ \\
\hline 126 & 20145038201 & INSTITUTO DE SALUD POPULAR & LIMA & LIMA & SALUD/ & $\begin{array}{l}\text { Política sanitaria y gestión administrativa. - Atención sanitaria } \\
\text { básica - Educación sanitaria - Formación personal sanitario - }\end{array}$ \\
\hline
\end{tabular}




\begin{tabular}{|c|c|c|c|c|c|c|}
\hline 127 & 20154935267 & $\begin{array}{l}\text { INSTITUTO PERUANO DE PATERNIDAD } \\
\text { RESPONSABLE }\end{array}$ & LIMA & LIMA & EDUCACION/MUJER Y DESARROLLO SOCIAL/SALUD/PCM/OTROS/ & $\begin{array}{l}\text { OTROS - DESARROLLO SOCIAL - AYUDA HUMANITARIA } \\
\text { - EDUCACION - SALUD Y NUTRICION - MUJER - } \\
\text { POBLACION - }\end{array}$ \\
\hline 128 & 20510720220 & $\begin{array}{l}\text { INSTITUTO PROMOVIENDO DESARROLLO SOCIAL } \\
\text { IPRODES }\end{array}$ & LIMA & LIMA & AGRICULTURA/MUJER Y DESARROLLO SOCIAL/SALUD/PCM/ & $\begin{array}{l}\text { SALUD BÁSICA - Administración pública. - Derechos } \\
\text { humanos. - Biodiversidad. - Mujer y desarrollo. - }\end{array}$ \\
\hline 129 & 20420582383 & $\begin{array}{l}\text { INSTITUTO PROYECTO SOLIDARIDAD GLOBAL - } \\
\text { IPSG }\end{array}$ & LIMA & LIMA & $\begin{array}{l}\text { AGRICULTURA/EDUCACION/ENERGIA } \\
\text { MINAS/INDUSTRIA/PRODUCCION/MUJER } \\
\text { SOCIAL/SALUD/OTROS/ }\end{array}$ & $\begin{array}{l}\text { EDUCACIÓN - Control enfermedades infecciosas - } \\
\text { Derechos humanos. - Desarrollo PYMEs. - PROTECCIÓN } \\
\text { GENERAL MEDIO AMBIENTE - Desarrollo rural. - }\end{array}$ \\
\hline 130 & 20336919712 & $\begin{array}{l}\text { INSTITUTO RUNA DE DESARROLLO Y ESTUDIOS } \\
\text { SOBRE GENERO }\end{array}$ & LIMA & LIMA & AGRICULTURA/ & $\begin{array}{l}\text { EDUCACION - SALUD Y NUTRICION - CULTURA - } \\
\text { POBLACION - }\end{array}$ \\
\hline 131 & 20153052400 & INSTITUTO SALUD Y TRABAJO & LIMA & LIMA & $\begin{array}{l}\text { AGRICULTURA/EDUCACION/MUJER } \\
\text { SOCIAL/SALUD/TRABAJO Y PROMOCION SOCIAL/OTROS/ }\end{array}$ & $\begin{array}{l}\text { OTROS - DESARROLLO SOCIAL - TRANSFERENCIA } \\
\text { TECNOLOGICA - MEDIO AMBIENTE - DESARROLLO } \\
\text { ECONOMICO - AYUDA HUMANITARIA - EDUCACION - } \\
\text { SALUD Y NUTRICION - GENERACION DE } \\
\text { EMPLEO/INGRESOS - AGRARIO - PEQUENA Y MEDIANA } \\
\text { EMPRESA - TURISMO - }\end{array}$ \\
\hline 132 & 20191195729 & INTEGRACION Y SOLIDARIDAD & LIMA & LIMA & $\begin{array}{l}\text { EDUCACION/MUJER Y DESARROLLO SOCIAL/SALUD/TRABAJO Y } \\
\text { PROMOCION SOCIAL/PCM/ }\end{array}$ & $\begin{array}{l}\text { OTROS - AYUDA HUMANITARIA - EDUCACION - SALUD } \\
\text { YNUTRICION - DESARROLLO Y PROTECCION DEL NIÑO } \\
\text { Y ADOLESCENTE - GENERACION DE } \\
\text { EMPLEO/NGRESOS - POBLACION - }\end{array}$ \\
\hline 133 & 20512741305 & INVESTIGACIONES MEDICAS EN SALUD & LIMA & LIMA & EDUCACION/MUJER Y DESARROLLO SOCIAL/SALUD/ & EDUCACIÓN - SALUD - MUJER Y DESARROLLO - \\
\hline 134 & 20544290453 & KROCHET KIDS PERU & LIMA & LIMA & EDUCACION/MUJER Y DESARROLLO SOCIAL/ & EDUCACIÓN - MUJER Y DESARROLLO - \\
\hline 135 & 20502954271 & MD+SALUD & LIMA & LIMA & SALUD/ & SALUD, GENERAL - \\
\hline 136 & 20503813158 & MINISTERIO EVANGELISTICO YIREH & LIMA & LIMA & EDUCACION/MUJER Y DESARROLLO SOCIAL/SALUD/ & EDUCACIÓN - SALUD - MUJER Y DESARROLLO - \\
\hline 137 & 20546782230 & MISION MEDICA CATOLICA - CMMB DEL PERU & LIMA & LIMA & SALUD/ & SALUD - \\
\hline
\end{tabular}




\begin{tabular}{|c|c|c|c|c|c|c|}
\hline 138 & 20513224525 & MOVIMIENTO APOSTOLICO DE LAICOS CCRISMA & LIMA & LIMA & EDUCACION/MUJER Y DESARROLLO SOCIAL/ & EDUCACIÓN - MUJER Y DESARROLLO - \\
\hline 139 & 20137285691 & $\begin{array}{l}\text { MOVIMIENTO DE ADOLESCENTES Y NIÑOS } \\
\text { TRABAJADORES HIJOS DE OBREROS CRISTIANOS }\end{array}$ & LIMA & LIMA & SALUD/PCM/ & $\begin{array}{l}\text { EDUCACION - SALUD Y NUTRICION - DESARROLLO Y } \\
\text { PROTECCION DEL NIÑO Y ADOLESCENTE - AYUDA Y/O } \\
\text { SEGURIDAD ALIMENTARIA - }\end{array}$ \\
\hline 140 & 20512574131 & NGO ESPERANZA & LIMA & LIMA & MUJER Y POBLACIONES VULNERABLES/EDUCACION/ & $\begin{array}{l}\text { EDUCACIÓN - ASISTENCIA A LA EMERGENCIA Y A LA } \\
\text { RECONSTRUCCION - }\end{array}$ \\
\hline 141 & 20514351334 & O.N.G. HARAMBEE SEZION PERU DE ONLUS & LIMA & LIMA & SALUD/ & SALUD - \\
\hline 142 & 20536839161 & OJO EN LA CERRADURA & LIMA & LIMA & AGRICULTURA/EDUCACION/MUJER Y DESARROLLO SOCIAL/ & $\begin{array}{l}\text { EDUCACIÓN - PROTECCIÓN GENERAL MEDIO } \\
\text { AMBIENTE - MUJER Y DESARROLLO - Desarrollo rural. - }\end{array}$ \\
\hline 143 & 20512625909 & $\begin{array}{l}\text { ONE TO ONE PERSONAL TEACHING ASOCIACION } \\
\text { CULTURAL EDUCATIVA AUSTRALIA PERU }\end{array}$ & LIMA & LIMA & EDUCACION/ & EDUCACIÓN - \\
\hline 144 & 20516840103 & ONG ASOCIACION PRO DESARROLLO PERU-VIDA & LIMA & LIMA & AGRICULTURA/MUJER Y DESARROLLO SOCIAL/SALUD/ & $\begin{array}{l}\text { EDUCACIÓN - SALUD - AGRICULTURA - MUJER Y } \\
\text { DESARROLLO - }\end{array}$ \\
\hline 145 & 20531930135 & ONG MANOS FUERTES & LIMA & LIMA & EDUCACION/MUJER Y DESARROLLO SOCIAL/SALUD/ & EDUCACIÓN - SALUD - MUJER Y DESARROLLO - \\
\hline 146 & 20544534344 & ONG SAN BENITO DE PALERMO & LIMA & CALLAO & $\begin{array}{l}\text { AGRICULTURA/EDUCACION/MUJER } \\
\text { SOCIAL/SALUD/ }\end{array}$ & $\begin{array}{l}\text { EDUCACIÓN - SALUD - PROTECCIÓN GENERAL MEDIO } \\
\text { AMBIENTE - MUJER Y DESARROLLO - Desarrollo y gestión } \\
\text { urbanos - }\end{array}$ \\
\hline 147 & 20506207275 & $\begin{array}{l}\text { ONG SOMOS MAS QUE VENCEDORES EN CRISTO } \\
\text { JESUS }\end{array}$ & LIMA & LIMA & EDUCACION/SALUD/VIVIENDA Y CONSTRUCCION/ & $\begin{array}{l}\text { EDUCACIÓN - SALUD - INFRAESTRUCTURA } \\
\text { ECONÓMICA Y SERVICIOS. - }\end{array}$ \\
\hline 148 & 20513614820 & ONG'D NUEVO RUMBO & LIMA & LIMA & ECONOMIA Y FINANZAS/EDUCACION/JUSTICIA/SALUD/ & $\begin{array}{l}\text { EDUCACION - SALUD - BANCA Y SERVICIOS } \\
\text { FINANCIEROS - }\end{array}$ \\
\hline 149 & 20509807583 & ONG'D LUZ Y ESPERANZA & LIMA & LIMA & VIVIENDA Y CONSTRUCCION/ & VIVIENDA - \\
\hline 150 & 20524251231 & ONGD POR LA DISCAPACIDAD EN EL PERU & LIMA & LIMA & EDUCACION/MUJER Y DESARROLLO SOCIAL/SALUD/ & $\begin{array}{l}\text { EDUCACIÓN - SALUD - MUJER Y DESARROLLO - Mujer y } \\
\text { desarrollo. - }\end{array}$ \\
\hline
\end{tabular}




\begin{tabular}{|c|c|c|c|c|c|c|}
\hline 151 & 20504825613 & ONGD SOS PAN PERU & LIMA & LIMA & $\begin{array}{l}\text { AGRICULTURA/EDUCACION/SALUD/TRANSPORTES/VIVIENDA } \quad Y \\
\text { CONSTRUCCION/ }\end{array}$ & $\begin{array}{l}\text { DESARROLLO SOCIAL - MEDIO AMBIENTE - } \\
\text { EDUCACION - SALUD Y NUTRICION - SANEAMIENTO } \\
\text { BASICO - }\end{array}$ \\
\hline 152 & 20511457719 & OPERACION SAN ANDRES-ONG & LIMA & LIMA & EDUCACION/MUJER Y DESARROLLO SOCIAL/SALUD/ & EDUCACIÓN - SALUD - MUJER Y DESARROLLO - \\
\hline 153 & 20507027408 & $\begin{array}{lll}\text { ORGANIZACION } & \text { INTERNACIONAL } & \text { DE } \\
\text { DESARROLLO } & & \end{array}$ & LIMA & LIMA & MUJER Y DESARROLLO SOCIAL/SALUD/ & $\begin{array}{l}\text { SALUD - PROGRAMAS / POLITICAS SOBRE POBLACIÓN } \\
\text { Y SALUD REPRODUCTIVA - MUJER Y DESARROLLO - }\end{array}$ \\
\hline 154 & 20515975595 & $\begin{array}{l}\text { ORGANIZACION NO GUBERNAMENTAL } \\
\text { AGUALIMPIA }\end{array}$ & LIMA & LIMA & SALUD/PCM/ & SALUD - PROTECCIÓN GENERAL MEDIO AMBIENTE - \\
\hline 155 & 20516297019 & $\begin{array}{l}\text { ORGANIZACION NO GUBERNAMENTAL DE } \\
\text { DESARROLLO DE CIRUGIA PLASTICA QORITO }\end{array}$ & LIMA & LIMA & EDUCACION/SALUD/ & EDUCACIÓN - SALUD - \\
\hline 156 & 20451742125 & PERU CHILDRENS CHARITY & LIMA & LIMA & EDUCACION/MUJER Y DESARROLLO SOCIAL/SALUD/ & EDUCACIÓN - SALUD - MUJER Y DESARROLLO - \\
\hline 157 & 20538195830 & PERU SOLIDARIOS VIDA SIN FRONTERAS & LIMA & LIMA & SALUD/VIVIENDA Y CONSTRUCCION/ & $\begin{array}{l}\text { SALUD - ABASTECIMIENTO Y DEPURACIÓN DE AGUA - } \\
\text { Abastecimiento y depuración de agua -sistemas menores - }\end{array}$ \\
\hline 158 & 20520704737 & PRESSERVARIS & LIMA & LIMA & SALUD/ & SALUD - \\
\hline 159 & 20432109390 & PROCESO KAIROS - PERU & LIMA & LIMA & EDUCACION/ & EDUCACIÓN - \\
\hline 160 & 20535704458 & $\begin{array}{l}\text { PROGRAMA DE APOYO NUTRICIONAL BASADO EN } \\
\text { SOYA (PAN-SOY) }\end{array}$ & LIMA & LIMA & MUJER Y DESARROLLO SOCIAL/SALUD/ & SALUD - MUJER Y DESARROLLO - \\
\hline 161 & 20537466759 & PROGRAMA DE SALUD Y DESARROLLO NACIONAL & LIMA & LIMA & AGRICULTURA/EDUCACION/SALUD/ & MEDIO AMBIENTE - EDUCACION - SALUD Y NUTRICION \\
\hline 162 & 20110304677 & PROGRAMA LABORAL DE DESARROLLO & LIMA & LIMA & $\begin{array}{l}\text { EDUCACION/MUJER Y } Y \text { DESARROLLO SOCIAL/TRABAJO } \\
\text { PROMOCION SOCIAL/ }\end{array}$ & EDUCACIÓN - MUJER Y DESARROLLO - \\
\hline 163 & 20144906633 & $\begin{array}{l}\text { PROMOCION Y CAPACITACION PARA EL } \\
\text { DESARROLLO }\end{array}$ & LIMA & LIMA & EDUCACION/MUJER Y DESARROLLO SOCIAL/ & EDUCACIÓN - MUJER Y DESARROLLO - \\
\hline
\end{tabular}




\begin{tabular}{|c|c|c|c|c|c|c|}
\hline 164 & 20120055128 & $\begin{array}{l}\text { PROMOTORA DE OBRAS SOCIALES Y DE } \\
\text { INSTRUCCION POPULAR }\end{array}$ & LIMA & CAÑETE & AGRICULTURA/SALUD/PCM/ & OTROS - SALUD Y NUTRICION - MUJER - AGRARIO - \\
\hline 165 & 20537582074 & $\begin{array}{l}\text { PROTECCION AMBIENTAL Y GENERACION DE } \\
\text { ENERGIA ALTERNATIVA }\end{array}$ & LIMA & LIMA & JUSTICIA/MUJER Y DESARROLLO SOCIAL/PCM/OTROS/ & $\begin{array}{l}\text { SALUD BÁSICA - GOBIERNO Y SOCIEDAD CIVIL - } \\
\text { Derechos humanos. - MUJER Y DESARROLLO - }\end{array}$ \\
\hline 166 & 20454585802 & $\begin{array}{lccc}\text { RED ANDINA DE } & \text { DESARROLLO } & Y \\
\text { CORRESPONSABILIDAD } & & \end{array}$ & LIMA & LIMA & EDUCACION/MUJER Y DESARROLLO SOCIAL/PCM/ & $\begin{array}{l}\text { EDUCACIÓN - PROTECCIÓN GENERAL MEDIO } \\
\text { AMBIENTE - MUJER Y DESARROLLO - }\end{array}$ \\
\hline 167 & 20525139442 & $\begin{array}{l}\text { RED NACIONAL POR LOS DERECHOS DE LAS } \\
\text { PERSONAS TRAVESTIS, TRANSGENEROS Y } \\
\text { TRANSEXUALES DEL PERU }\end{array}$ & LIMA & LIMA & SALUD/ & $\begin{array}{l}\text { Política sanitaria y gestión administrativa. - Control } \\
\text { enfermedades infecciosas - Educación sanitaria - }\end{array}$ \\
\hline 168 & 20511732361 & RED UNIENDO MANOS PERU & LIMA & LIMA & EDUCACION/MUJER Y DESARROLLO SOCIAL/ & EDUCACIÓN - MUJER Y DESARROLLO - \\
\hline 169 & 20549750584 & REDES SOLIDARIAS & LIMA & LIMA & EDUCACION/JUSTICIA/MUJER Y DESARROLLO SOCIAL/SALUD/ & $\begin{array}{l}\text { EDUCACIÓN - SALUD - Derechos humanos. - Desarrollo } \\
\text { rural. - }\end{array}$ \\
\hline 170 & 20126098503 & SERVICIO DE MEDICINAS PRO-VIDA & LIMA & LIMA & EDUCACION/MUJER Y DESARROLLO SOCIAL/SALUD/OTROS/ & $\begin{array}{l}\text { OTROS - DESARROLLO SOCIAL - AYUDA HUMANITARIA } \\
\text { - SALUD Y NUTRICION - DESARROLLO Y PROTECCION } \\
\text { DEL NIÑO Y ADOLESCENTE - POBLACION - }\end{array}$ \\
\hline 171 & 20513296861 & SI, DA VIDA & LIMA & LIMA & SALUD/ & SALUD - \\
\hline 172 & 20492809048 & $\begin{array}{l}\text { SOCIEDAD PARA LA DEMOCRACIA Y } \quad \text { EL } \\
\text { DESARROLLO HUMANO }\end{array}$ & LIMA & LIMA & $\begin{array}{l}\text { EDUCACION/INDUSTRIA/MUJER } \\
\text { SOCIAL/SALUD/PCM/ }\end{array}$ & $\begin{array}{l}\text { EDUCACIÓN - SALUD - INDUSTRIA - PROTECCIÓN } \\
\text { GENERAL MEDIO AMBIENTE - MUJER Y DESARROLLO - }\end{array}$ \\
\hline 173 & 20143306667 & SOCIEDAD PERUANA DE LA CRUZ ROJA & LIMA & LIMA & EDUCACION/SALUD/ & $\begin{array}{l}\text { EDUCACION - SALUD Y NUTRICION - DESARROLLO Y } \\
\text { PROTECCION DEL NIÑO Y ADOLESCENTE - } \\
\text { SANEAMIENTO BASICO - }\end{array}$ \\
\hline 174 & 20547889160 & SOLIDARITAS PERU & LIMA & LIMA & EDUCACION/SALUD/OTROS/ & $\begin{array}{l}\text { EDUCACIÓN - SALUD - PROTECCIÓN GENERAL MEDIO } \\
\text { AMBIENTE - }\end{array}$ \\
\hline 175 & 20537941147 & SONCCOLLAY PERU, CORAZONCITO PERU & LIMA & LIMA & EDUCACION/MUJER Y DESARROLLO SOCIAL/SALUD/ & EDUCACIÓN - SALUD - MUJER Y DESARROLLO - \\
\hline
\end{tabular}




\begin{tabular}{|c|c|c|c|c|c|c|}
\hline 176 & 20520579223 & SONRISA FELIZ & LIMA & LIMA & AGRICULTURA/EDUCACION/INDUSTRIA/OTROS/ & $\begin{array}{l}\text { EDUCACIÓN - Desarrollo PYMEs. - Protección biosfera. - } \\
\text { Ayuda multisectorial - }\end{array}$ \\
\hline 177 & 20524951992 & SONRISAS PARA EL FUTURO & LIMA & LIMA & EDUCACION/MUJER Y DESARROLLO SOCIAL/SALUD/ & $\begin{array}{l}\text { INFRAESTRUCTURAS SOCIALES Y SERVICIOS - } \\
\text { Educación primera infancia - Atención sanitaria básica - } \\
\text { Nutrición básica - }\end{array}$ \\
\hline 178 & 20145917965 & $\begin{array}{l}\text { TALLER DE CAPACITACION E INVESTIGACION } \\
\text { FAMILIAR }\end{array}$ & LIMA & LIMA & AGRICULTURA/EDUCACION/SALUD/PCM/ & EDUCACION - SALUD Y NUTRICION - \\
\hline 179 & 20543843947 & THE VINE TRUST (PERU) & LIMA & LIMA & MUJER Y DESARROLLO SOCIAL/SALUD/ & $\begin{array}{l}\text { SALUD - AYUDA EN ESPECIES Y ASISTENCIA GENERAL } \\
\text { A PROGRAMAS - }\end{array}$ \\
\hline 180 & 20504127258 & TIERRA DE NIÑ@S & LIMA & LIMA & $\begin{array}{l}\text { EDUCACION/MUJER Y DESARROLLO SOCIAL/SALUD/VIVIENDA Y } \\
\text { CONSTRUCCION/ }\end{array}$ & $\begin{array}{l}\text { DESARROLLO Y PROTECCION DEL NINONO Y } \\
\text { ADOLESCENTE - EDUCACIÓN - SALUD - MUJER Y } \\
\text { DESARROLLO - APOYO AL DESARROLLO DE } \\
\text { PROGRAMAS DE SEGURIDAD ALIMENTARIA - } \\
\text { ASISTENCIA A LA EMERGENCIA Y A LA } \\
\text { RECONSTRUCCION- }\end{array}$ \\
\hline 181 & 20517410561 & TIERRA Y SER & LIMA & LIMA & EDUCACION/MUJER Y DESARROLLO SOCIAL/SALUD/ & EDUCACIÓN - SALUD - MUJER Y DESARROLLO - \\
\hline 182 & 20514774138 & TRASCIENDE PERU & LIMA & LIMA & $\begin{array}{l}\text { ECONOMIA Y FINANZAS/EDUCACION/MUJER Y DESARROLLO } \\
\text { SOCIAL/SALUD/OTROS/ }\end{array}$ & $\begin{array}{l}\text { Servicios médicos - Educación sanitaria - Desarrollo PYMEs. } \\
\text { - Mujer y desarrollo. - Programas de Seguridad Alimentaria y } \\
\text { Ayuda de Alimentos - ASISTENCIA A LA EMERGENCIA Y A } \\
\text { LA RECONSTRUCCION - }\end{array}$ \\
\hline 183 & 20502886178 & UN DIA DE ESPERANZA & LIMA & CALLAO & SALUD/ & SALUD - \\
\hline 184 & 20516033208 & UNIENDO CORAZONES EN EL MUNDO & LIMA & LIMA & AGRICULTURA/EDUCACION/INDUSTRIA/SALUD/PCM/OTROS/ & $\begin{array}{l}\text { EDUCACIÓN - SALUD - GOBIERNO Y SOCIEDAD CIVIL - } \\
\text { AGRICULTURA - INDUSTRIA - }\end{array}$ \\
\hline 185 & 20392909100 & $\begin{array}{l}\text { VIDA ABUNDANTE. ASOCIACION CRISTIANA PARA } \\
\text { EL DESARROLLO SOSTENIBLE }\end{array}$ & LIMA & LIMA & EDUCACION/MUJER Y DESARROLLO SOCIAL/ & EDUCACIÓN - MUJER Y DESARROLLO - \\
\hline 186 & 20500418754 & VIDA DIGNA & LIMA & LIMA & VIVIENDA Y CONSTRUCCION/ & VIVIENDA - \\
\hline
\end{tabular}


\begin{tabular}{|l|l|}
\hline 187 & 20523018745 \\
\hline 188 & 20458862550 \\
\hline
\end{tabular}

VIDA INTEGRAL CON DIGNIDAD

VISION PARA EL DESARROLLO
LIMA

LIMA
LIMA

LIMA
EDUCACION/MUJER Y DESARROLLO SOCIAL/SALUD/

AGRICULTURA/EDUCACION/MUJER

SOCIAL/SALUD/TRABAJO Y PROMOCION SOCIAL/OTROS
EDUCACIÓN - SALUD - MUJER Y DESARROLLO

DESARROLLO OTROS - EDUCACION - SALUD Y NUTRICION SANEAMIENTO BASICO - POBLACION - AGRARIO - 
ANEXO 4: Guía de Indagación Entrevistas a Especialistas

\begin{tabular}{|c|c|}
\hline \multicolumn{2}{|c|}{ Segmento: Especialistas en ONG's } \\
\hline Preguntas & Objetivos \\
\hline $\begin{array}{l}\text { ¿Cuál es el principal factor de } \\
\text { sensibilización? }\end{array}$ & $\begin{array}{l}\text { Identificar el principal factor de sensibilización de una } \\
\text { persona natural, que realiza una donación monetaria a } \\
\text { las ONG's que favorecen a niños. }\end{array}$ \\
\hline $\begin{array}{l}\text { ¿Cuál es la motivación más } \\
\text { importante de donación } \\
\text { monetaria? }\end{array}$ & $\begin{array}{l}\text { Identificar la motivación más importante de una persona } \\
\text { natural, que realiza una donación monetaria a las ONG's } \\
\text { que favorecen a niños. }\end{array}$ \\
\hline $\begin{array}{l}\text { ¿Qué aspecto de las ONG's } \\
\text { valora más un donante? }\end{array}$ & $\begin{array}{l}\text { Identificar el aspecto más importante que valora de una } \\
\text { ONG una persona natural, que realiza una donación } \\
\text { monetaria a las ONG's que favorecen a niños. }\end{array}$ \\
\hline $\begin{array}{l}\text { ¿Cuál es la percepción del } \\
\text { trabajo de las ONG’s? }\end{array}$ & $\begin{array}{l}\text { Identificar la percepción del trabajo de las } \mathrm{ONG}^{\prime} \mathrm{s} \text { de } \\
\text { una persona natural, que realiza una donación monetaria } \\
\text { a las ONG's que favorecen a niños. }\end{array}$ \\
\hline $\begin{array}{l}\text { ¿Cuál es la frecuencia con la } \\
\text { que más realiza una donación? }\end{array}$ & $\begin{array}{l}\text { Identificar la principal frecuencia de donación de una } \\
\text { persona natural, que realiza una donación monetaria a } \\
\text { las ONG's que favorecen a niños. }\end{array}$ \\
\hline $\begin{array}{l}\text { ¿Qué medio usa más una } \\
\text { persona para realizar una } \\
\text { donación monetaria? }\end{array}$ & $\begin{array}{l}\text { Identificar el medio principal por el cual realiza una } \\
\text { donación monetaria una persona natural, que realiza una } \\
\text { donación monetaria a las ONG's que favorecen a niños. }\end{array}$ \\
\hline
\end{tabular}




\begin{tabular}{|l|l|}
\hline $\begin{array}{l}\text { ¿Quién o quiénes influencia } \\
\text { principalmente a una persona a } \\
\text { realizar una donación? }\end{array}$ & $\begin{array}{l}\text { Identificar el principal influenciador de una persona } \\
\text { natural, que realiza una donación monetaria a las ONG's } \\
\text { que favorecen a niños. }\end{array}$ \\
\hline $\begin{array}{l}\text { ¿Qué medio prefiere para } \\
\text { enterarse de cómo realizar una } \\
\text { donación? }\end{array}$ & $\begin{array}{l}\text { Identificar el medio principal por el cual realiza una } \\
\text { donación monetaria una persona natural, que reside en } \\
\text { San Borja, que realiza una donación monetaria a las } \\
\text { ONG's que favorecen a niños. }\end{array}$ \\
\hline $\begin{array}{l}\text { ¿Cuál es el freno que tiene una } \\
\text { persona para realizar una } \\
\text { donación? }\end{array}$ & $\begin{array}{l}\text { Identificar el principal freno de donación de una persona } \\
\text { natural, que reside en San Borja, para que no realice una } \\
\text { donación monetaria a las ONG's que favorecen a niños. }\end{array}$ \\
\hline
\end{tabular}


ANEXO 5: Cuestionario para la encuesta

Filtro:

Personas que viven en el distrito de San Borja

Rango de edad: 25 años a más

1. Género:

Femenino Masculino

2. Grado de Instrucción:

Técnico incompleto

Técnico completo

Universitario incompleto

Universitario completo

Superior Postgrado

Otro:

3. Rango de edad:

25-34 años 35-44 años $\quad 45-55$ años 55 años a más 
4. Estado civil:

Soltero sin hijos Conviviente sin hijos Casado (a) sin hijos

Soltero con hijos Conviviente con hijos Casado (a) con hijos

Divorciado (a) sin hijos Viudo (a) sin hijos

Divorciado (a) con hijos Viudo (a) con hijos

5. ¿Alguna vez ha realizado una donación monetaria a una ONG?

SI NO

Si su respuesta es "No" pasar a la pregunta 12.

6. ¿Hace cuánto tiempo realiza donaciones monetarias a ONG’s?

a. Menos de un año

b. Más de un año y menos de dos años

c. Más de dos años

d. Única vez

e. Recurrente (realizó donaciones siempre) 
7. ¿Marque a que ONG donó?

\begin{tabular}{|l|l|}
\hline & Marque con una X \\
\hline Aldeas Infantiles & \\
\hline Techo para mi país & \\
\hline Unicef & \\
\hline Ponle Corazón & \\
\hline Cáritas del Perú & \\
\hline Liga contra el Cáncer & \\
\hline Fundades & \\
\hline Aprendo Contigo & \\
\hline Aniquem & \\
\hline Otro & \\
\hline
\end{tabular}

8. Seleccione tres opciones y ordene según su importancia los factores que le generan mayor sensibilización para que realice una donación monetaria a las $\mathrm{ONG}^{\prime}$ s que favorecen niños en la ciudad de Lima, donde 1 significa el de mayor y 3 el de menor sensibilización.
a. Niños en pobreza extrema
b. Niños enfermos físicamente

c. Niños víctimas (explotados laboralmente, sexualmente, etc.)

d. Niños abandonados que están en la calle

e. Otro:

9. Indique ¿Cuál es el factor que lo motivó a realizar una donación monetaria a ONG que favorecen niños en la ciudad de Lima?

a. Solidaridad (me gusta compartir)

b. Justicia (igualdad social)

c. Satisfacción personal (me siento bien) 
10. Indique ¿Cuál es el aspecto que valora en una ONG que favorecen niños en la ciudad de Lima para que realice una donación monetaria?

a. El nombre de la institución

b. La causa que favorece la institución

c. La confianza en la institución

d. La información del uso de los fondos

e. Otro:

11. Indique ¿Cuál es el nivel de percepción que tiene del trabajo de las siguientes ONG’s que favorecen niños en la ciudad de Lima?

\begin{tabular}{|l|l|l|l|l|l|l|}
\hline ONG's & $\begin{array}{l}\text { Muy } \\
\text { Malo }\end{array}$ & Malo & Regular & Bueno & $\begin{array}{l}\text { Muy } \\
\text { Bueno }\end{array}$ & Desconozco \\
\hline Aldeas Infantiles & & & & & & \\
\hline Techo para mi país & & & & & & \\
\hline Unicef cl & & & & & & \\
\hline Ponle Corazón & & & & & & \\
\hline Cáritas del Perú & & & & & \\
\hline $\begin{array}{l}\text { Liga de Lucha contra eláncer } \\
\text { Cándes }\end{array}$ & & & & & & \\
\hline Fundades & & & & & & \\
\hline Aprendo Contigo & & & & & & \\
\hline Aniquem & & & & & \\
\hline
\end{tabular}

12. ¿Cuál es el motivo por el cual usted no realiza una donación monetaria a las ONG’s que favorecen niños?

a. Mis necesidades económicas no lo permiten

b. Prefiero colaborar con otro tipo de donaciones (voluntariado, ropa,comida,etc) 
c. Colaboro con personas de su entorno de otra manera

d. No vale de nada colaborar con una ONG

e. No confío en las ONG's, porque yo o mi familia hemos sido engañados

f. Alguien cercano a mí ha tenido una mala experiencia

g. No me lo han pedido, no sé el procedimiento

h. No es mi responsabilidad

i. Otro:

13. ¿Con qué frecuencia usted realiza una donación monetaria de forma voluntaria a una ONG's que favorece niños en Lima? (por ej. una donación de S/.20)
a. Mensualmente
b. Trimestralmente
c. Semestralmente
d. Anualmente
e. Por Única vez

14. ¿De qué manera realiza su donación monetaria a las $\mathrm{ONG}^{\prime}$ s que favorecen a niños?

a. Débito automático

b. Efectivo 
c. Tarjeta de Crédito

d. Transferencia directa y personal

e. Otro:

15. ¿A través de qué medio le gusta enterarse de la forma que puede donar a las ONG*s?
a. Correo electrónico
b. Página web de la ONG
c. Medios digitales (Facebook, Youtube, Instagram, etc)
d. Medios impresos (Periódicos)
f. TV

g. Que me aborden en la puerta de mi casa

h. Que me aborden en un lugar público (supermercado, centro comercial o un evento)

i. Otro:

16. ¿Quién es la persona que influencia en su decisión de realizar una donación monetaria a

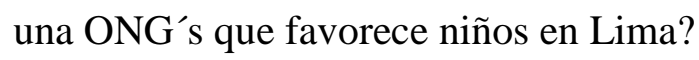
a. Cónyuge o pareja
b. Hijos
c. Otros familiares
d. Amigos 
e. Publicidad

f. Nadie me influencia, es mi decisión

g. Otro: 
ANEXO 6: Fichas Técnicas de entrevistas a profundidad con especialistas

\section{Ficha técnica de entrevista a profundidad $\mathrm{N}^{\circ} 01$}

\section{Objetivo del estudio}

1.1 Identificar la motivación más importante de una persona natural, que reside en San Borja,

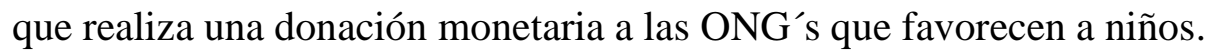

1.2 Identificar el aspecto más importante que valora de una ONG una persona natural, que

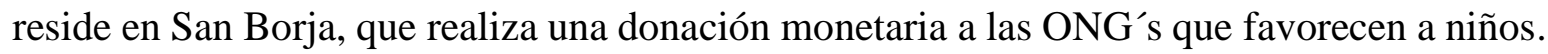

1.3 Identificar la percepción del trabajo de las $\mathrm{ONG}^{\prime}$ s de una persona natural, que reside en San Borja, que realiza una donación monetaria a las $\mathrm{ONG}^{\prime}$ s que favorecen a niños.

1.4 Identificar el principal freno de donación de una persona natural, que reside en San Borja, para que no realice una donación monetaria a las $\mathrm{ONG}^{\prime}$ s que favorecen a niños en la ciudad de Lima.

\section{Metodología y muestra}

\subsection{Tipo de investigación}

Es de fuente primaria, ya que fue obtenida directamente de una persona que labora en una ONG. La metodología de investigación que se utilizó es cualitativa exploratoria, donde se busca recopilar las opiniones de especialista en el mercado de $\mathrm{ONG}^{\prime}$ s.

\subsection{Técnica e instrumento a utilizar}

La técnica utilizada es entrevista a profundidad y el instrumento es la guía de indagación.

\subsection{Acerca de la entrevista}

Antes de la entrevista: El entrevistado fue puntual, ya que se conectó vía telefónica a la hora pactada, la cual previamente fue coordinada por correo electrónico. 
Durante la entrevista: El entrevistado fue bastante amable, en todo momento mostró disposición a responder las preguntas y hasta ofreció su ayuda para futuras consultas sobre captación de donantes.

Después de la entrevista: El entrevistado se encuentra en Chile, por lo que sólo se le brindó unas palabras de agradecimiento por su tiempo.

\subsection{Muestra:}

Profesional con estudios superiores, que cuenta con un mínimo de cinco años de experiencia en puestos gerenciales o jefatura en $\mathrm{ONG}^{\prime}$ s generando recursos para las fundaciones.

Nombre Cargo ONG

Giorgi Pablo Muñoz Dezerega Jefe de Proyectos COANIQUEM Chile

\section{$2.4 \quad$ Fecha de campo}

La entrevista se realizó el 19 de Abril del 2018 a las 6:30 pm, vía telefónica. El entrevistado estaba en su centro laboral en Chile y los entrevistadores en el centro laboral de una de las integrantes del equipo de Tesis en Magdalena del Mar.

\section{Perfil del experto:}

Profesional con estudio universitario concluido, que cuenta con un mínimo de cinco años de experiencia en puestos gerenciales o jefatura en ONG's generando recursos para las fundaciones y que tienen conocimiento del manejo del sistema en ONG's. 


\section{Ficha técnica de entrevista a profundidad $\mathrm{N}^{\circ} 02$}

\section{Objetivo del estudio}

1.1 Identificar la motivación más importante de una persona natural, que reside en San Borja, que realiza una donación monetaria a las $O N_{G}^{\prime}$ s que favorecen a niños.

1.2 Identificar la percepción del trabajo de las $\mathrm{ONG}^{\prime}$ s de una persona natural, que reside en San Borja, que realiza una donación monetaria a las ONG's que favorecen a niños.

1.3 Identificar el principal freno de donación de una persona natural, que reside en San Borja, para que no realice una donación monetaria a las $\mathrm{ONG}^{\prime}$ s que favorecen a niños.

\section{Metodología y muestra}

\section{1 Tipo de investigación}

Es de fuente primaria, ya que fue obtenida directamente de una persona que labora en una ONG. La metodología de investigación que se utilizó es cualitativa exploratoria, donde se busca recopilar las opiniones de especialista en el mercado de ONG's.

\subsection{Técnica e instrumento a utilizar}

La técnica utilizada es entrevista a profundidad y el instrumento es la guía de indagación.

\subsection{Acerca de la entrevista}

Antes de la entrevista: La entrevistada fue puntual al momento de recibirnos en su oficina, en su centro laboral según lo acordado previamente por correo electrónico.

Durante la entrevista: La entrevistada en todo momento fue amable, siempre con un tono de voz calmada y sus gestos no verbales fueron siempre de apertura.

Después de la entrevista: Se le agradeció por su disponibilidad de tiempo para la entrevista. 


\subsection{Muestra:}

Profesional con estudios superiores, que cuenta con un mínimo de cinco años de experiencia

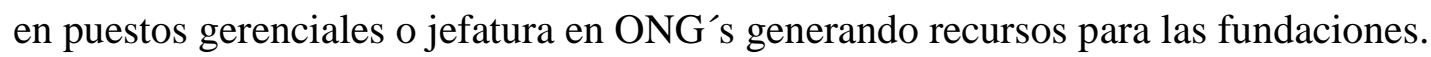

\begin{tabular}{|c|c|c|c|c|c|}
\hline Nombre & & Cargo & \multicolumn{3}{|c|}{ ONG } \\
\hline Yvette & Muñoz de & Coordinadora de & Imagen & $\mathrm{y}$ & Aprendo \\
\hline Blanco & & Recursos & \multicolumn{3}{|c|}{ Contigo } \\
\hline
\end{tabular}

\subsection{Fecha de campo}

La entrevista se realizó el 25 de Abril del 2018 a las 10:00 am, en su centro laboral ubicado en Miraflores.

\section{Perfil del experto:}

Profesional con estudio universitario concluido, que cuenta con un mínimo de cinco años de experiencia en puestos gerenciales o jefatura en ONG's generando recursos para las fundaciones y que tienen conocimiento del manejo del sistema en ONG's.

\section{Ficha técnica de entrevista a profundidad $N^{\circ} 03$}

\section{Objetivo del estudio}

1.1 Identificar el principal factor de sensibilización de una persona natural, que reside en San Borja, que realiza una donación monetaria a las ONG's que favorecen a niños.

1.2 Identificar la motivación más importante de una persona natural, que reside en San Borja, que realiza una donación monetaria a las $O N_{G}^{\prime}$ s que favorecen a niños. 
1.3 Identificar el aspecto más importante que valora de una ONG una persona natural, que reside en San Borja, que realiza una donación monetaria a las $\mathrm{ONG}^{\prime}$ s que favorecen a niños.

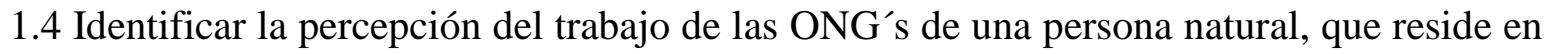
San Borja, que realiza una donación monetaria a las ONG's que favorecen a niños.

1.5 Identificar la principal frecuencia de donación de una persona natural, que reside en San Borja, que realiza una donación monetaria a las ONG's que favorecen a niños.

1.6 Identificar el medio principal por el cual realiza una donación monetaria una persona natural, que reside en San Borja, que realiza una donación monetaria a las ONG's que favorecen a niños.

1.7 Identificar el medio principal por el cual una persona natural, que reside en San Borja, que realiza una donación monetaria a las ONG's que favorecen a niños prefiere enterarse cómo realizar una donación monetaria.

1.8 Identificar el principal influenciador de una persona natural, que reside en San Borja, que realiza una donación monetaria a las $\mathrm{ONG}^{\prime} \mathrm{s}$ que favorecen a niños para que realice una donación.

1.9 Identificar el principal freno de donación de una persona natural, que reside en San Borja, para que no realice una donación monetaria a las ONG's que favorecen a niños.

\section{Metodología y muestra}

\section{1 Tipo de investigación}

Es de fuente primaria, ya que fue obtenida directamente de una persona que labora en una ONG. La metodología de investigación que se utilizó es cualitativa exploratoria, donde se busca recopilar las opiniones de especialista en el mercado de ONG's.

\subsection{Técnica e instrumento a utilizar}

La técnica utilizada es entrevista a profundidad y el instrumento es la guía de indagación. 


\subsection{Acerca de la entrevista}

Antes de la entrevista: La entrevistada fue puntual al momento de recibirnos en su oficina, en su centro laboral según lo acordado previamente por vía telefónica.

Durante la entrevista: La entrevistada en todo momento fue amable, con gestos de apertura y muy entusiasta ante las preguntas realizadas.

Después de la entrevista: Se le agradeció por su disponibilidad de tiempo para la entrevista.

\subsection{Muestra:}

Profesional con estudios superiores, que cuenta con un mínimo de cinco años de experiencia en puestos gerenciales o jefatura en $\mathrm{ONG}^{\prime}$ s generando recursos para las fundaciones.

\begin{tabular}{lllllll}
\hline Nombre & \multicolumn{2}{c}{ Cargo } & & \multicolumn{2}{c}{ ONG } \\
& & & & \\
\hline Juana & Teresa & Burga \\
Neyra & & & $\begin{array}{l}\text { Coordinadora general de Amigos de } \\
\text { Aniquem }\end{array}$ & & & Aniquem
\end{tabular}

\subsection{Fecha de campo}

La entrevista se realizó el 27 de Abril del 2018 a las 5:00 pm, en su centro laboral ubicado en Magdalena del Mar.

\section{Perfil del experto:}

Profesional con estudio universitario concluido, que cuenta con un mínimo de cinco años de experiencia en puestos gerenciales o jefatura en ONG's generando recursos para las fundaciones y que tienen conocimiento del manejo del sistema en ONG's. 
ANEXO 7: Resultados de la encuesta

\section{Género}

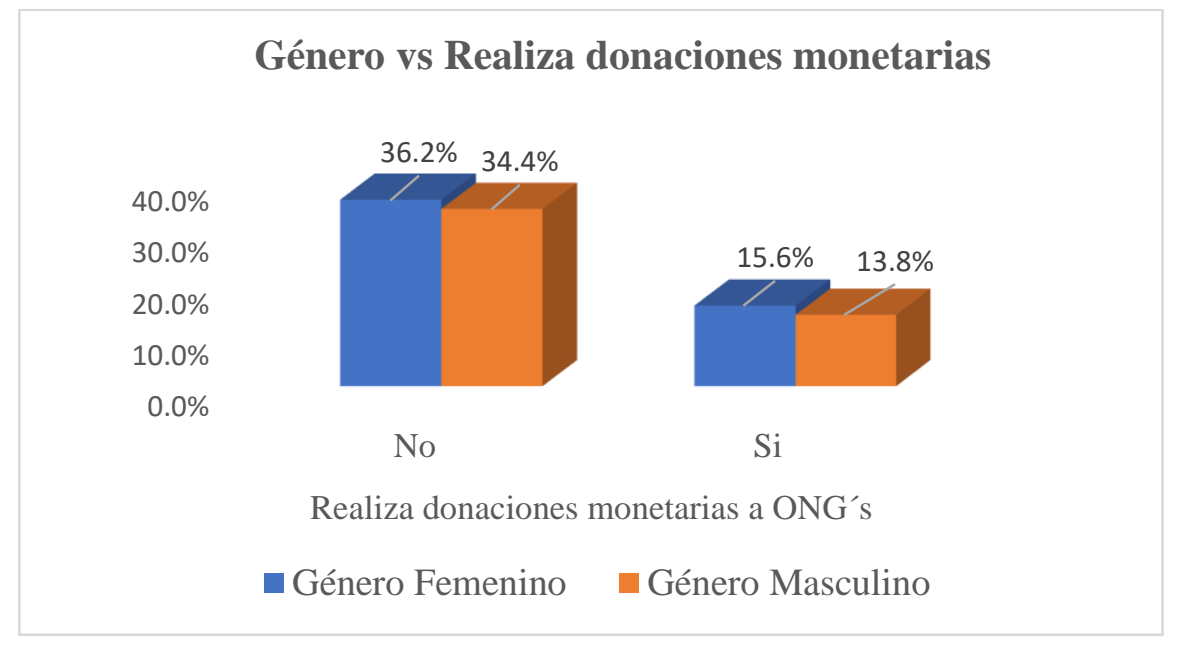

Fuente: Elaboración Propia

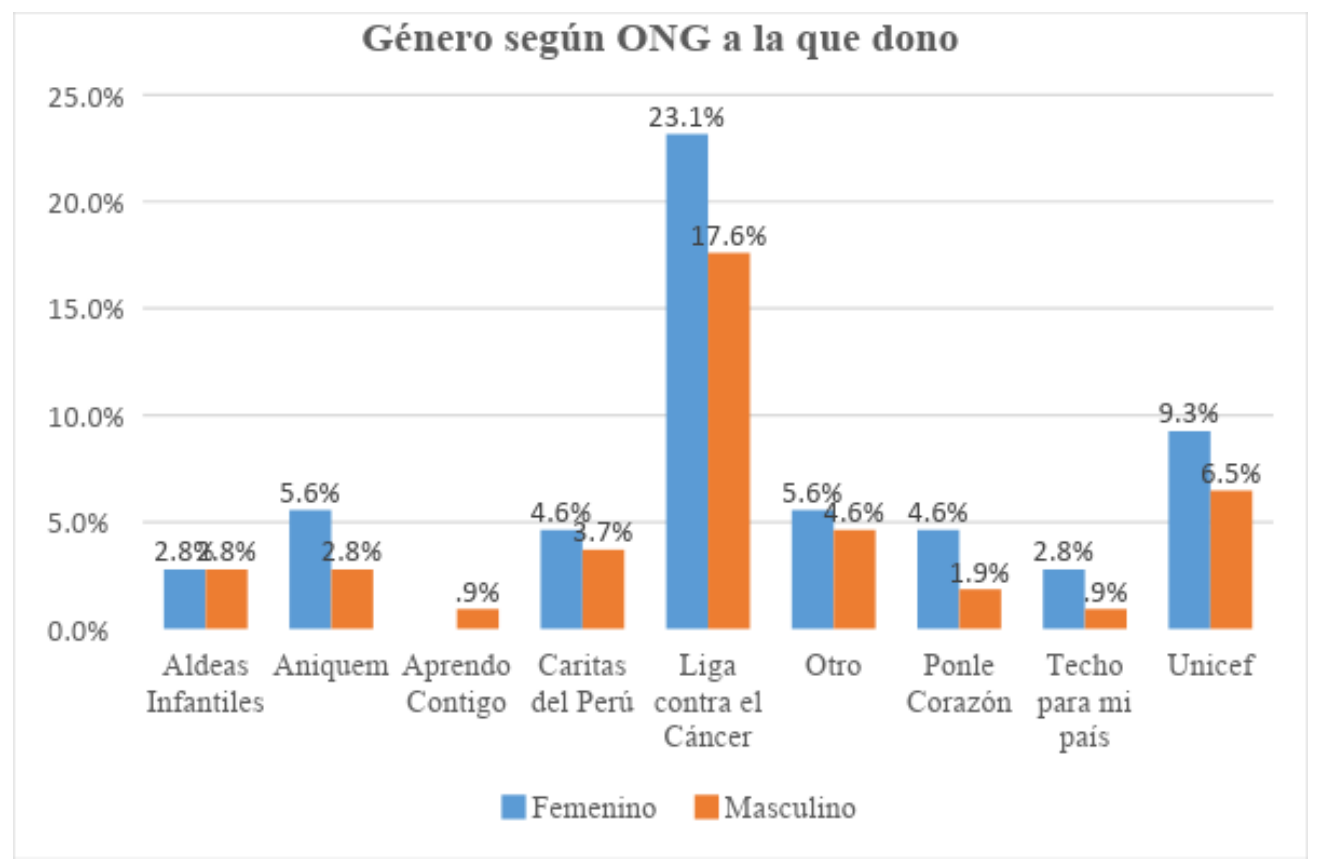

Fuente: Elaboración Propia 


\section{Grado de instrucción}

Realiza donaciones monetarias a ONG's según Grado de Instrucción

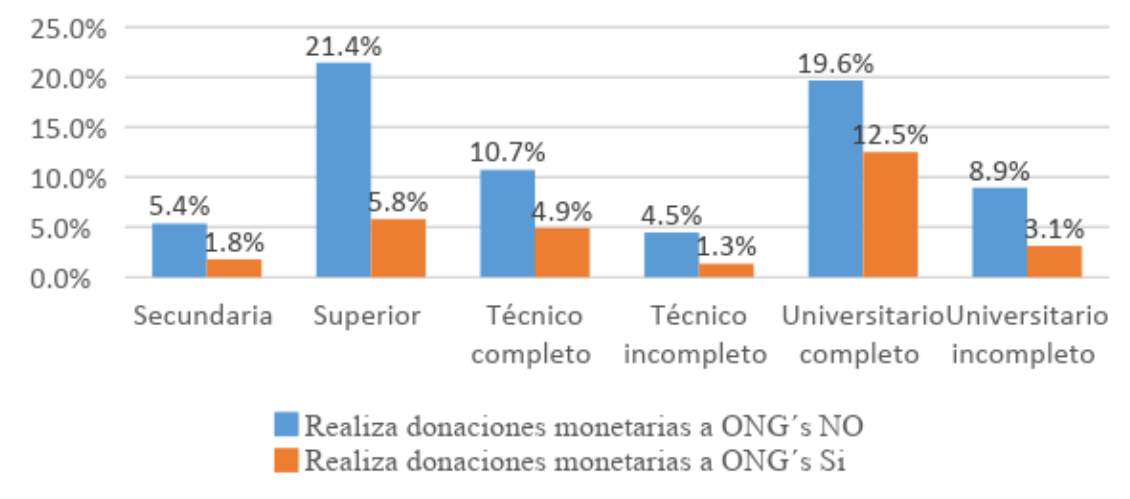

\section{Fuente: Elaboración Propia}

\section{Edad}

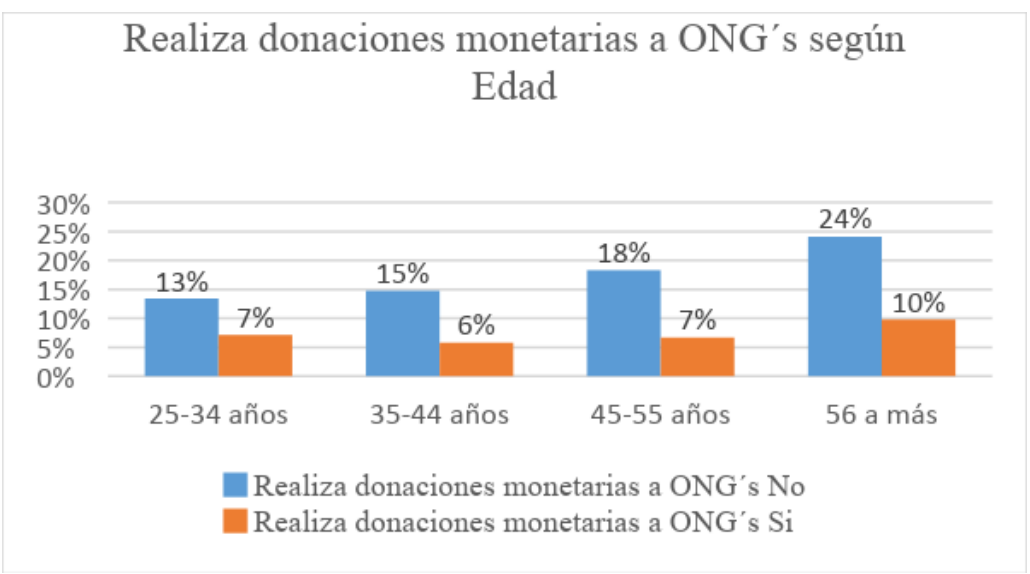

Fuente: Elaboración Propia 


\section{Estado Civil}

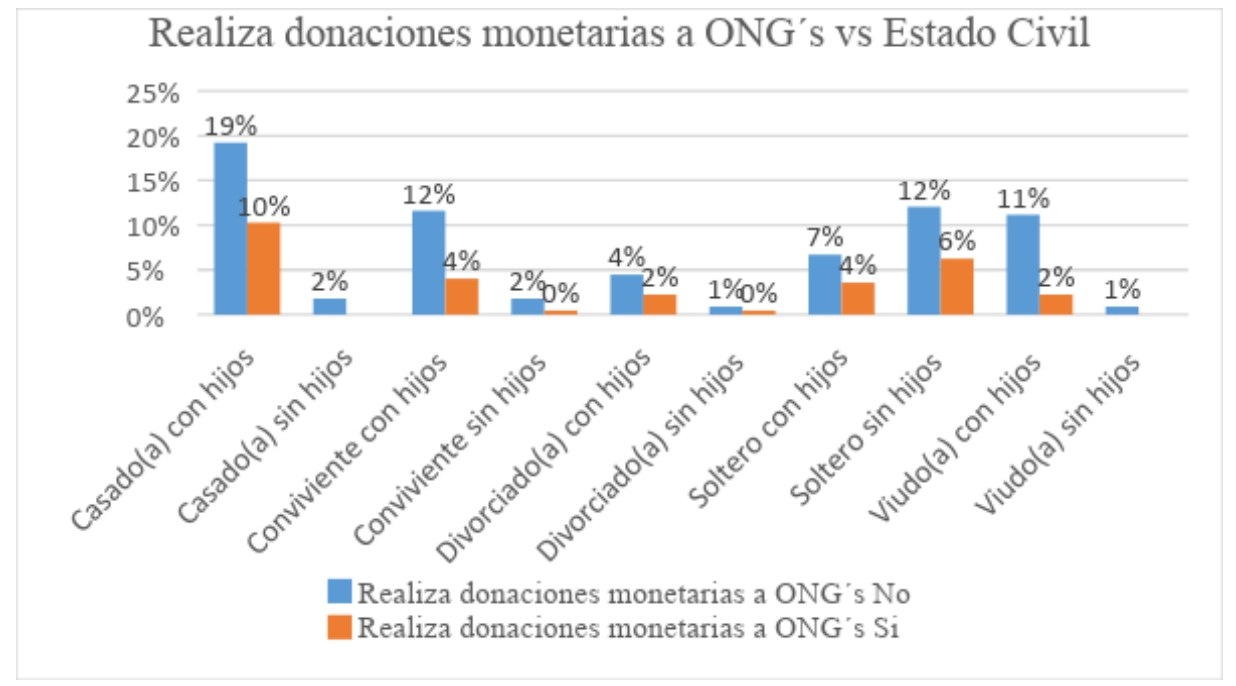

Fuente: Elaboración Propia

\section{Realiza donaciones monetarias a ONG's}

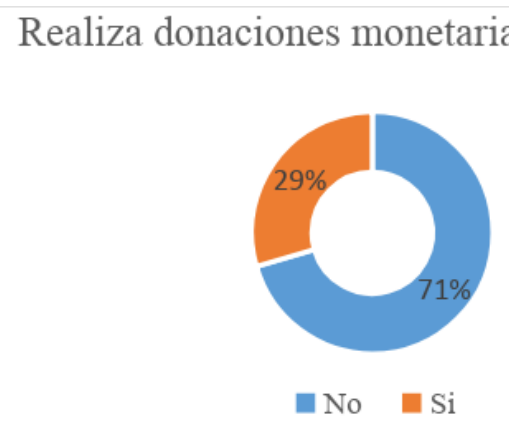

Fuente: Elaboración Propia 


\section{Tiempo que realiza donaciones monetarias a ONG's}

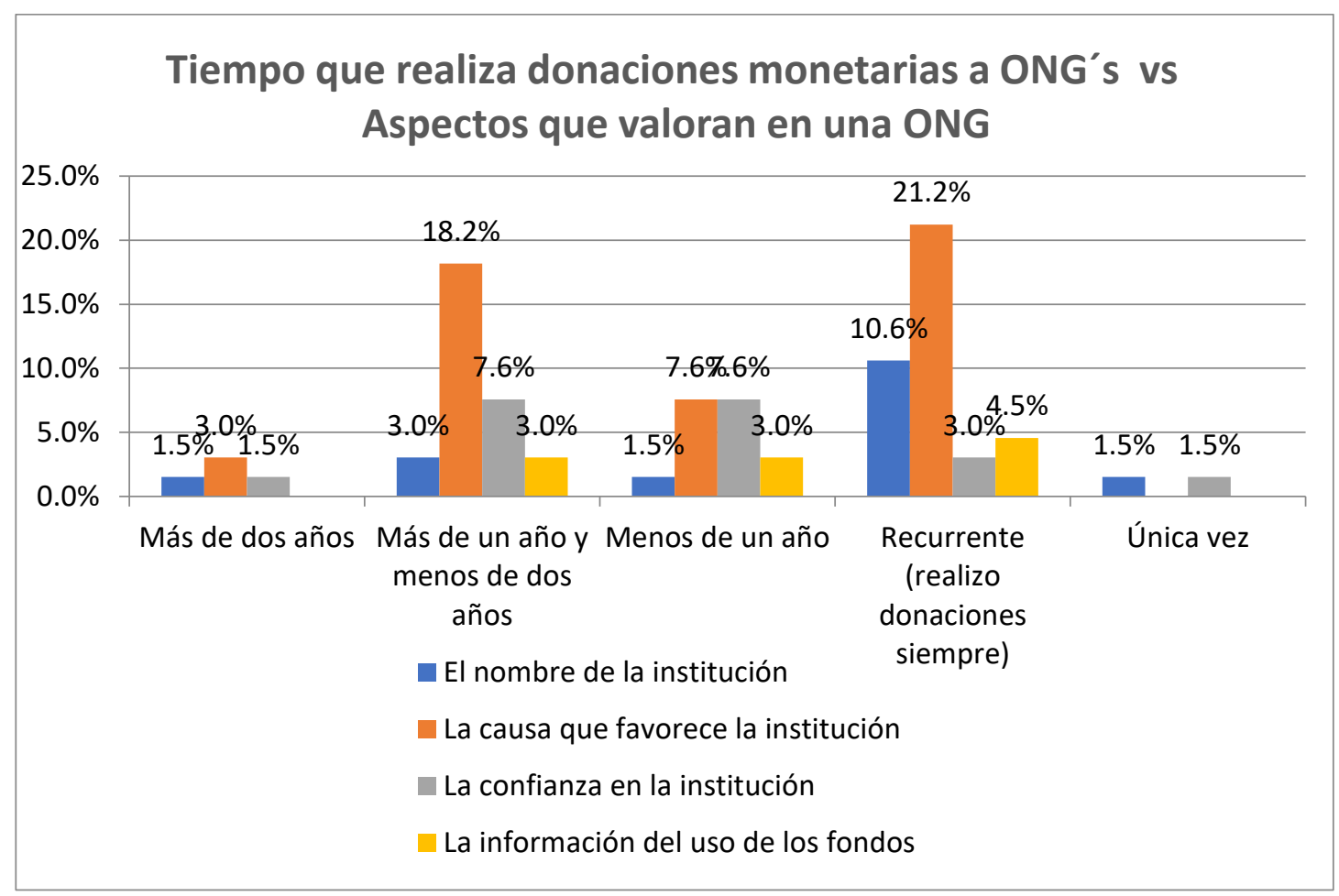

Fuente: Elaboración Propia 


\section{ONG a la que dono}

\section{ONG a la que dono según edad}

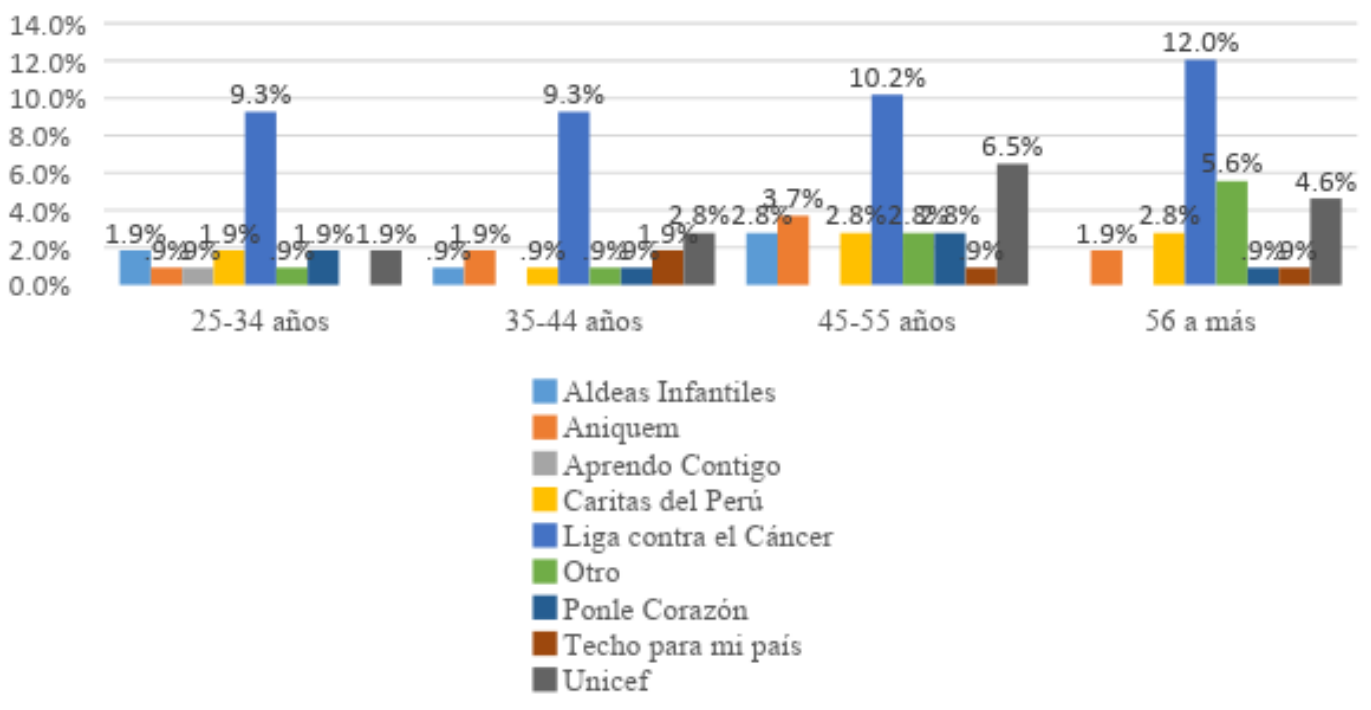

Fuente: Elaboración Propia

\section{Factor más importante de sensibilización}

\section{Factores más importantes de sensibilización según nivel de} importancia

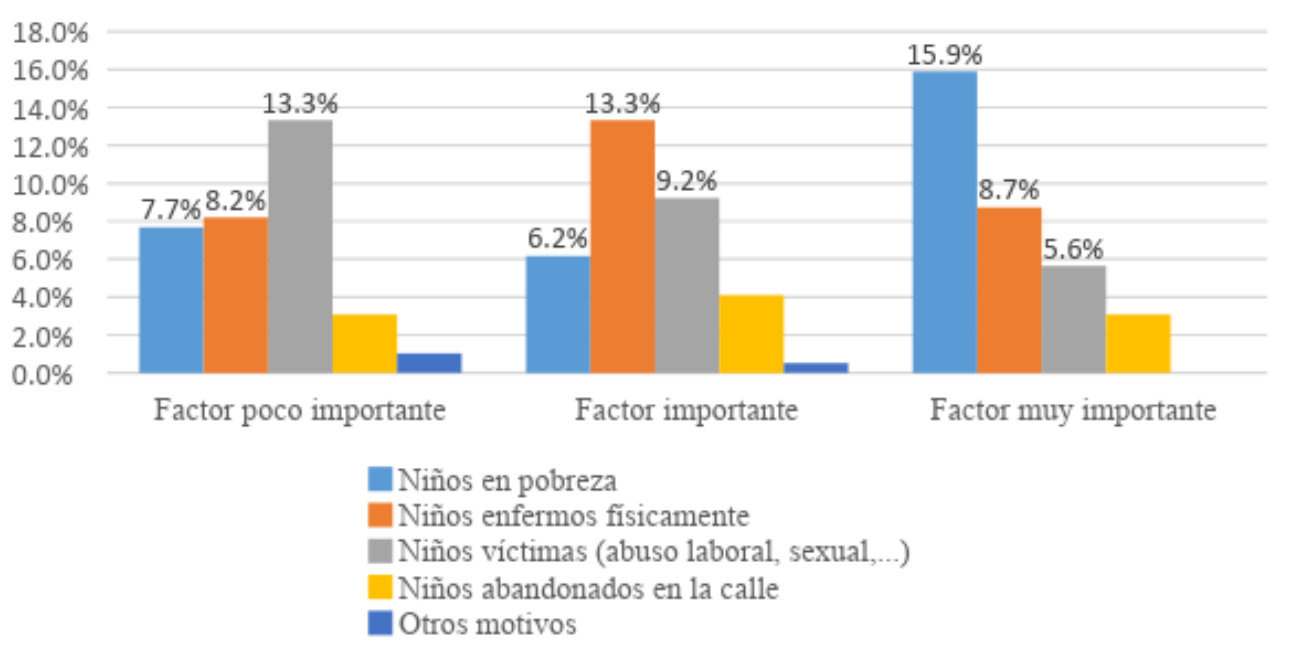

Fuente: Elaboración Propia 


\section{Motivo por el que realiza una donación a una ONG}

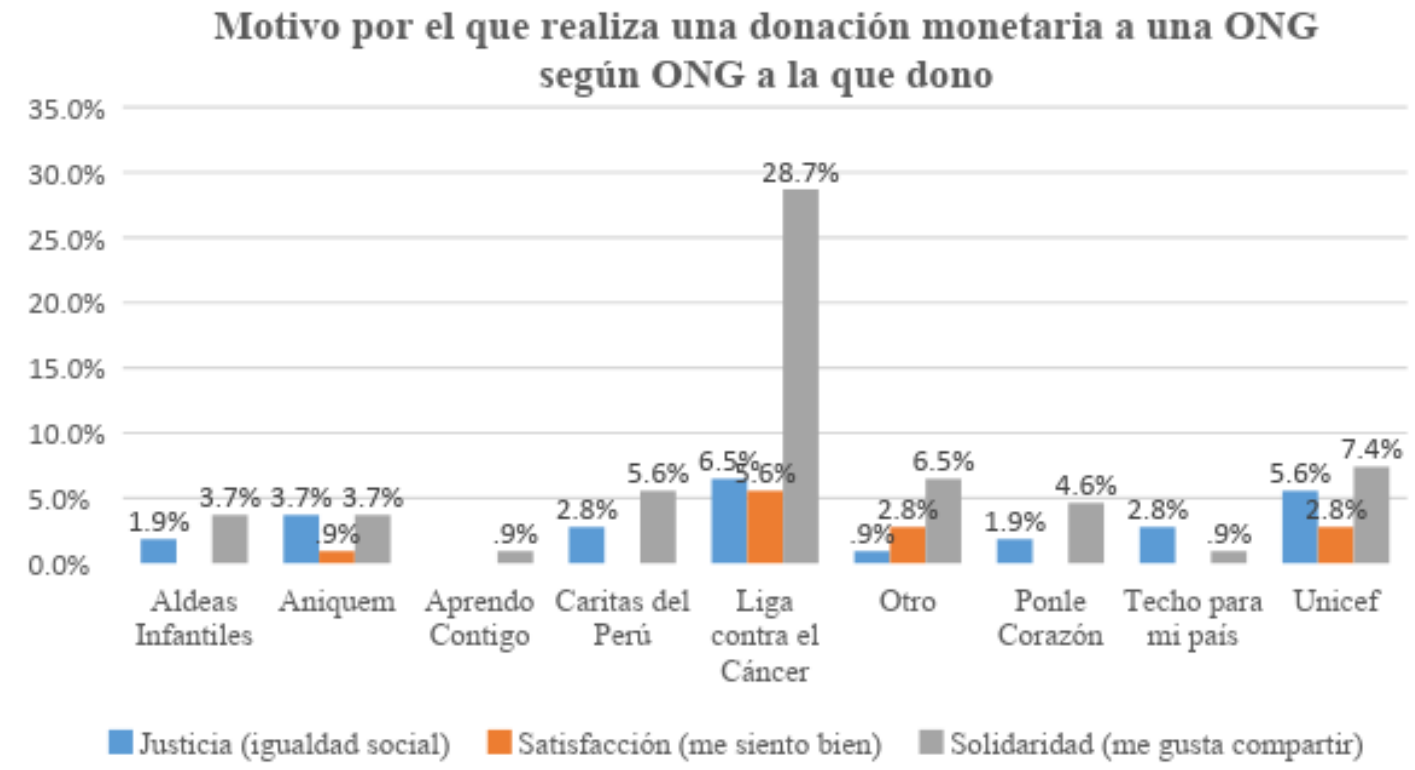

Fuente: Elaboración Propia

\section{Aspectos que valoran en una ONG}

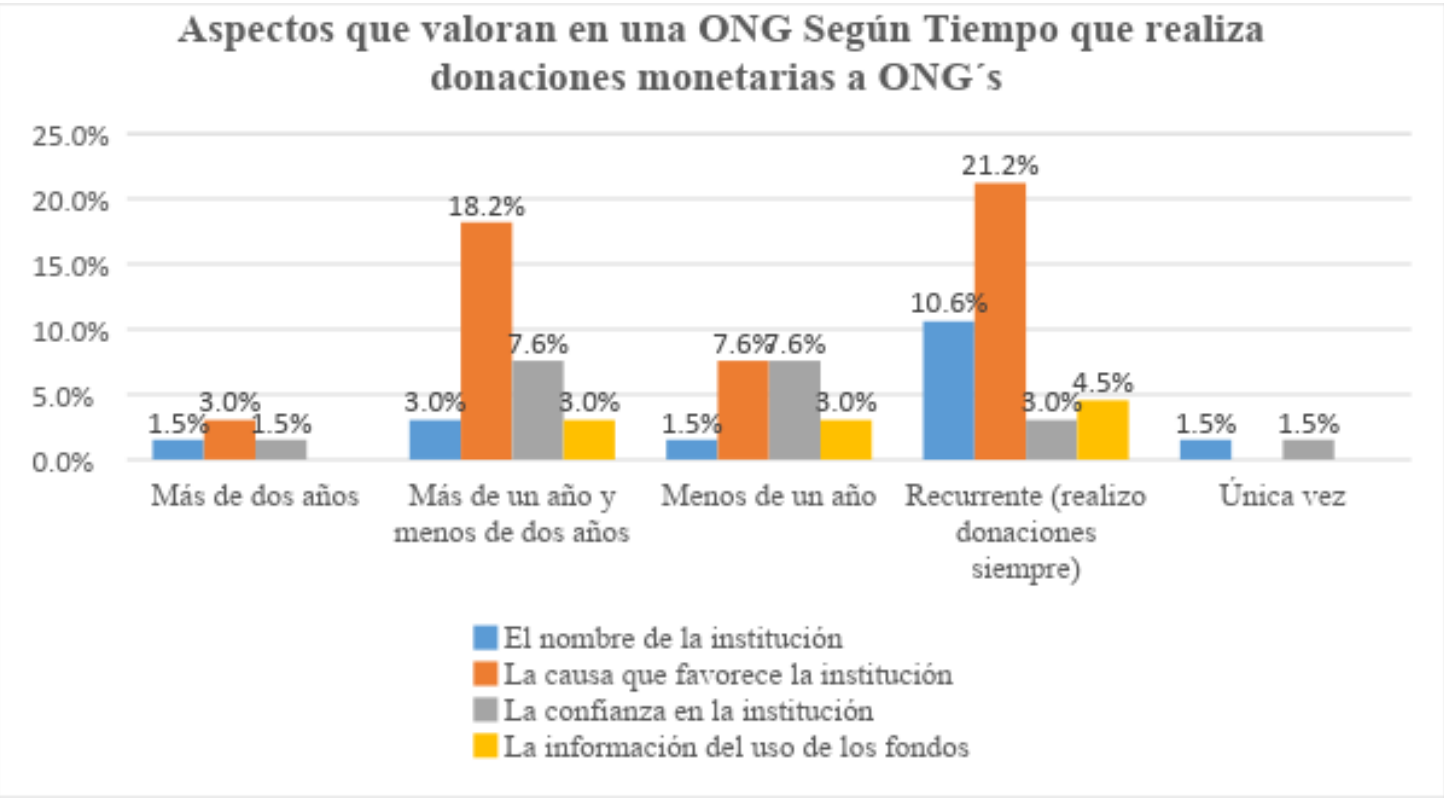

Fuente: Elaboración Propia 


\section{Percepción del trabajo según ONG's}

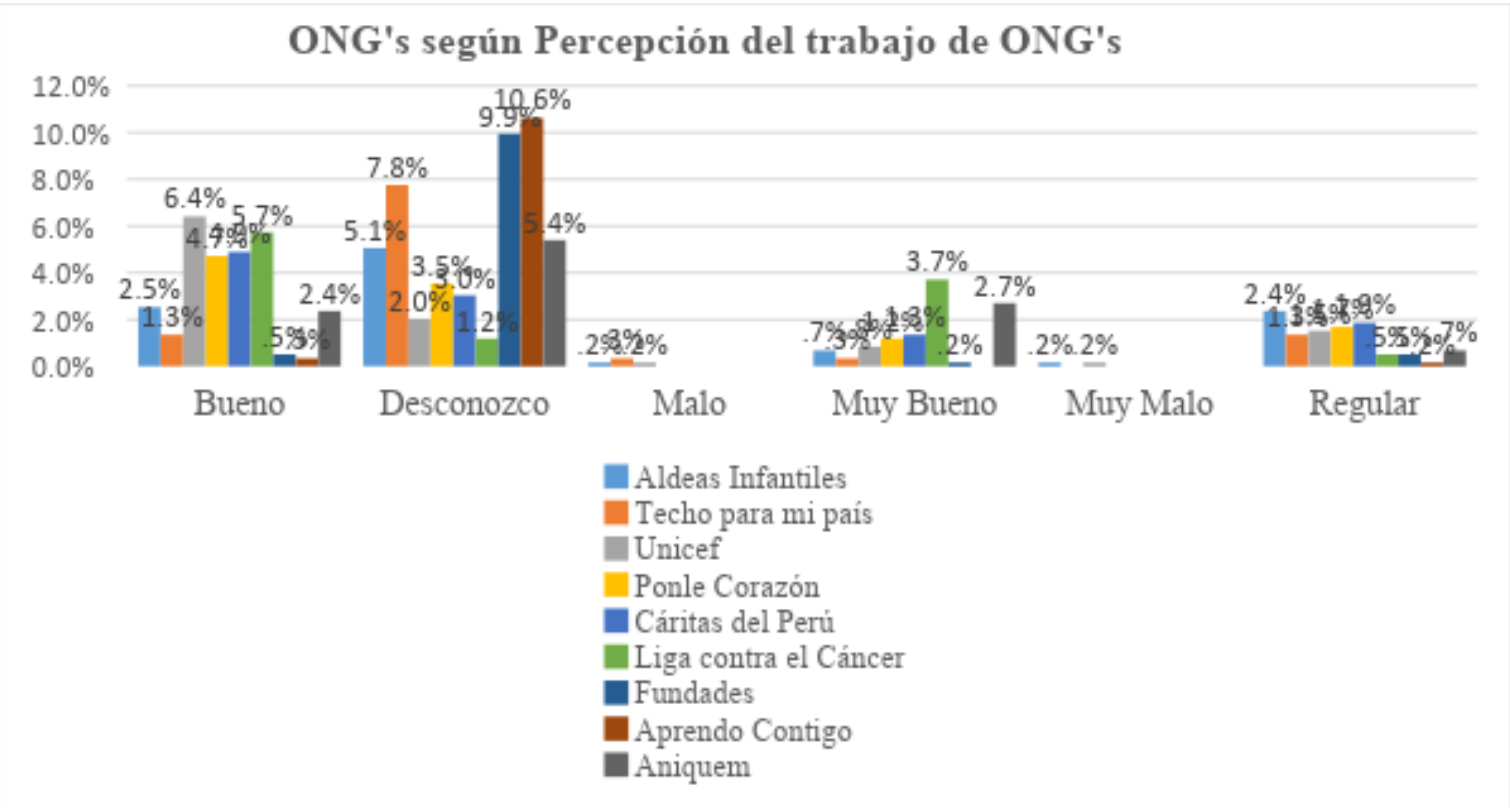

Fuente: Elaboración Propia 


\section{Motivos por lo que no realiza donaciones monetarias a ONG's}

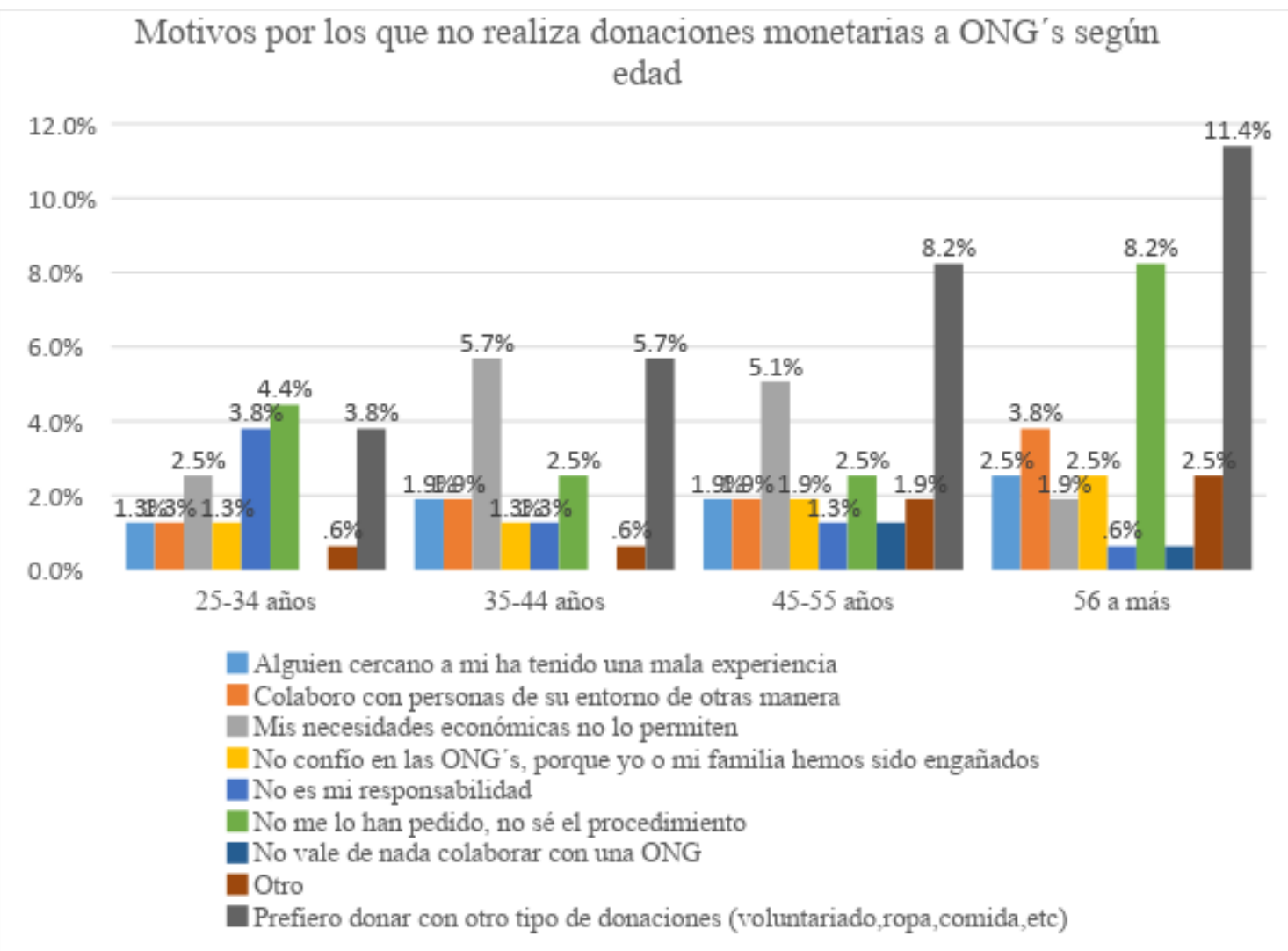

Fuente: Elaboración Propia

\section{Frecuencia de donaciones a ONG's}

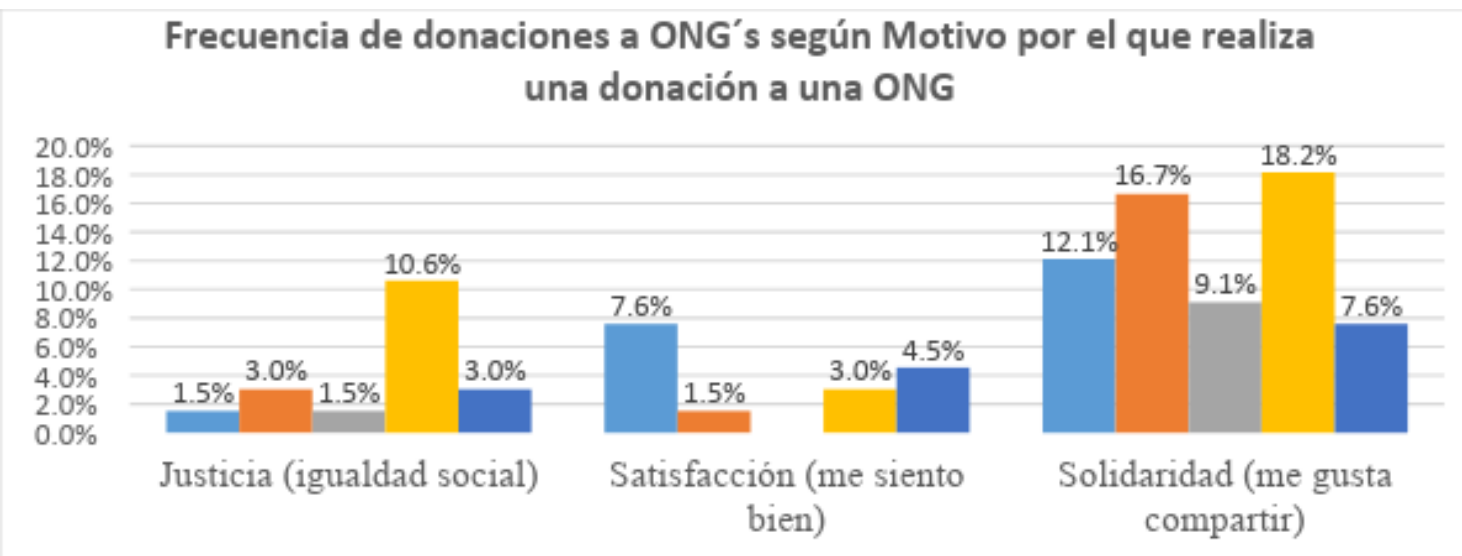

mensualmente $\square$ Trimestralmente $\square$ Semestralmente $\square$ Anualmente $\square$ Por única vez

Fuente: Elaboración Propia 


\section{Medio de donación a la ONG}

Medio de donación a la ONG según Frecuencia de donaciones a ONG'S
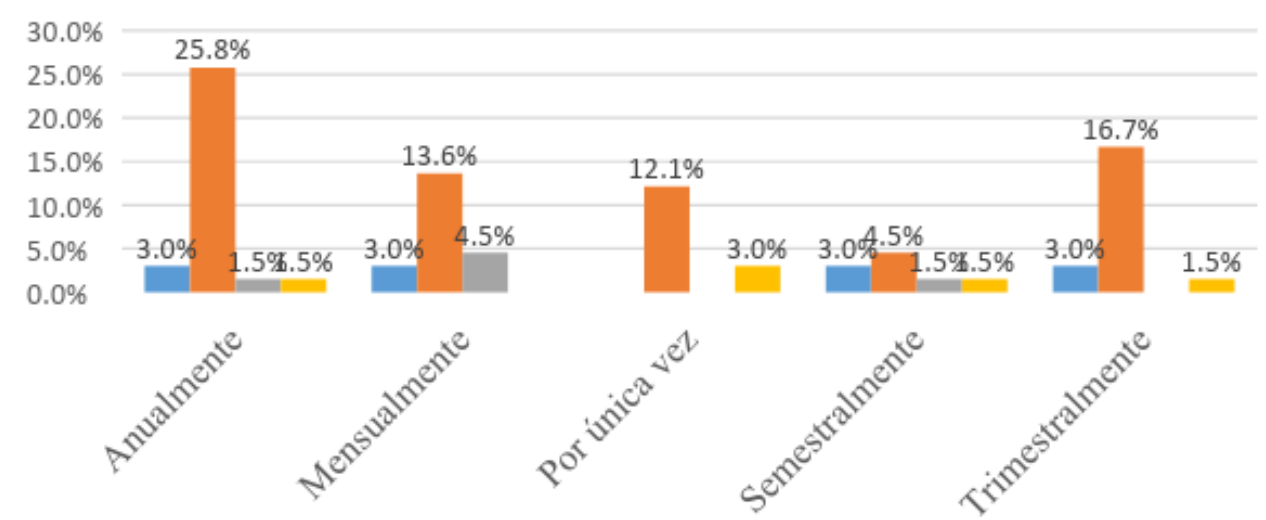

Débito automático

Efectivo

Tarjeta de Crédito

Transferencia directa y personal

Fuente: Elaboración Propia

\section{Medio por el que se informa de donación a $\mathrm{ONG}^{\prime} \mathrm{s}$}

Medio por el que se informa de donación a ONG's según frecuencia de donaciones

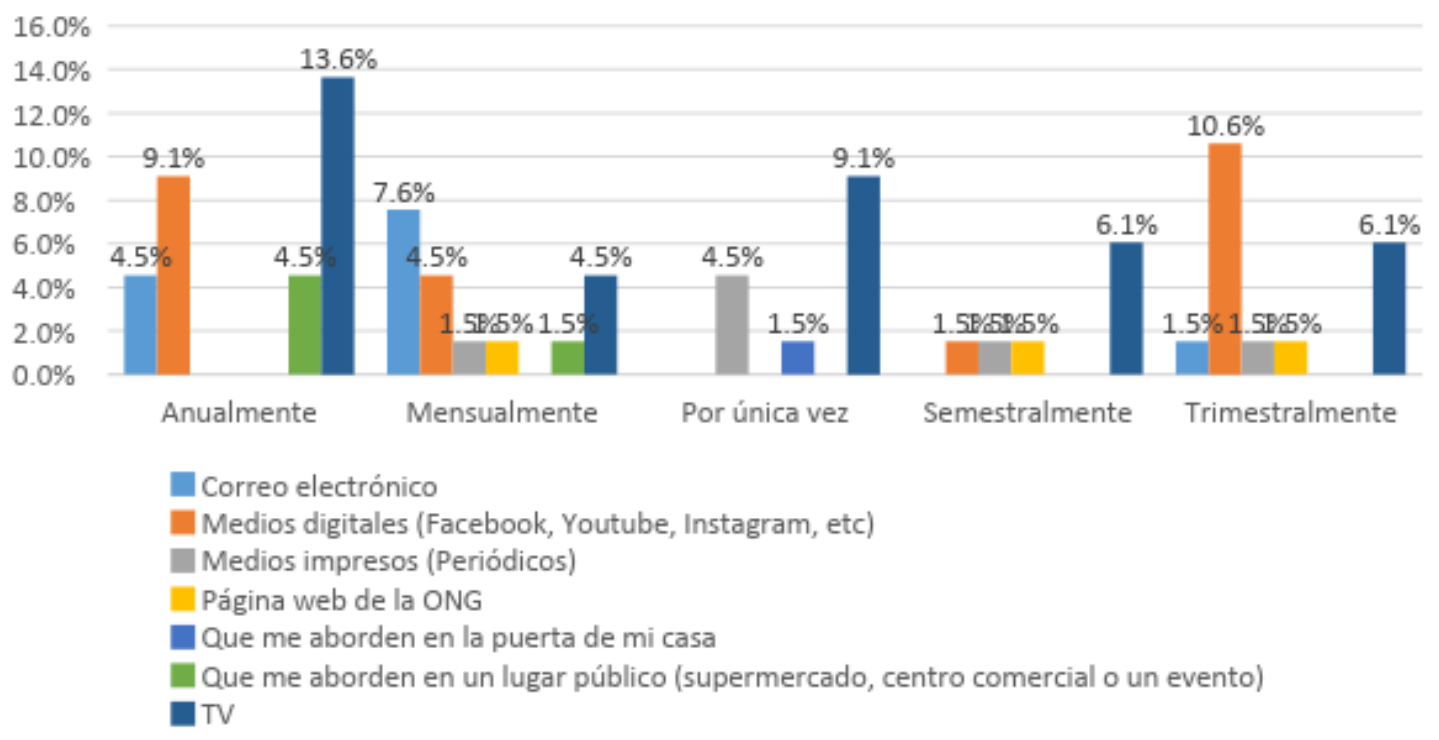

Fuente: Elaboración Propia 


\section{Influencia en la decisión de donación a $\mathrm{ONG}^{\prime} \mathrm{s}$}

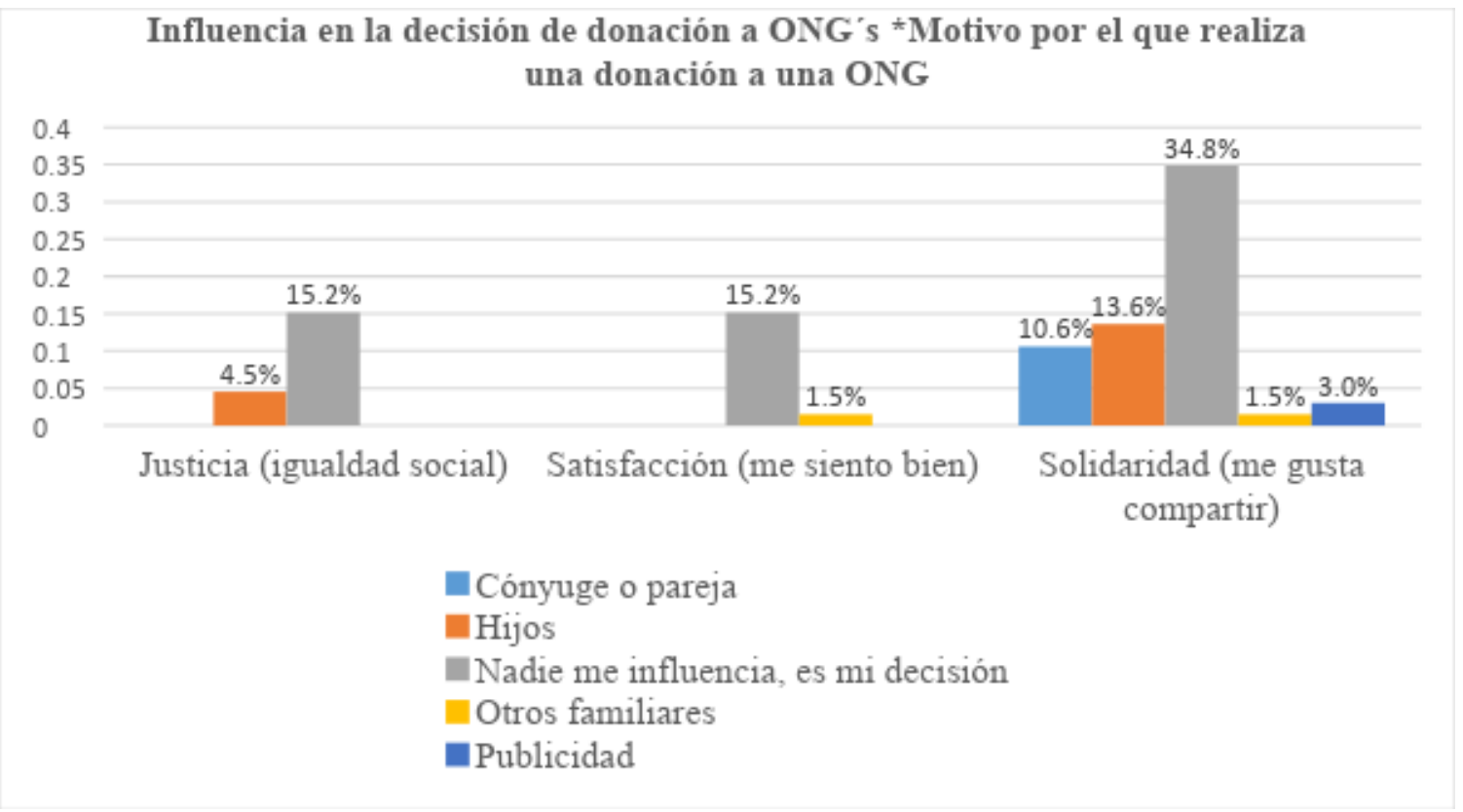

Fuente: Elaboración Propia 
ANEXO 8: Mapa Conceptual

Perfil del donante natural que reside en Lima Metropolitana, que realiza una donación monetaria a las $\mathrm{ONG}^{\prime}$ s que favorecen a niños en la ciudad de Lima.

¿Cuál es el perfil de una persona natural que reside en Lima Metropolitana, que realiza una donación monetaria a las ONG“"s que favorecen a niños en la ciudad de Lima?

Perfil

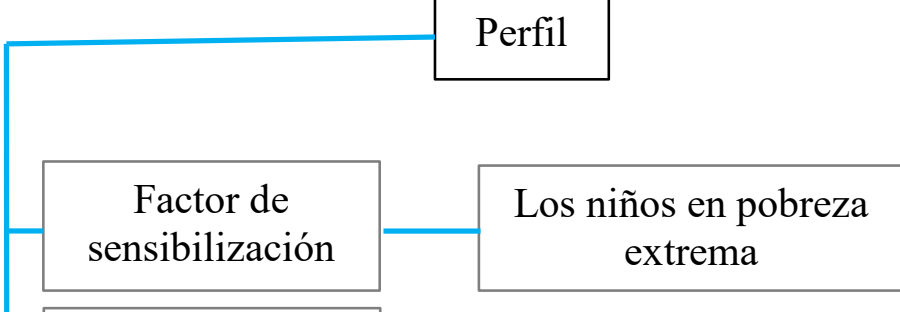

Factor de

Motivación

Solidaridad

Aspectos que

valora de una ONG

Percepción del Trabajo de una $\mathrm{ONG}$
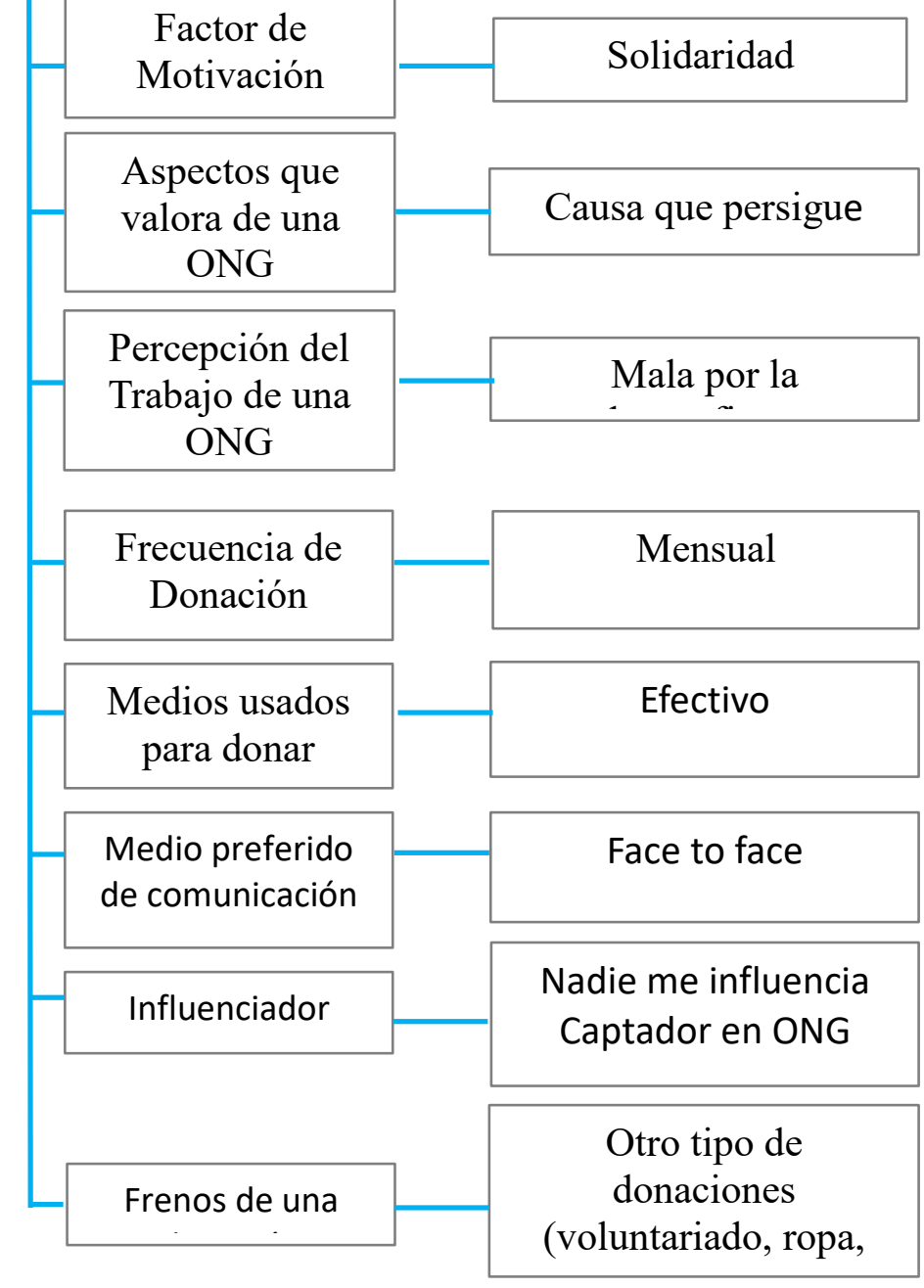